\title{
Retinal Stimulation Strategies to Restore Vision: Fundamentals and Systems
}

Lan Yue Ph. $D^{[1]^{*}}$, James D. Weiland Ph. ${ }^{[1]}$, Botond Roska M.D, Ph. $D^{[2,3]}$, Mark S. Humayun M.D, Ph.D ${ }^{[1]^{*}}$

[1] USC Eye Institute, Institute for Biomedical Therapeutics, University of Southern California, Los Angeles, CA, 90033, USA

[2] Neural Circuit Laboratories, Friedrich Miescher Institute for Biomedical Research, Maulbeerstrasse 66, 4058 Basel, Switzerland

[3] Department of Ophthalmology, University of Basel, Basel, Switzerland

${ }^{*}$ Corresponding author

\begin{abstract}
Retinal degeneration, a leading cause of blindness worldwide, is primarily characterized by the dysfunctional/degenerated photoreceptors that impair the ability of the retina to detect light. Our group and others have shown that bioelectronic retinal implants restore useful visual input to those who have been blind for decades. This unprecedented approach of restoring sight demonstrates that patients can adapt to new visual input, and thereby opens up opportunities to not only improve this technology but also develop alternative retinal stimulation approaches. These future improvements or new technologies could have the potential of selectively stimulating specific cell classes in the inner retina, leading to improved visual resolution and color vision. In this review we will detail the progress of bioelectronic retinal implants and future devices in this genre as well as discuss other technologies such as optogenetics, chemical photoswitches, and ultrasound stimulation. We will discuss the principles, biological aspects, technology development, current status, clinical outcomes/prospects, and challenges for each approach. The review will cover functional imaging documented cortical responses to retinal stimulation in blind patients.
\end{abstract}

(C) 2016. This manuscript version is made available under the Elsevier user license http://www.elsevier.com/open-access/userlicense/1.0/ 


\section{Contents}

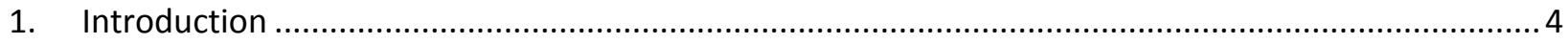

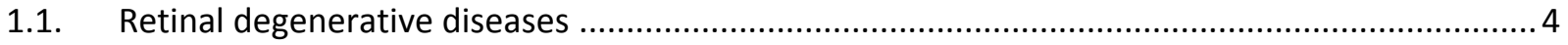

1.2. Treatment options and opportunities for retinal stimulation ............................................. 4

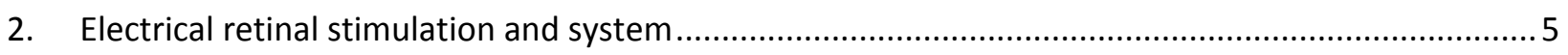

2.1. Fundamentals of electrical retinal stimulation .................................................................... 5

2.2. Proof-of-concept studies: leap from phosphenes to prosthetic vision .................................... 7

2.3. Retinal prosthetic systems and clinical implications ............................................................ 8

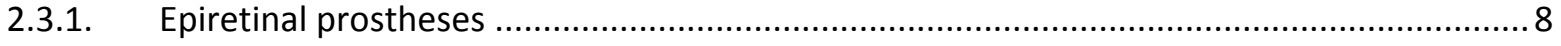

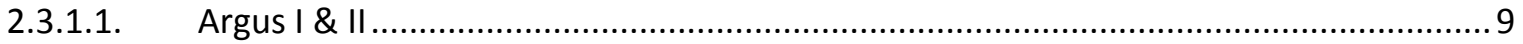

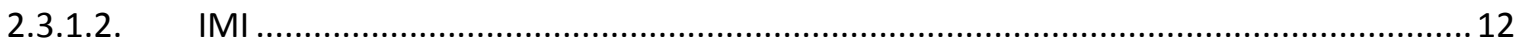

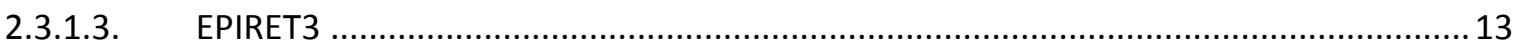

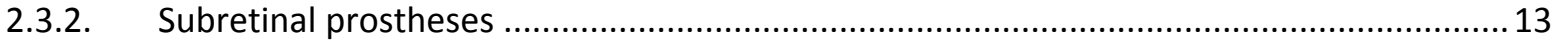

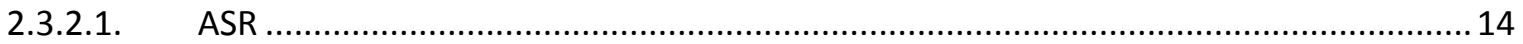

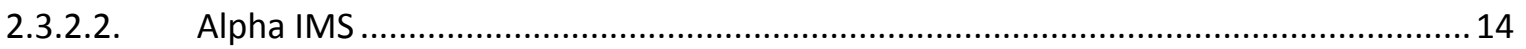

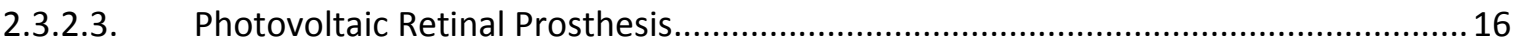

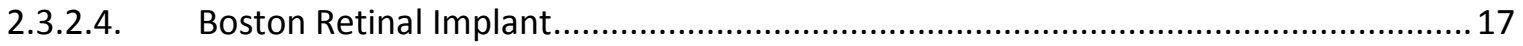

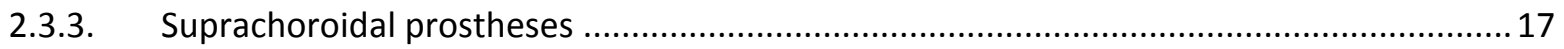

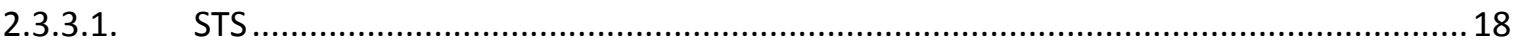

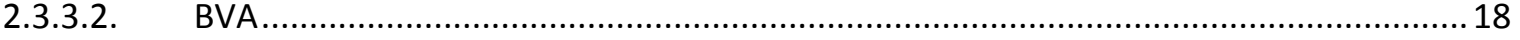

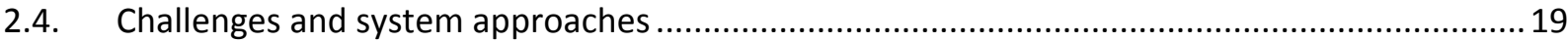

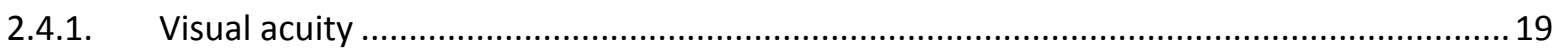

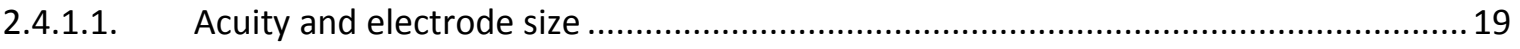

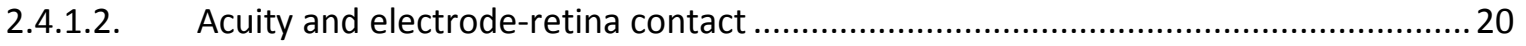

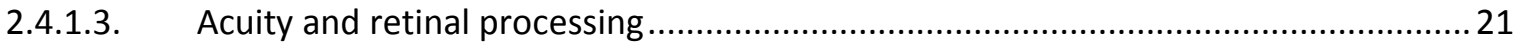

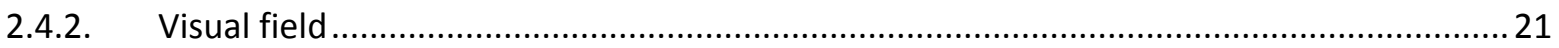

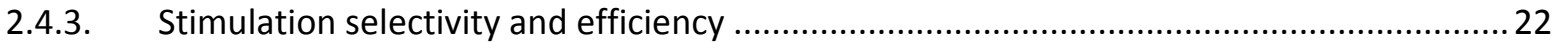

2.4.3.1. Ganglion cell response and phosphene fading, streaking …....................................22

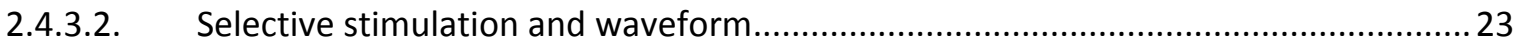

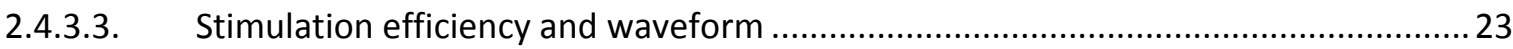

2.4.4. Eye movement and intraocular camera...................................................................... 24

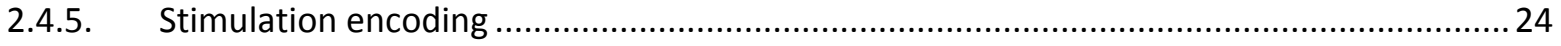




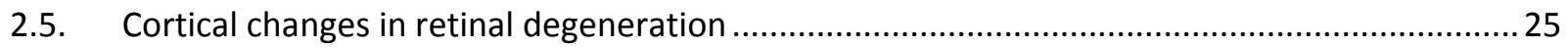

3. Light retinal stimulation: optogenetics and chemical photoswitches …........................................26

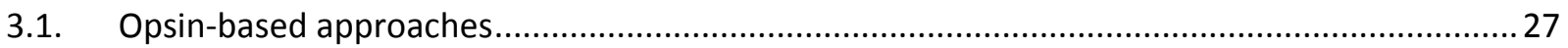

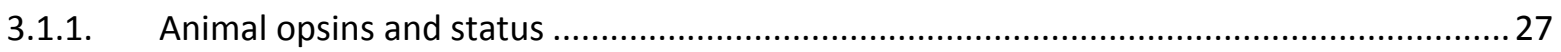

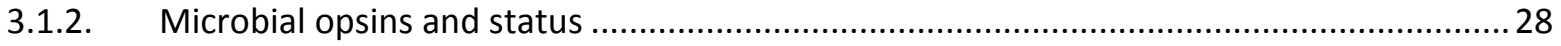

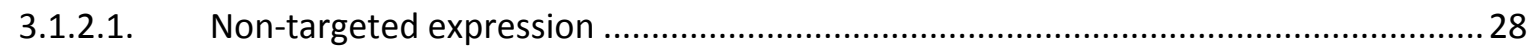

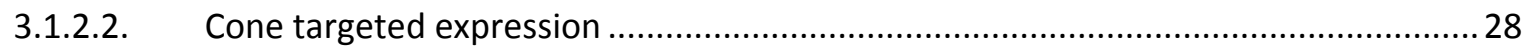

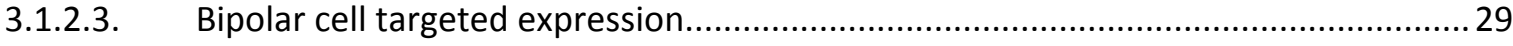

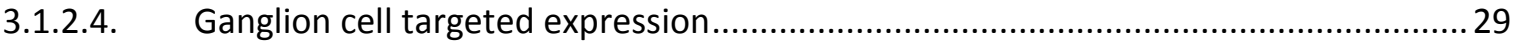

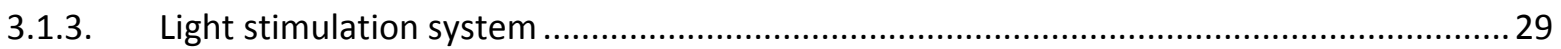

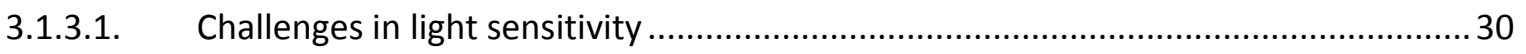

3.1.3.2. Light processing and enhancement goggle ............................................................. 30

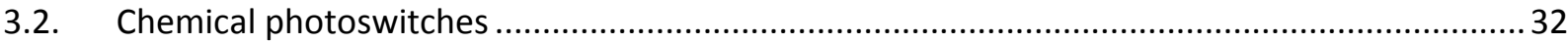

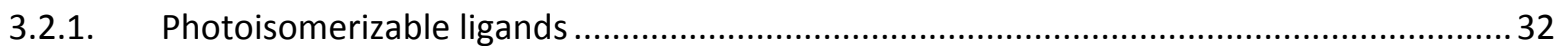

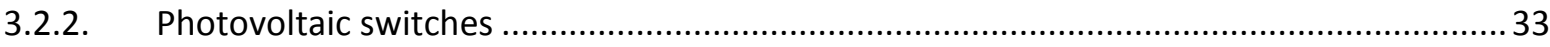

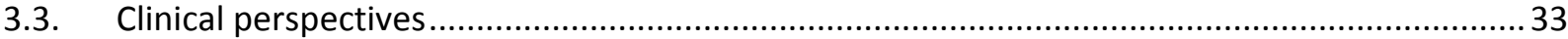

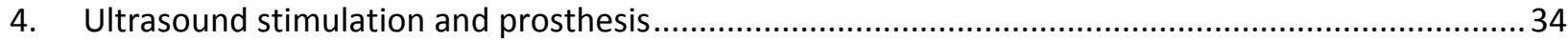

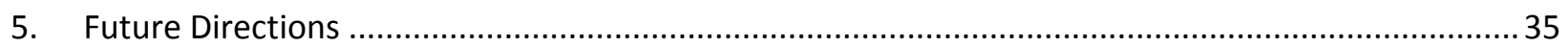




\section{Introduction}

\subsection{Retinal degenerative diseases}

Retina is a stratified light sensitive tissue that lines the back of the eye. It is $\sim 0.5 \mathrm{~mm}$ in thickness and the retinal neural network consists of several layers of cells bodies and their neural processes of dendrites and axons, as illustrated in Figure 1A. The Retinal Pigment Epithelium (RPE) cell layer, lying adjacent to the neural retina, is involved in recycling the visual pigments and maintaining the health of photoreceptors, the light sensor in healthy retina. Visual signals, initiated at the photoreceptors, sequentially travel through the bipolar cells and ganglion cells and propagate to the higher visual centers in the brain via the optic nerves (axons of the ganglion cells). Signals also receive lateral modulation from horizontal cells and amacrine cells, as part of the neural processing in inner retina. As shown in Figure $1 \mathrm{~A}$, cell distribution profiles are very different in central vs. peripheral retina. Cone photoreceptors are densely packed in the macula while rod photoreceptors predominate in the peripheral region. Retinal signaling in the macular region is analogous to "private line" transmission from individual cones whereas a high level of convergence occurs in peripheral retina.

Retinal degeneration involving progressive deterioration and loss of function of photoreceptors is a major cause of permanent vision loss (Busskamp et al., 2010; Curcio et al., 2000). Age-related macular degeneration (AMD) and retinitis pigmentosa (RP) are the two most prevalent forms of retinal degenerative diseases. Epidemiologic studies show that the onset of AMD occurs predominantly in the elderly while RP afflicts children and young adults (Wong et al., 2011). Together, they account for millions of cases of blindness and visual impairment worldwide. Figure 1B shows representative patterns of vision loss in AMD and RP.

AMD begins by primarily affecting cone photoreceptors in macula, leading to blurred central vision. As AMD progresses, the blurred area may grow larger and the patient may develop blind spots in the center of the visual field (Jackson et al., 2002). AMD affects 30-50 million people globally and more than 2 million in the United States alone (Bressler, 2004; Friedman et al., 2004). There are two main forms of AMD: the dry form and the wet form. The dry form accounts for $85 \%-90 \%$ percent of the AMD cases and it is characterized by drusen, a yellow deposit in macula that grows over time and leads to retinal atrophy. The wet form, accounting for $10 \%$ of the AMD occurrences, involves neovascularization from choroid underneath the macula. Growth of the blood vessels and leakage of blood into the retina induce blur or distortion in vision and when scar is formed, permanent vision loss occurs.

RP initiates with progressive degeneration of rod photoreceptors in peripheral retina, manifesting early symptoms as loss of peripheral vision and night vision (Hartong et al., 2006; Wells et al., 1993). Degeneration of rods is followed by damages to RPE cells and deterioration of cones, resulting in the visual decline from "tunnel vision" to blindness. RP is estimated to affect 1.5 million people in the world (den Hollander et al., 1999). It may occur alone, arise syndromically, with other genetic disorders, or be secondary to other systemic diseases (Daiger et al., 2014; Hartong et al., 2006). Multiple gene mutations, including mutations in rhodopsin, have been associated with RP phenotype (Daiger et al., 2014).

\subsection{Treatment options and opportunities for retinal stimulation}


There's no cure for either AMD or RP and the current therapies mostly aim to slow down the cell death and the concomitant vision loss. Nutritional supplements have been used to prevent the progression of AMD and RP (Richer et al., 2004); anti-VEGF injections and lasers have been used to slow neovascularization or remove abnormal vessels in wet AMD (Heier et al., 2012; Wood et al., 2000). However these treatments are very limited in blocking or reversing the progression of the disease. Novel treatments such as gene therapy and cell transplantation are under investigation (Beltran et al., 2012; Rakoczy et al., 2015). Since only limited mutations have been recognized in a multitude of gene defects associated with retinal degeneration, gene therapy is, at present, only applicable to a small number of patients. Stem cell transplantation to replace damaged RPE or photoreceptors in end-stage degeneration has also been intensively investigated (Schwartz et al., 2015; Singh et al., 2013; Wong et al., 2011). Increased understanding of the conditions needed for stem cells to differentiate into specialized cells has led to encouraging results demonstrating some functional photoreceptor replacement in animal models (Huang et al., 2011). However, issues involving cell function and cell connectivity by the transplanted stem cells remain to be addressed.

In advanced stages of photoreceptor degeneration, the neural retina is also significantly altered. Lack of regular input from the photoreceptors, which are non-responsive or absent, leads to significant neural remodeling. A number of negative physiological processes are heralded by advanced photoreceptor degeneration, including neuronal and glial migration, extensive neurite sprouting of horizontal and amacrine cells, formation of synaptic microneuromas and evolution of a fibrotic glial seal that increasingly isolates the remaining retina from RPE and choroid (Fariss et al., 2000; Marc et al., 2003). Despite reorganization and cell loss, the inner retinal neurons largely retain the capacity for signal transmission. Morphometric analyses have shown that, based on the nuclei count, over $50 \%$ of the ganglion cells survive wet AMD and the ganglion cell density in dry AMD does not differ significantly from that in normal eyes, even in retinal areas with virtually no remaining photoreceptors (Kim et al., 2002; Medeiros and Curcio, 2001). Morphologic studies in severe human RP patients reveal moderate preservation of inner retinal neurons: $70-80 \%$ of the bipolar cells and $25-40 \%$ of the ganglion cells (Humayun et al., 1999b; Santos et al., 1997; Weiland et al., 2011).

Inner retinal preservation supports the possibility of vision restoration by establishing a stimulation mechanism that bypasses the damaged photoreceptor layer and directly interfaces with the remaining inner retinal neurons. Work in this area has been largely built upon several stimulation modalities, including bioelectronic, optogenetic, photochemical and more recently, ultrasonic stimulation. These distinct approaches are detailed in this article, in terms of the fundamental mechanisms and the prosthetic systems.

\section{Electrical retinal stimulation and system}

\subsection{Fundamentals of electrical retinal stimulation}

Electrical stimulation of the nervous system dated back to the $18^{\text {th }}$ century. In 1775 , LeRoy created light sensations in the blind by passing electrical currents around the head. In 1780, Galvani discovered twitching in the muscles of dead frogs' legs that were struck by electricity. Two decades later, Volta 
reported receiving a jolt in the head and then hearing bubbling sound when he inserted two electrodes in his own ears. Over the past two centuries, these primitive experiments at the electrode-tissue interface have progressively evolved into a variety of programmable, chronically stable bioelectronic implants, such as visual prosthesis, cochlear implant, pacemaker, deep brain stimulator and bladder control, that serve to regulate or restore certain physiological functions (Beck et al., 2010; Kringelbach et al., 2007; Niparko, 2009; van Balken et al., 2004; Weiland and Humayun, 2008).

Electrode-based extracellular stimulation operates by injecting current into the tissue of interest via a single or an array of electrode placed nearby. In bioelectronic retinal implants, an electrode array is placed in close proximity to the retina, forming an electrochemical interface with the physiological saline. Current, injected by the stimulating electrodes, passes through the retinal tissues to the return electrode, either locally placed on the array or at a distant location. Current delivered into the extracellular region causes charge redistribution on the cell membrane of the retinal neurons. Firing of action potentials is initiated when membrane depolarization exceeds a threshold.

Models of electrical stimulation predict the effects of stimulus pulse polarity and proximity between the electrode and neuron. Rattay modeled the ideal situation of an extracellular electrode as a point source a fixed distance from a uniform, infinitely long axon. While retinal stimulation is more complex, the Rattay model is nevertheless useful to form a basic understanding of neural activation via extracellular electrodes. Polarity and extent of the membrane polarization in axonal stimulation with a monopolar electrode is illustrated in Figure 2A-B. In cathodic stimulation, negative charges build up on the outside of the membrane underneath the electrode, driving the intracellular movement of the positive charges from the neighboring compartments to this region, resulting in strong membrane depolarization close to the electrode and weak hyperpolarization further away (Figure $2 A$ ). In anodic stimulation, however, due to reversed electric field, strong hyperpolarization occurs in the membrane segment proximal to the electrode and weak depolarization in the distal ends (Figure 2B), making anodic phase notably less efficient in generating action potentials than the cathodic phase, requiring a 3-7 fold higher current injection (Merrill et al., 2005; Rattay, 1986).

For electrical stimulation of a complex neural network such as retina, charge redistribution on the membrane of axons, soma and dendrites will all contribute to the depolarization of the retinal neurons (Figure 2C). The axon initial segment (AIS) of the RGC is located at the proximal end to the soma and contains a high density of sodium channels. Extracellular stimulation localized to different compartments of the retinal ganglion cells shows that the AIS has the lowest activation threshold, followed by other axonal sections and the soma, with the dendrites exhibiting the highest threshold to the electrical stimuli (Tsai et al., 2012). At the subcellular level, action potentials initiated at one neuronal element may propagate to another, significantly affecting the temporal and spatial response dynamics of the cell. For example, it has been demonstrated that activation of the passing ganglion cell axons that is in close proximity to the electrode may result in the perturbation of the membrane potential that travels orthodromically toward the distal end of the axon and antidromically towards the soma (Tsai et al., 2012). The antidromically propagated depolarization may evoke spiking of the soma that is located further away from the electrode, causing diffused activation map of the retina. At the network level, synaptic transmission in inner retina shapes up the indirect activation of the ganglion cells 
and presumably in the modulation of the ganglion cell signaling. As will be further discussed in the Section 2.4, stimulation waveform is identified as a key factor in the response pattern of the retina. Variations in the pulse strength, duration and frequency have exhibited influence on the population selectivity, activation spatial profile and stimulation efficiency (Nanduri et al., 2012; Tsai et al., 2012; Weitz et al., 2014; Weitz et al., 2015).

The choice of stimulation waveform also needs to factor in the electrochemical safety considerations. It has been found in the stimulation of the monkey cerebral cortex that a monophasic current pulse, consisting only of a cathodic or an anodic phase that is not charge balanced, creates damages, including loss of electrical excitability and tissue viability, whereas no damage was noted with biphasic chargebalanced stimulation of similar strength (Lilly et al., 1952; Lilly et al., 1955). Blood brain barrier breakdown was observed at the power density exceeding $0.5 \mathrm{~mW} / \mathrm{cm}^{2}$ in monophasic stimulation, but not in biphasic stimulation until the charge density was increased by 16 folds (Mortimer et al., 1970). It is revealed by these and other studies (Brummer and Turner, 1975) that a symmetry of electrochemical processes serves to maintain the integrity of the electrodes and to avoid net charge accumulation at the electrode-tissue interface which will eventually lead to unsafe chemical reactions. More recently, stimulation with biphasic pulse trains of $50 \mathrm{~Hz}$ in the rabbit eyes at various charge densities reveals evidence of structural changes in the retina when the pulse exceeds $442 \mu \mathrm{C} / \mathrm{cm}^{2} /$ phase, underscoring the importance of carefully calibrating the charge injection in the chronic stimulation of retina (Cohen et al., 2011). Retinal implants today mostly employ charge balanced biphasic waveforms consisting of a cathodic phase for stimulation and a charge-balancing anodic phase for accelerated electrode discharge. This stimulation paradigm is recently challenged by the study of Boinagrov et al. (2014), which argues that anodic first pulses are more efficient in generating network-mediated indirect responses of ganglion cells. Despite that a voltage pulse is capable of rapid electrode discharge, voltage controlled stimulation is less frequently used for the following reasons: 1 ) the electrode-electrolyte system is not entirely capacitive thus any resistance in the electrical conduction path decreases the stimulation current; 2 ) the huge capacitive current that occurs at the onset of the voltage pulse may result in uncontrolled electrode polarization; 3) stimulation efficiency peaks at the maximum current and decreases sharply during the pulse as the capacitive current is replaced by the resistive current; 4) individual differences in the tissue resistance potentially reduce the reproducibility in the clinical use (Merrill et al., 2005).

\subsection{Proof-of-concept studies: leap from phosphenes to prosthetic vision}

In late 1960s, a study by Brindley and Lewin (1968) revealed that light sensation, termed phosphenes, could be produced by electrically activating the visual cortex. Potts and Inoue (1969) reported similar patterns of electrically evoked potentials in RP patients and in normally sighted volunteers, when stimulated with cornea electrodes. These early works showed that electrical stimulation of the human visual system was perceived as light. In more recent years, electrical prostheses interfacing with the visual system respectively at the level of retina, optic nerve, geniculate nucleus and visual cortex have all been descried (Dobelle et al., 1974; Dowling, 2009; Pezaris and Eskandar, 2009; Veraart et al., 1998). 
Among these methodologies, retinal prostheses garner the most attention for a variety of reasons, including easier accessibility, lower surgical risks, well preserved retinotopic mapping and the ability to make use of the remaining retinal circuitry for signal processing.

In the late 1990s Humayun et al. (1999a) demonstrated, in acute settings, that electrical current delivered from a multi-electrode array to retina generated phosphenes in blind subjects. The subjects were able to report the location of the perception in their visual field, which was consistent with retinotopy, and to track perception as the electrode was moved to different locations in the retina. In another proof-of-concept trial of acute retinal stimulation, RP patients reported the ability to discriminate two separate stimulation points (Rizzo et al., 2003). These important pilot studies reveal some retinotopic correlation between the stimulation and the phosphenes generated, demonstrating the feasibility of using a multielectrode array to elicit visual percepts that, to some degree, reflect the stimulation pattern. Since then, the field of retinal prosthesis has advanced rapidly, spawning the Argus II implant (Second Sight Medical Products, Inc.) the Alpha IMS implant (Retina Implant AG) that are commercially available, as well as several other prototype systems that are currently in clinical trials.

\subsection{Retinal prosthetic systems and clinical implications}

A retinal prosthesis functions as an integral system that consists of multiple components. Typically, it contains an image acquisition device, an image processor, a stimulator chip and an electrode array. The image acquisition device captures images from the visual field that are directly or indirectly translated into stimulation patterns for the multi-electrode array that is positioned near the retina. In a cameraelectrode based system, images are captured by a video camera and converted by a specialized processor to the stimulation patterns that are subsequently delivered to the implanted stimulator chip. In contrast, in a photodiode based system, the visual information, sometimes preprocessed, is directly detected by the electrode-coupled photodiodes to generate electrical stimuli. . When needed, the power and data transmission between the external part of the device and the implant often take the form of radio frequency (RF) telemetry and/or optical link that is minimally invasive. Despite similarities in the basic architectures of different retinal prosthesis systems, their specific designs diversify, largely depending on the locations where the electrode array is implanted and the complexity of the implanted

electronics. Three main types of retinal implants have been developed: epiretinal prostheses, anchored to the inner surface of retina; subretinal prostheses, embedded between retina and RPE/choroid; and suprachoroidal prostheses, implanted between choroid and sclera (Figure 3).

\subsubsection{Epiretinal prostheses}

Epiretinal prostheses, sitting on the innermost layer of retina, have several advantages: 1) Ease of surgery: the prosthesis contacts the retina on the inner surface that is accessible from the vitreous and the vitreous cavity makes room for surgical maneuvers, reducing risks of mechanical damage to the retina; 2) Heat dissipation: besides choroidal perfusion, fluid in the vitreous cavity serves as an additional heat sink that enhances the removal of the heat generated by the electronics of the implant, lowering thermal risks for chronic use (Opie et al., 2012); 3) Proximity to the ganglion cells: the device directly stimulates ganglion cells, thus is potentially useful in extended retinal degeneration where inner 
retina circuitry is altered. The disadvantages of the epiretinal prostheses include the difficulty of fixating the electrode array on the retina and the perfused/distorted visual percepts due to undesired activation of the axons of passage. A large share of efforts in retinal prosthesis development has been directed towards the epiretinal type. Groups that have reported most progress in this arena are Second Sight Medical Products (SSMP) Inc. in Sylmar, California, USA, Intelligent Medical Implants (IMI) GmbH (acquired by Pixium Vision SA., France) and EpiRet GmbH in Germany. Devices from these three groups all use external cameras and wireless power and data transmission to avoid transcutaneous wires.

\subsubsection{Argus I \& II}

Two generations of devices, Argus I and Argus II, were developed by SSMP. Argus I is a first-generation epiretinal prosthesis approved for an investigational clinical trial by the United States Food and Drug Administration (FDA). Studies on the Argus I demonstrated the safety of long-term stimulation, motivating the development of the more advanced Argus II retinal implant, which received European Union approval (CE Mark) in 2011 and FDA market approval in 2013. Argus I was a modified cochlear implant and strictly an experimental device, while Argus II was designed as a retinal prosthesis intended for commercial use.

The basic operations of the Argus series systems are similar, both consisting of a miniature camera mounted on a pair of glasses, an external video processing unit (VPU) worn by the user, as well as an extraocular and an intraocular implant that are interconnected via a transscleral cable. The camera captures visual scenes and sends the information to the VPU for advanced pixilation and processing (Figure 4A). The extraocular electronics, along with a transceiver antenna, converts the RF signals it receives wirelessly from the VPU to the electrical pulses whose amplitude corresponds to the brightness of the local pixel. The extraocular electronics are packaged in a hermetic enclosure formed by a titanium (Argus II) or ceramic (Argus I) case joined to a feedthrough, a substrate with isolated conductors that bridge the electrical connection across the case (Figure 4B). Stimulation pulses are delivered by the cable to the intraocular electrode array that is attached to the retina via a tack.

The extraocular component of Argus I was surgically implanted in the temporal bone and the intraocular array contains 16 electrodes in a $4 \times 4$ arrangement, with a center-to-center separation of $800 \mu \mathrm{m}$. Two electrode diameters, $250 \mu \mathrm{m}$ and $500 \mu \mathrm{m}$, were used to determine how size affected impedance and perceptual threshold, i.e., the minimum current needed to generate a phosphene. Clinical studies using arrays with alternating sizes showed that size was not as important as other factors, such as stimulation amplitude and frequency, and that threshold was low enough to allow even greater reduction in electrode size (de Balthasar et al., 2008). As a result, a reduced electrode diameter was used for Argus II to allow for a higher number of electrodes on the array. The intraocular electrode array of Argus II contains $6 \times 10$ electrodes of $200 \mu \mathrm{m}$ diameter, separated by $575 \mu \mathrm{m}$. Distinct from Argus I, the extraocular electronics of the Argus II implant, packaged in a metal case, is sutured to the episclera under the rectus muscles in the superotemporal quadrant, and is held in place by a scleral band. Figure 4C illustrates the electrode layout used in Argus I and Argus II, respectively. 
Argus I was implanted monocularly in 6 subjects blinded by RP (de Balthasar et al., 2008; Horsager et al., 2009; Mahadevappa et al., 2005; Yanai et al., 2007). All subjects perceived light when the device was activated and they could perform visual spatial and motion tasks after a short period of training. Safety was observed with all devices even though one subject had the device explanted for unrelated health reasons. The early and interim results, collected up to 4 years after implantation, presented several important findings: 1) Subjects described phosphenes as round, oval and elongated shapes (de Balthasar et al., 2008; Nanduri et al., 2008). 2) Phosphene brightness increased as a function of stimulation amplitude and frequency but phosphene size exhibited much higher dependence on the amplitude than frequency (de Balthasar et al., 2008; Nanduri et al., 2012). 3) Perceptual thresholds maintained well below the safe limit of the platinum electrodes (charge density of $0.35 \mathrm{mC} / \mathrm{cm}^{2}$ per pulse), allowing safe and chronic suprathreshold stimulation (de Balthasar et al., 2008; Mahadevappa et al., 2005). 4) The distance between the retinal surface and the electrode is a critical determinant of the efficiency of stimulation, underscoring the importance of keeping the array in close proximity of the retina (de Balthasar et al., 2008; Mahadevappa et al., 2005). 5) Synchronized stimulation at different retinal locations was able to produce visual percepts at an acuity level that matched the spacing of electrodes in the array (Caspi et al., 2009; Humayun et al., 2003). Additionally, these studies found no evidence of tissue damage or electrode corrosion. The long term safety and effectiveness of Argus I is further demonstrated by a recent report on the 10-year followup of one subject (Yue et al., 2015a). OCT and other ophthalmic images showed a stable physical retina-implant interface, despite the formation of fibrotic tissues around the tack in early months after the surgery. The fibrosis did not progress or spread to other retinal areas. While similar perceptual thresholds were obtained on $250 \mu \mathrm{m}$ and $500 \mu \mathrm{m}$ electrodes initially, the larger $500 \mu \mathrm{m}$ electrodes exhibited significantly lower thresholds 10 years postsurgery (Yue et al., 2015a). The implication that larger electrodes may form a more stable functional interface with the retina in the long run, although at the expense of spatial resolution, offers a new perspective to the design of the electrodes for future implants.

Compared with Argus I, the Argus II array not only contains a higher electrode (pixel) density for increased spatial resolution, but also covers a larger retinal area to accommodate a greater visual field. Single electrode of Argus II subtends a visual angle of $\sim 0.7^{\circ}$ and the entire array $\sim 11^{\circ} \times 19^{\circ}$, as $270 \mu \mathrm{m}$ on retina approximates $1^{\circ}$ in visual field. Between 2007 and 2009, a total of 30 subjects ( 29 with RP and 1 with choroideremia) received the Argus II implant in the United States and Europe (Ho et al., 2015). Among these 30 devices, 29 remain implanted and functional, only 1 was explanted due to recurrent conjunctival erosion, rather than device failure. All subjects were able to perceive light during electrical stimulation (Weiland and Humayun, 2014). Since the camera of Argus II is mounted on the head, but not in the eye, the association between the visual scene and the eye movement as in normally sighted people no longer exists. To compensate, the subjects were trained to keep the gaze ahead and use head movement to scan the visual scene. All subjects adapted after a short period of training and a majority of them performed significantly better with the system ON vs. OFF in visual function tasks (Ho et al., 2015).

The standard clinical visual function tests of Argus II include target localization, motion detection and grating visual acuity (Luo and da Cruz, 2016). Target localization requires the subjects to scan the visual 
scene and point to a white square that appeared on a black screen at random locations. The recently published 3 year results indicate that, with the system ON, $89 \%$ of the 28 subjects were able to localize the target with a higher accuracy than with the system OFF (Ho et al., 2015). Motion detection examines the subjects' ability to temporally resolve sequential activation of electrodes in an array. It relies on retinotopic preservation and temporal processing of the remaining visual pathway. With the system ON, $56 \%$ of the 27 subjects better recognized the direction of a white bar moving across the black screen at a random angle (Ho et al., 2015). Grating visual acuity, following the principles similar to the standard Early Treatment Diabetic Retinopathy Study letter chart, measures subjects' ability to differentiate the orientation of black and white gratings of varying spatial frequencies (Zhou et al., 2013). No subject scored on the scale in this test with their system OFF whereas $33 \%$ and $48 \%$ of the subjects scored 2.9logMAR or above with the system ON at year 3 and year 1 , respectively. The average acuity value at these two time points were both 2.5logMAR (20/6325) and the best acuity obtained so far is $1.8 \log$ MAR (20/1262) (Ho et al., 2015; Humayun et al., 2012). The orientation and mobility tasks in more real-lifelike settings, such as finding a door on the wall and following a line on the floor, offer further evidence that the implant provides functional vision, and thus is of long-term benefits to the test subjects (Zhou et al., 2013).

Besides the standard clinical tests, laboratory-based exploration of Argus II-produced prosthetic vision was carried out in subsets of the subjects. Notably, Arsiero et al. (2011) demonstrated in 11 subjects that their ability to identify high contrast shapes was significantly improved by the implant. Da Cruz et al. (2013) reported that, with the system ON, 21 subjects showed ability to read white letters on a black screen in a darkened room and the average time taken to correctly identify the letters across different subjects ranged between 6 and 221 seconds. Furthermore, 6 subjects were able to consistently read letters of reduced sizes, the smallest measuring $0.9 \mathrm{~cm}$ at $30 \mathrm{~cm}$ and 4 were able to correctly identify simple 2-4 letter words. These studies offer compelling evidence that Argus II users can discriminate forms. More recently, Luo et al. (2014a; 2014b) took the testing from 2D to 3D by examining the ability of 7 subjects to identify common daily life objects that were presented in high contrast settings. Overall, subjects with the implant activated exhibited improved performance but the improvement is largely dependent on the contrast at the edge.

Interestingly, despite the fact that Argus II was not designed to produce color percepts, it has been reported that up to 9 different colors can be elicited depending on the stimulation parameters. The most prominent colors are white, yellow and blue (Stanga et al., 2011). Different colors could be stimulated from the same retinal area but with different parameters, such as stimulation frequency. Additionally, the subjects could simultaneously perceive two distinct colors at two retinal sites (Stanga et al., 2012). Albeit far from generating controlled color vision, these results, for the first time, shed light on the use of electrical stimulation to control the color of phosphenes. Color perception would significantly enhance the amount of visual information that could be delivered by electrical pulses, which, in the current stimulation paradigm, are mostly gray level encoded. The nature and stability of the electrically-elicited color percepts is still unclear and therefore awaits further investigation in order to develop a comprehensive stimulation algorithm that provides color vision to the blind patients in a reliable and predictable manner. 
In 2015, surgeons in Manchester, UK performed the first case of Argus II implantation in a dry AMD patient, as part of a phase I clinical trial aimed to evaluate the safety and utility of Argus II in late-stage AMD. The patient, at the age of 80 , had a total loss of his central vision and relied entirely on his peripheral vision before the surgery. The implant partially restored his central vision, enabling him to "see the outline of people and objects effectively" and "walk around the garden and see things" (Rose, 2015). This study, though at an early phase, suggests the potential of the Argus II and similar bioelectronic prostheses to enhance the visual experience of the advanced AMD patients beyond their remnant peripheral vision.

Overall, as the first retinal implant with regulatory approval, Argus series systems offer exciting opportunities to study prosthetic vision in a relatively large cohort of patients. Results from clinical trials provide strong evidence that electronic retinal implant is effective in restoring meaningful vision to patients blinded by photoreceptor degeneration. The restored visual acuity, to a large extent, depends on the spatial resolution of stimulation. Major challenges faced by these and similar devices will be discussed in Section 2.4 .

\subsubsection{IMI}

The IMI retinal implant consists of a visual interface, a pocket processor and a retina stimulator (Hornig et al., 2007). IMI operates similar to Argus II and the difference lies in the wireless transmission. Distinct from Argus II that uses a single pair of RF transceiver coil for power and data transmission, IMI employs two wireless links: RF transmission for power and infrared (IR) optical link for data. The IR transmitter, consisting of IR LEDs, is embedded in the visual interface and located in front of the eye. The IR receiver lies intraocular, as part of the implant. The optical link allows for high data rate and it can be actively interrupted by simply closing the eyelid, as an instinctive response in normally sighted people. The prototype IMI carries 49 iridium oxide electrodes that are connected via a cable to the retina stimulator electronics encapsulated by polyimide (Figure 4D), without additional hermetic packaging that would endure in physiological environment. Lack of hermetic sealing likely poses a major obstacle in the chronic use of this system.

Acute stimulation with the IMI electrode array was demonstrated to be effective in eliciting visual perception in 19/20 patients with advanced RP. The visual percepts were reported in different shapes, sizes, colors and brightness, even if only one electrode was activated (Hornig et al., 2007). The threshold charge, measured from 15 patients, ranged from 20 to $768 \mathrm{nC}$, all within the safe limit of charge capacity of the iridium oxide electrodes (Keseru et al., 2012). The chronic performance of the device was evaluated in 4 subjects during a follow-up period of over 9 months and the results showed that the implant did not cause tissue damage or abnormal cell growth in the eye. The patients were able to discriminate two stimulation points and recognize simple shapes when multiple electrodes were activated (Richard et al., 2007). Device performance beyond 9 months, however, is unclear.

In 2016, Pixium Vision, which acquired and further developed IMI, launched a clinical trial to assess the safety and effectiveness of IRIS II, a 150-electrode epiretinal device, in 10 patients with retinal dystrophy. Though the technical details of the IRIS II system are not publicized yet, several distinguishing features 
have been unveiled - a higher number of electrodes than the existing epiretinal systems, an explantable design that allows the electrode array to be safely removed and a smart camera that captures changes of the visual scene to avoid temporal redundancy that is common to the conventional frame-based image acquisition methods. The concept of the event-based image sensor was described by Lorach et al. (2012).

\subsubsection{EPIRET3}

EPIRET3 is the latest retinal implant model from Epi-Ret. A prominent distinguishing feature of EPIRET3 is that the implant, apart from the external camera and the image processor, fits entirely within the eyeball, unlike the Argus and IMI implants that both have intraocular electrodes connected transclerally to extraocular electronics. This completely wireless design eliminates the need to suture any component on the outside of the eyeball. RF signaling between the implant and the external device is established by a transmitter coil placed in front of the eye and a receiver coil that is in place of the lens. The receiver module and the stimulation chip, carried on a polyimide substrate, are connected to the electrode array by a microcable that extends to the back of the eye. The array is attached to the retina, in the region of macula, with 2 tacks. It contains 25 protruding electrodes, each measured $100 \mu \mathrm{m}$ in diameter and 25 $\mu \mathrm{m}$ in height, arranged in a hexagonal array with a center-to-center distance of $500 \mu \mathrm{m}$ (Klauke et al., 2011; Roessler et al., 2009). These electrodes are manufactured from gold covered with a thin layer of iridium oxide. The entire implant is coated with parylene $C$ to ensure biocompatibility and encapsulatedby silicone to protect the electronics. Encapsulation of the device using a conformal layer of polymer enjoys the benefit of a compact size but typically has a shorter lifetime than hermetic packaging (Vanhoestenberghe and Donaldson, 2013).

EPIRET3 was implanted in 6 RP patients in 2006 and removed 4 weeks later, according to the study design (Klauke et al., 2011). All subjects reported visual sensations as a result of electrical stimulation. The stimulation thresholds were within the electrochemical safe limit for charge injection of the iridium oxide electrodes. The protruding electrodes may have lowered the thresholds by having improved contacts with the retina. The ability to elicit visual percepts in these subjects exhibited a stronger dependence on the duration than the amplitude of the stimulation pulse. The subjects were able to differentiate simple stimulation patterns, such as a circle or a line. A 2-year follow-up study in 5 subjects after the removal of the device indicate that, other than moderate gliosis at the tacks (which were left in place), no major structural disruption or alteration occurred in the eye, suggesting the surgical safety of this entirely intraocular approach (Menzel-Severing et al., 2012).

\subsubsection{Subretinal prostheses}

Subretinal prostheses sit between the degenerated photoreceptor layer and the RPE. It passes current to the outer and middle sections of retina (e.g. bipolar cells), therefore taking advantage of the existing neural processing in these retinal layers and meanwhile possibly avoiding the direct stimulation of ganglion cell axons that causes distortion of the visual perception. The limited subretinal space puts a constraint on the implant size, but it allows the implant to be held in place by pressure, without the need of a tack as is used for epiretinal prostheses, although subretinal implants may use a silicone oil 
tamponade (Stingl et al., 2013a). Compared to epiretinal implantation where the vitreous flow and choroidal perfusion is unhindered, subretinal implantation may block the fluid communication between the retina and the choroid, obstructing the heat dissipation from the retina and the nutrient transport to the retina. Whether this could result in the atrophy of the retinal tissues around the implant area in the long term is under debate (Peachey and Chow, 1999; Rizzo and Wyatt, 1997; Sailer et al., 2007).

Two basic approaches to subretinal stimulation have been developed: one that uses a standard electrode array and the other that uses a microphotodiode array (MPDA). From the system perspective, the first approach is similar to the aforementioned epiretinal implants in the sense that images are still acquired and processed by the external devices and the electrode array only functions as a slave current source under the command of the stimulator chip. In contrast, MPDA itself detects light, eliminating the need for cameras as the visual scene is projected by the lens on the array. Each microphotodiode in the array functions independently by transforming local luminance level, in a proportional manner, into electrical pulses and directly stimulating the retinal neurons nearby. Since the MPDA is intraocularly located, patients enjoy the benefits of using eye movement, instead of head movement, to scan the visual scene.

\subsubsection{ASR}

Artificial silicon retina (ASR) from Optobionics, a Chicago based company, is the first implant of this kind that entered clinical trials (Chow et al., 2004). The ASR microchip ( $2 \mathrm{~mm}$ in diameter and $25 \mu \mathrm{m}$ in thickness) is a silicon-based device that contains approximately 5000 isolated microphotodiodes separated from each other by $5 \mu \mathrm{m}$. Each photodiode pixel has a size of $20 \times 20 \mu \mathrm{m}$ and is bonded with a $9 \times 9 \mu \mathrm{m}$ iridium oxide electrode. This device is electrically passive, only driven by light. ASR was implanted in 10 RP patients and 6 of them had vision levels that allowed a follow-up of $>7$ years (Chow et al., 2010). The device was well tolerated and visual function improvements were observed in most of the patients, however, mostly in areas far from the implant site (Chow et al., 2010; Chow et al., 2004). The investigators attributed the improvements to the neurotropic effects of the implant that rescued or preserved the damaged retinal tissues, rather than the electrical activation of the neurons. Examination of the output current of these microphotodiodes revealed amplitude of several $\mathrm{nA}$, far below the $\mu \mathrm{A}$ level needed for neuronal activation (Palanker et al., 2005), thus proving inadequate to drive meaningful prosthetic vision if solely relying on the incident light. Technological variants that aim to provide enhanced photocurrents are demonstrated more promising in vision restoration.

\subsubsection{Alpha IMS}

Alpha IMS, developed by Retina Implant AG in Germany, also uses a MPDA for light detection and current generation, but includes externally powered circuits to amplify the photocurrents. Two forms of power supply to the circuits are developed: wired and wireless. In the investigational device, power is supplied by a percutaneous cable that crosses the skin behind the ear, while in the commercial device (Alpha-IMS), the percutaneous cable is replaced by a subdermal power module for wireless transmission (Stingl et al., 2013b; Wilke et al., 2011a). In both cases, the power and control signals received from the external module, including a transmitter coil, a power pack and a control unit, travel along the 
subdermal cable and an intraocular polyimide foil to the MPDA that is surgically placed beneath the fovea (Stingl et al., 2013b; Zrenner et al., 2011) (Figure 5A). The MPDA chip consists of 1500 independently operating elements that each includes a light sensitive photodiode connected to a differential amplifier, whose output is coupled to a square-shaped titanium nitride (TiN) electrode (50 $\times$ $50 \mu \mathrm{m}$ ). The chip is programmed to acquire images at a defined frequency (tunable but typically 5-7 Hz) in synchrony by all photodiodes, generating voltage pulses at the electrodes with an amplitude distribution corresponding to a $38 \times 40$ pixel luminance map of the image. Each pulse lasts about $1 \mathrm{~ms}$. The chip has a size of $3 \times 3 \mathrm{~mm}$, estimated to cover a visual angle of $11^{\circ} \times 11^{\circ}$ and a thickness of approximately $70 \mu \mathrm{m}$ when placed on the polyimide foil. The investigational device has an additional $4 \times 4$ array of light insensitive TiN electrodes $(50 \times 50$ or $100 \times 100 \mu \mathrm{m})$ on the tip of the chip for direct stimulation independent from the photodiode outputs. These electrodes were added to enable detailed studies of the electrode-retina interface not constrained by the MPDA capabilities. For example, relative efficacy of pulse polarity was studied using the direct stimulation electrodes (Wilke et al., 2011a; Zrenner et al., 2011). It was found from the direct stimulation that the minimum charge transfer of a single electrode located at the subretinal space to generate visual percepts was typically between 20 and $60 \mathrm{nC}$ per pulse (Zrenner et al., 2011).

11 patients blinded by end-stage retinal dystrophies received the investigational device, 7 of whom had RP, 3 had cone-rod dystrophy and 1 had choroideremia (Zrenner et al., 2011). In experimentercontrolled direct stimulation, $8 / 11$ reported phosphene perception upon stimulation with multiple electrodes and among these 8 patients, 6 reported phosphene perception upon single electrode stimulation. The investigators noted that sequential activation of the electrodes may be preferred over concurrent activation in pattern identification. 6 patients reliably identified simple patterns such as horizontal and vertical bars and 1 of them was able to discern more complex geometric forms and letters. Phosphenes elicited by single electrode stimulation was described by most as round, whitish/yellowish spots, although 2 patients reported seeing elongated, arc shaped phosphenes. Having demonstrated that direct subretinal electrical stimulation presents a feasible approach in generating spatially resolved visual percepts, the investigators examined MPDA-elicited vision. All 3 patients tested were able to locate bright objects on a dark table without training, 2 of whom could discern black and white stripes below the spatial frequency of 0.34 and 0.22 cycles/degree, respectively. 1 patient was able to distinguish different letters (5-8 cm height, Tahoma font) and recognize objects that share similar contours but differ in detail (e.g. a knife and a fork).

The interim report of the clinical trial of Alpha-IMS, the wirelessly powered commercial version of the device, was recently published (Stingl et al., 2015). Since 2009, Alpha-IMS has been implanted in 29 patients with end-stage hereditary eye diseases: 25 with RP and 4 with cone-rod dystrophy. Within 12 months postoperative, 25 patients reported light perception and 21 showed significant improvements in the performance of visually guided daily living tasks, recognition tasks and mobility. Among these patients, 13 deemed the implant useful in daily life. 3 patients were able to read some letters that subtended a visual angle between 5 and $10^{\circ}$. The spacing of $70 \mu \mathrm{m}$ between each neighboring offers a theoretical visual acuity of 20/250. Grating visual acuity measured from these patients roughly matched this theoretical limit, as the best grating acuity reported was $20 / 200$. However, the highest Landolt C 
acuity of the very same patient was 20/546. Not surprisingly, visual function outcome depends on foveal eccentricity as foveal placement of the device allows superior performance compared to the parafoveal and nonfoveal placement (Stingl et al., 2015; Stingl et al., 2013c). The investigators noted a decrease of visual function over time in a number of patients, due to technical failure of the implants that usually occurred 3-12 months after the implantation. One problem common to the early devices was cable breakage that was caused by the mechanical stress on the intraorbital cable by eye movement. This problem was successfully solved by surgical introduction of a parabulbar loop that minimized the stress. Short lifetime of the hermetic seal is another major issue causing the device failure, as the corrosion of the chip gradually led to the loss of its function. According to the investigators, modified encapsulation technology has shown encouraging results in animal studies and is currently under assessment in the ongoing clinical trial (Stingl et al., 2013b; Stingl et al., 2015). Ideally, the improved encapsulation will be transparent to the incident light in order to maximize photon absorption by the photodiodes.

\subsubsection{Photovoltaic Retinal Prosthesis}

Different from Alpha-IMS that relies on external power supply to amplify the stimulation currents, the photovoltaic retinal prosthesis developed by Palanker et al. (Mathieson et al., 2012; Palanker et al., 2005) offers an alternative that obviates the need for complex electrical circuitry and trans-scleral cabling. Instead of electrical amplification, this approach adopts optical amplification by converting ambient visual inputs into high intensity near infrared (NIR, 880-915 nm) laser pulsing that is projected onto the subretinal photodiode array. The laser projection system increases the photocurrent by a factor of 1000, sufficient to drive retinal neural stimulation. Specifically, in this system, images captured by a head-mounted camera are processed by a portable image processor and subsequently projected on the retina in NIR laser pulses by a video goggle. The goggle is transparent to visible light so that the remaining neurons in the retina can still sense visible light while being largely insensitive to the NIR light. The NIR received by the photodiode array generates local electrical current pulses for retinal stimulation. Each element in the array consists of a central iridium oxide electrode surrounded by 2 or 3 photodiodes in series arranged in a hexagonal pattern (Figure 5B). Photodiodes in series double or triple the output voltage, significantly increasing the dynamic range of the charge injection from the electrodes, while maintaining the light energy at physiologically safe levels. Implants of two pixel sizes (70 and $140 \mu \mathrm{m}$ ) have been fabricated, containing 20 and $40 \mu \mathrm{m}$ electrodes, respectively. All pixels are separated by $5 \mu \mathrm{m}$ trenches. Return electrode common to all pixels, as oftentimes seen in other retinal implant design, is replaced by the local return electrodes in the circumference of each pixel to spatially confine electric field and reduce electrical crosstalk between pixels (Lorach et al., 2015a; Mathieson et al., 2012).

This device has not yet entered clinical phase, therefore its safety and efficacy in human subjects have not been determined. Nonetheless, with a prototype chip $(1 \mathrm{~mm}$ wide hexagonal pattern and $70 \mu \mathrm{m}$ pixel size), the investigators demonstrated reliable activation of retinal ganglion cells in Royal College Surgeon (RCS) rats, an animal model of retinal degeneration. In vivo cortical recordings showed a spatial resolution of $64 \pm 11 \mu \mathrm{m}$, corresponding to half of the normal visual acuity in normal rats (Lorach et al., 2015b). In addition, similar to normal eyes, flicker fusion occurred at high stimulation frequency, suggesting the possibility to produce continuous visual perception with photovoltaic stimulation. NIR stimulation with pulse duration between 1 to $20 \mathrm{~ms}$ and peak irradiance ranging from 0.06 to 4 
$\mathrm{mW} / \mathrm{mm}^{2}$ were applied. The threshold in the RCS rats was found to be $\sim 1 \mathrm{~mW} / \mathrm{mm}^{2}$, exceeding the natural retinal irradiance by a factor of 1,000 (Lorach et al., 2015b). The investigators argue that the pulsed delivery of NIR at this intensity level results in an average irradiance far below the maximum permissible dose of NIR to retina for chronic exposure (Lorach et al., 2016). Since it's not clear from the group's publications whether long term changes occurred at the implant-retina interface, physically and functionally, their arguments in terms of ocular safety awaits further verification. In addition, no explicit statement of the packaging strategy has been made of the reported prototype, which is crucial for the safety and lifetime of a clinically stable chronic device. The availability of the goggles that can project NIR light to the retina in sufficient speed and energy is not reported but a holographic optical stimulation design has been described (Goetz et al., 2013).

\subsubsection{Boston Retinal Implant}

The MIT-Harvard group that forms the Boston Retinal Implant Project is one of the earliest groups in retinal prosthesis. Their subretinal system was derived from the epiretinal design and it uses a passive electrode array (i.e., no MPDA) for stimulation. The group has progressed from the first generation device that contained 15 electrodes to a new generation 256 channel prototype. The marked increase in the number of electrodes presented substantial challenges to the electronic system and hermetic sealing. In order to drive 256 independently controlled channels, telemetry system with enhanced power capacity and higher data rate is desired. As shown in Figure $5 \mathrm{C}$, the investigators relocated the transceiver secondary coils from the temporal region of the eye to the anterior to allow for a much bigger size that improves inductive coupling efficiency with the external primary coils (Kelly et al., 2011; 2013b). This prototype has the integrated chip enclosed in a metal case that is sutured to the sclera in the superior-nasal quadrant. High density 256 individual channels, in addition to demanding a high degree of compactness of the circuitry, added tremendous difficulty to hermetic packaging. The current version of the prototype features a novel design of co-fired high-count 256 ceramic feedthroughs in a titanium case (Figure 5C Right), the hermeticity of which was evaluated by the helium leak detection (Kelly et al., 2013b; Shire et al., 2014). The leak rate measured between $10^{-9}$ and $10^{-8}$ standard cc/sec, expected to afford the enclosure a lifetime of 5-10 years, although a more definitive assessment warrants further testing in carefully controlled physiological environments.

This device is currently at pre-clinical stage. Mockups of the earlier 15-channel prototype were implanted in 7 minipigs (Kelly et al., 2011; Kelly et al., 2013b). Examinations up to 1 year after surgery showed good tolerance and continued function of the device. Studies with the mockups of the 256channel device are not yet reported.

\subsubsection{Suprachoroidal prostheses}

Suprachoroidal prostheses have electrodes between choroid and sclera. In comparison with the epiretinal and subretinal counterparts, suprachoroidal implants are relatively distant from the retina. Separation of the implant from the retina potentially reduces the risks of retinal damage from the surgery and the implant. Abundance of blood vessels at choroid makes the thermal dissipation of less concern as heat generated at the choroid layer should be carried away by the increased blood flow 
(Hadjinicolaou et al., 2015; Parver et al., 1983). But on the other hand, with lengthened current travel path from the electrode to the target tissue, this stimulation site may be disadvantaged by the elevated perceptual threshold and worsened spatial resolution (Yamauchi et al., 2005). To better steer the current flow through the retina, a return electrode is typically located in the anterior part of the eye, for example, inside the vitreous cavity or on the cornea, to be less invasive.

\subsubsection{STS}

Semichronic suprachoroid transcleral (STS) prosthesis (Figure 6A) developed by Fujikado et al. in Japan, was tested in 2 RP patients in 2011 (Fujikado et al., 2011). The electronic metal case was placed subdermal behind the ears and the implant in a scleral pocket $(6 \times 5 \mathrm{~mm})$ formed by cutting a flap in the sclera (Morimoto et al., 2011). The stimulation chip contained an array of 49 platinum electrodes (500 $\mu \mathrm{m}$ diameter and $700 \mu \mathrm{m}$ separation), among which 9 were active, mostly likely due to limits in the electronics at the time. Biphasic current pulses $(0.5 \mathrm{~ms}$ width and $20 \mathrm{~Hz})$ were delivered and the amplitude was controlled under $1 \mathrm{~mA}$ for safety. Only 4-6 out of these 9 electrodes were able to elicit phosphenes within the current limit, and the charge levels were considerably higher than those reported with the epiretinal implants. Nonetheless, it allows the patients to localize objects and reach for them better than the chance level. Neither retinal detachment nor hemorrhage was observed after the surgeries. The device was removed 4 weeks after implantation so long term information is not available.

\subsubsection{BVA}

Bionic Vision Australia (BVA) Consortium, a joint team of researchers from different Australian research institutes, is developing several prototypes simultaneously with the aim to achieve wide-view suprachoroidal prosthetic vision and high resolution epiretinal prosthetic vision. From 2012 to 2014, their early suprachoroidal prototype was tested in 3 RP patients in a Phase I clinical trial. The intraocular array, inserted in the scleral pocket, consists of 33 platinum stimulating electrodes ( $400 \mu \mathrm{m}$ and $600 \mu \mathrm{m}$ diameter) and 2 large return electrodes ( $2000 \mu \mathrm{m}$ diameter) on silicone substrate (Figure 6B). The 13 stimulating electrodes on the outer ring were shorted together to form a large common ground. In addition, a third electrode was implanted subcutaneously behind the ear, serving as an extraocular return (Ayton et al., 2014; Shivdasani et al., 2014). Thus the implant contains a total of 20 individually addressable stimulating electrodes and 4 optional returns. The intraocular electrode array is connected by a helical lead wire to a percutaneous plug behind the ear. The plug, similar to what has been used in cochlear implants, serves as an exposed connector to the external control, allowing direct and flexible stimulation without the need for complex electronics and telemetry in this early prototype. The investigators noted that, in future devices, the plug will be replaced by wireless communication systems.

Post-surgical monitoring up to 2 years indicates that the implant remains stable and functional in the suprachoroidal space without causing significant retinal edema or atrophy. Phosphenes were reliably evoked in all 3 patients below the charge density of $158 \mu \mathrm{C} / \mathrm{cm}^{2}$ for $600 \mu \mathrm{m}$ electrodes and $237 \mu \mathrm{C} / \mathrm{cm}^{2}$ for $400 \mu \mathrm{m}$ electrode (Ayton et al., 2014), within the safe limit for chronic stimulation of platinum electrodes $\left(350 \mu \mathrm{C} / \mathrm{cm}^{2}\right)$. The threshold was found to be dependent on retina-electrode distance, similar 
to what was reported on epiretinal implants (de Balthasar et al., 2008). An increase of the threshold was observed over time along with an increase in the measure of the retina-electrode distance, but the cause is unclear. Various return configurations were tested, showing higher efficacy with monopolar pattern (1 large return distant from the stimulating electrode) (Shivdasani et al., 2014). In visual function tests, all 3 patients were able to localize light spots markedly better than the chance level and 1 patient achieved an estimated Landolt-C visual acuity of 2.62longMAR (20/8397) (Ayton et al., 2014).

\subsection{Challenges and system approaches}

Electrode characteristics and the key clinical results of the aforementioned bioelectronic retinal prosthetic systems are summarized in Table 1 . Several of these devices have been demonstrated to be effective in restoring some sight to the blind, yet physiological and technical challenges remain, limiting the visual experience of the subjects. Advanced understanding of the retinal responses to electrical stimulation reveals several key limiting factors and the corresponding system modification strategies.

\subsubsection{Visual acuity}

Visual acuity is a measure of the spatial resolution of the visual system. In normally sighted people, photoreceptors are capable of differentiating even slight changes in spatial patterns of the incident light, owing to the small receptive field of a single photoreceptor and also the fact that the incident light underwent very limited lateral diffusion when passing through the ocular optical system. That said, the image presented to the viewer is projected point-to-point by the lens on the retina, given no refractive errors. The cross section of the outer segment of rod and cone photoreceptors ranges between 0.5 to 4 $\mu \mathrm{m}$, comprising the basic light sensing element for optical stimulation. Correspondingly, the 20/20 vision represents the ability to resolve two points separated by 1 arcmin, equivalent to $4.5 \mu \mathrm{m}$ on retina. In pixelated visual stimulation, it is estimated that at least $\sim 600$ pixels are needed to allow for acceptable performance of visually guided activities such as navigation and reading (Cha et al., 1992b;

Sommerhalder et al., 2004). Unlike the optical stimulation, where the incident beam can be as narrow as the width of a photoreceptor, electrode-based activation is limited by the physical size of the electrodes as well as the lateral current spread. In addition, since bipolar and/or ganglion cells are being activated, the density and receptive field properties of the target cells contribute to visual acuity. Stimulation at different retinal locations may also result in differential levels of visual acuity as the receptive field converges as a function of eccentricity - the receptive field varies from 1:1 photoreceptors : ganglion cells at the fovea to thousands: 1 at the peripheral retina. Thus, the acuity is dependent not only on the spacing of pixels, but also on the pixel size and the contact with the target neurons.

\subsubsection{Acuity and electrode size}

The electrode size found in the current prosthetic systems ranges from tens to hundreds of $\mu \mathrm{m}$ in width. Passive multi-electrode arrays usually use larger electrodes in a relatively sparse array, in part owing to challenge of routing signals from a stimulator chip away from the retina to the multi-electrode array on the retina. The best grating acuity reported with the epiretinal Argus II implant is 20/1260, close to the theoretical limit imposed by the electrode spacing. The MPDA approach obviates the routing issue since the circuit and electrode are integrated on a single substrate. Thus, a denser array of electrodes is 
possible. The subretinal Alpha-IMS implant with an interelectrode spacing of $70 \mu \mathrm{m}$ has been reported to produce a grating visual acuity of $20 / 200$ at the best performance. It is important to note that electrode size is correlated with the upper limit of charge injection at the electrode-tissue interface. Two primary mechanisms of charge injection occur at the electrode-electrolyte interface: the reversible charging and discharging of the double layer capacitance/pseudocapacitance and the irreversible Faradaic reactions that onset at higher charge injection levels. Rule of thumb in designing an electrical stimulation system is to restrict the charge injection at a level low enough to be fully accommodated by the reversible process to avoid the irreversible charge transfer that may degrade the electrodes and produce harmful chemical species (Cogan, 2008; Merrill et al., 2005). Interestingly, it is the total charge delivered, rather than the charge density, that shows a strong correlation with the evoked neural response, evidenced by the finding that the charge density threshold of the cellular response increases rapidly with the decrease in the electrode size (Sekirnjak et al., 2006). In another word, to maintain similar response level, reduction in the electrode size will inevitably introduce increased charge density and the concomitant risks of electrode degradation. Therefore, choice of electrode material that has high reversible charge storage capacity is crucial to electrode miniaturization. Superior to bulk platinum with a charge density limit of $0.35 \mathrm{mC} / \mathrm{cm}^{2}$, advanced materials such as platinum gray $\left(1 \mathrm{mC} / \mathrm{cm}^{2}\right.$ ) (Zhou et al., 2013), titanium nitride $\left(0.9 \mathrm{mC} / \mathrm{cm}^{2}\right.$ ) (Weiland et al., 2002) and iridium oxide $\left(4 \mathrm{mC} / \mathrm{cm}^{2}\right.$ ) (Meyer et al., 2001) can inject 3-10 fold higher charges. Clinically, Argus II and Alpha IMS used platinum gray and iridium oxide, respectively. Charge density is also constrained by the safe stimulation limit of the neurons without causing damages. It has been found that increased charge density reduces total charge that can safely be delivered to the tissue per phase (McCreery et al., 1990; Shannon, 1992). Considering these constraints on charge density, electrode size cannot be picked arbitrarily small and it needs to satisfy safety requirements for chronic stimulation.

\subsubsection{Acuity and electrode-retina contact}

Spatial extent of electrical activation is also dependent on the electrical contact of the electrodes with the retina. To ensure trans-retina flow of the currents, return electrodes are conventionally placed on the opposite side of retina distant from the stimulating electrodes. This configuration, however, does little to confine the current spread or reduce the crosstalk between channels, since retina, along with the physiological saline, acts as inhomogeneous conductive medium in which current is dispersed. Various current focusing strategies have been explored, for example, utilizing recessed electrodes to constrain the electric field (Suesserman et al., 1991; Wilke et al., 2011b). The subretinally implanted well-shaped 3D electrodes exhibited increased selectivity compared to the planar electrodes of the similar dimensions. Interestingly, the bipolar cells were found to migrate into the cavity of these electrodes, providing an even more selective neural interface (Butterwick et al., 2009; Djilas et al., 2011). Additionally, Palanker et al. (2005) used distributed return localized to each stimulating electrode and reported focal activation of the target cells. Similar findings were described by Joucla and Yvert (2009). More recently, Habib et al. (2013) investigated a hexagonal configuration that has one stimulating electrode surrounded by 6 "guard" electrodes using a wholemount rabbit retina model. The response threshold of the retinal ganglion cells outside the area bound by the hex guard was found to be $>2$ fold higher than those inside, demonstrating localized cellular stimulation. However, this improved spatial 
confinement comes with the sacrifice in stimulation efficiency, as the current threshold was elevated compared with the conventional monopolar configuration. The close proximity between the stimulating and the return electrodes causes the current to be partly shorted by the more conductive physiological saline, bypassing the less conductive retina. This is especially true with the epiretinal implants, as the electrode array is usually 20-50 $\mu \mathrm{m}$ away from the ganglion cell layer, separated by the saline. An Origami-like design of 3D spherical arrays that potentially yields better electrical contact, by maximizing array apposition to the retina, has been under investigation (Liu et al., 2013; Monge and Emami, 2014). Such a 3D array is constructed from a 2D parylene-C film with designed folding crease patterns. When placed on a convex surface, the film can be folded at the crease to form a curved 3D shape that conforms to the surface curvature (Figure 7A). As illustrated in Figure 7B, the wrinkles that form between the unpatterned film (ii) and the sphere, indicating a nonconformal contact, are eliminated for the patterned structure (i).

\subsubsection{Acuity and retinal processing}

Another limiting factor to visual acuity may lie in the physiological response of retina to electrical signals. There has been some controversy over whether retinal activation down to single ganglion cell resolution is feasible. Stimulation and recording with high density multi-electrodes by the Chichilnisky group supports the idea that stimulation with small electrodes $(6-25 \mu \mathrm{m})$ is able to selectively evoke action potential firing from individual ganglion cells without activating the neighboring cells (Jepson et al., 2013; Sekirnjak et al., 2006). In contrast, Behrend et al. (2011), utilizing calcium imaging, found that activation area only scaled with the electrode diameter for larger electrodes and when the electrode size dropped below $60 \mu \mathrm{m}$, the minimum activation area remained at $150 \mu \mathrm{m}$. This discrepancy may arise from the sensitivity difference in the two measures of the local response threshold, but it is suggestive of some electrical signal spreading at the ganglion cell level. Indirect stimulation of ganglion cells through retinal network has been demonstrated to activate wider areas in the ganglion cell layer (Behrend et al., 2011). Retino-cortical spread function has been investigated in cat cortex (Eckhorn et al., 2006; Wilms et al., 2003). It was found that the epi- and sub-retinal thin film electrodes of $100 \mu \mathrm{m}$ produced a resolution of $\sim 1-1.2^{\circ}$ visual angle and the use of smaller fiber-cone electrodes with $20 \mu \mathrm{m}$ base achieved a higher, but nonlinearly improved resolution of $\sim 0.7^{\circ}$ (Eckhorn et al., 2006). These observations further imply that retina and visual centers in the brain may interpret electrical signals differently from the normal visual inputs, possibly fundamentally limiting the spatial resolution of electrically evoked visual percepts.

\subsubsection{Visual field}

A different aspect of prosthetic vision, complimentary to visual acuity but equally important, is visual field. The normal monocular human vision field subtends a horizontal angle of almost $180^{\circ}$ and a vertical angle of $150^{\circ}$, with the macula encompassing a radius corresponding to $17^{\circ}$ and the fovea to the central $5.2^{\circ}$ (Zhu and Yang, 2002). Studies in low vision patients indicate that increased visual field adds significantly to patients' mobility and overall visual experience. It was found in RP patients that the level of visual field is strongly correlated with the perceived difficulty in performing common activities (Szlyk et al., 1997). Psychophysical experiments conducted in normally sighted subjects revealed that $27^{\circ}-30^{\circ}$ of visual angle provided adequate mobility (Cha et al., 1992b; Dagnelie et al., 2007). To fully restore normal 
visual field, the stimulation array should cover the entire retina, with an estimated dimension of $\sim 4 \mathrm{~cm}$ (Weiland and Humayun, 2014). The actual size of the array, however, is limited, largely by surgical and mechanical considerations. An epiretinal array is inserted into the intraocular space through an incision on the eyeball. The incision that can be safely made is less than $5 \mathrm{~mm}$, placing a constraint on the width of the array. The array of Argus II, affixed to the fovea region of the retina, has a dimension of $4 \times 6 \mathrm{~mm}$, covering a maximum diagonal visual angle of $22^{\circ}$. For subretinal implantation, the retina has to be detached first in order for the array to be slid underneath, therefore increasesing the array size risks detaching the entire retina, which is detrimental to the long-term health of the retina and the functionality of the device. Array of the Alpha IMS implant covers a diagonal visual angle of $15^{\circ}$.

Various approaches have been taken to improve the prosthetically restored visual field. Wide field arrays aimed to cover a large retinal area and meanwhile being surgically safe are being explored. A foldable epiretinal array that could provide $34^{\circ}$ of visual field was recently reported (Ameri et al., 2009). The concentric array (Figure 8), when folded, can be inserted through a $5 \mathrm{~mm}$ scleral incision and it will expand into a $10 \mathrm{~mm}$ wide array inside the vitreous cavity. Efficient stimulation stipulates on the close proximity between the array and the retina, making the mechanical conformity of the array to the curved shape of the retina especially desirable. This foldable array has been shown to maintain good contact with the canine retinas 3 months after implantation (Zhang et al., 2013). Another strategy involves projecting wide-field images uncropped to a small retinal area, equivalent to converging the view. This approach, however, comes at the expense of visual acuity and image minification (Cha et al., 1992a; Hayes et al., 2003). Conversely, image magnification can be achieved by zooming in on the visual field. This feature was tested in Argus II and reportedly enabled 20/200 vision with 16x magnification in the test patient (Sahel et al., 2013), but the high sensitivity of image shifting to the subject's head movement may compromise its appeal for daily use.

\subsubsection{Stimulation selectivity and efficiency}

\subsubsection{Ganglion cell response and phosphene fading, streaking}

Visual percepts elicited by electrical currents are dependent on the types of retinal neurons stimulated. Retinal ganglion cells can be activated directly or indirectly via synaptic transmission. Ganglion cells respond to indirect stimulation by firing in bursts after a significant latency ( $\sim 10$ s of milliseconds), likely reflecting neural processing by the presynaptic bipolar cells and other interneurons such as amacrine cells (Jensen et al., 2005). In contrast, direct stimulation of the ganglion cells elicits single spike firing within 5 ms following the stimulus pulse (Fried et al., 2006; Sekirnjak et al., 2008). The spike bursts from the indirect stimulation resemble the natural spiking pattern of ganglion cells to visual stimuli, suggesting the use of indirect stimulation for prosthetic vision. However, exacerbated desensitization of the retinal ganglion cell responses to repeated indirect stimulation argues otherwise. It is well documented that, depending on the stimulation frequency, the sensitivity of retinal ganglion cells to electrical stimulation progressively decreased with the repeated stimulation (Freeman and Fried, 2011; Jensen and Rizzo III, 2007). This desensitization in the cellular response is observed in the electrical recording from multiple animal models and is believed to be highly correlated with the decay in the phosphene brightness perceived by the subjects implanted with the retinal prostheses (Ahuja et al., 
2008; Stronks and Dagnelie, 2014). Dissection of desensitization time course in rabbit retina reveals two components resembling the two phases of phosphene fading reported from Argus II clinical trials, one acting rapidly (hundreds of millisecond) and the other acting more slowly (tens of seconds), related to interneuron inhibition (Freeman and Fried, 2011; Perez Fornos et al., 2012). While synaptically mediated indirect activation of ganglion cells undergoes significant desensitization, threshold for direct stimulation remains stable. Ganglion cell responses from tiger salamander retina explant closely follows direct stimulation up to $500 \mathrm{~Hz}$ (Ahuja et al., 2008). Although direct stimulation provides superior temporal resolution, it activates the passing axon bundles of the ganglion cells whose soma are located much further away from the electrode, producing streak-like perceptions limited in spatial resolution (Nanduri et al., 2008). As illustrated in Figure 9, elongated visual percepts were reported by Argus I and II subjects.

\subsubsection{Selective stimulation and waveform}

Various stimulation strategies aimed to improve the temporal and spatial profiles of the retinal response have been studied. Selective activation of bipolar cells and ganglion cells is possible by altering stimulus waveform (Freeman et al., 2010; Fried et al., 2006; Margalit and Thoreson, 2006). Retinal ganglion cells are more susceptible to short duration pulses $(<150 \mu \mathrm{s})$ whereas inner retinal neurons favor longer pulse width. Bipolar cells are preferentially activated by sinusoidal stimulus at $25 \mathrm{~Hz}$ and ganglion cells at 100 $\mathrm{Hz}$, thus rectangular waveforms employed by retinal prostheses are likely to activate both cell types (Freeman et al., 2010). Within the ganglion cell population, specific activation of single ON and OFF parasol cells was initially accounted by Sekirnjiak et al. (2008), using small electrodes (9-15 $\mu \mathrm{m}$ diameter) and short duration (0.05-0.1 ms) biphasic stimulation. With similar approach, localized activation of ON and OFF midget cells and bistratified retinal ganglion cells was achieved, but at only 50\% of the time, due to the unwanted axonal activation (Jepson et al., 2013). It remains a challenge to preferentially activate specific ganglion cell populations by variation in pulses alone, regardless of spatial factors such as electrode size. Jensen and Rizzo (2006) found that, in subretinal stimulation, ON and OFF cells exhibited differential thresholds for anodic-leading current pulses but not for cathodic-leading pulses, possibly unveiling a mechanism for the targeted stimulation of ON and OFF signaling pathways.

\subsubsection{Stimulation efficiency and waveform}

Changes in the stimulus waveform influence the stimulation efficiency. Addition of an interphase gap between the leading cathodic phase and the following anodic phase has been demonstrated effective in reducing electrical stimulation thresholds for the epiretinal Argus II prosthesis (Weitz et al., 2014). Increasing the brightness of phosphenes can be achieved by either increasing amplitude or frequency of stimulation, but the latter allows for enhancement in brightness without increasing phosphene size (Nanduri et al., 2012). The working frequency of the subretinal Alpha IMS implant is typically set at 5-20 $\mathrm{Hz}$, though some patients preferred a lower frequency to prevent phosphene fading (Stingl et al., 2015). Freeman and Fried (2011) proposed a fade-resistant strategy that consists of longer duration desensitizing pulses ( $1 \mathrm{~ms}$ ) interspersed in the short duration stimulating pulse trains. The desensitizing pulses, expected to diminish the synaptically mediated response, are continuously delivered independent of luminance. The effectiveness of this strategy is not experimentally validated yet. 


\subsubsection{Eye movement and intraocular camera}

In normal vision, motion of the head, eye and hands coordinates naturally for quick and accurate execute of the visual tasks, such as mobility, navigation and object acquisition (Binsted et al., 2001; Marconi et al., 2001). Coupling of the eye-head movement is essential for fixation and the involuntary microsaccades are important in preventing the image from fading (Martinez-Conde et al., 2006), exemplifying the significance of incorporating eye movement in the visual prosthesis. For head-mounted cameras used in Argus II and some other systems, patients use head movement to compensate for the lack of eye controlled gaze. While no controlled comparison in patients has been performed, head scanning is most likely less effective.

Prostheses such as Alpha IMS that feature subretinally implanted photodiode array for image acquisition generate visual percepts intrinsically dependent on the direction of gaze. Evidence of ocular drifts and microsaccades has been noted in Alpha IMS-implanted patients (Stingl et al., 2015; Zrenner et al., 2015). These involuntary eye movements refresh the images and may contribute significantly to mitigating the phosphene fading and maintaining the perceptual stability. For implants that rely on external devices to capture images, miniaturized implantable cameras may be a solution. Stiles et al. (2011) proposed an intraocular camera that can be placed within the crystalline lens sac and connected to the microstimulator array (Figure 10). The device is housed in a small cylindrical hermetic capsule that will fit in the sac. Inside the housing, an aspherical lens with a very short back focal length ( $1 \mathrm{~mm})$ forms images on the CMOS sensor array. In an all intraocular design, image output of the camera is delivered to the stimulator chip, driving the electrode array for stimulation. Simulation of the intraocular camera function suggests that, by controlling the field of view with eye movement, users can perform the visual tasks in a more natural manner (Weiland and Humayun, 2014). Alternatively, an eye-tracking extraocular camera that detects the direction of gaze and captures images accordingly may offer similar benefits as an intraocular camera.

\subsubsection{Stimulation encoding}

Retina is a highly diversified network of over 80 different neuronal populations that form the building blocks for about 20 circuit mosaics for parallel visual signal processing (Dacey, 1999; Dacey, 2008). These 20 separate mosaics are interwoven over the entire retina, oftentimes with overlapping receptive fields, and each extracts a distinct feature of the image flow, such as luminance, contrast, shape, color and motion. Outputs of these mosaics are carried to the higher visual centers in the brain each via a specific ganglion cell channel, encoded by the spatiotemporal patterns of spiking (da Silveira and Roska, 2011; Trenholm and Roska, 2014). In the presence of the same visual stimuli, these anatomically distinct ganglion cell types are known to exhibit differential responses that are integrated and decoded by the cortex to generate sense of vision. Therefore a stimulation algorithm that incorporates the firing patterns specific to each mosaic has the potential to produce retinal outputs more readily interpretable to the cortex. Such strategies are particularly appealing for highly localized stimulations with small electrodes. Due to various constraints on the electrode size as discussed in Section 2.4.1.1, current devices only allow simultaneous activation of multiple cell populations. Nevertheless, technical advances in flexible electronics may someday enable human devices with single cell stimulation capabilities, so it 
is worthwhile to consider retinal processing algorithms that would be combined with such an implant to recreate ganglion cell firing.

Earlier electrophysiological studies have demonstrated the feasibility to predict primate ganglion cell responses by a linear-nonlinear (LN) cascade model with a difference-of-Gaussians or wavelet-shaped characteristic spatial profile (Frishman et al., 1987; Meister and Berry, 1999; Rodieck et al., 1962; Van Rullen and Thorpe, 2001). Eckmiller et al. (2005) conceived a tunable retina encoder module for epiretinal prostheses a decade ago. The proposed encoder treats the retina as an ensemble of spatialtemporal filters with parameters adjusted in iterative steps, through machine learning and subject feedbacks, to optimally mimic retinal information processing. Bomash et al. (2013) developed a LN model that adapts to a wide range of stimuli to better study population encoding. Lorach et al. (2012) demonstrated the feasibility to reconstruct the spatiotemporal properties of several ganglion cell groups with the visual inputs from an asynchronous contrast sensor, which supposedly provides improved temporal precision compared to the conventional frame-based image inputs. More recently, incorporating the involuntary eye movements (microsaccades, drifts and tremor) in the retina models was shown to improve the visual sensitivity to temporal and spatial changes in luminance (Olmedo-Payá et al., 2015). This type of retina encoder conceptualized a retinotopic input-output transformation, but it was far from a cell-specific strategy.

In 2014, Jepson et al. (2014) reported activation of a small mosaic of 6 ON parasol ganglion cells in healthy primate retinas with high temporal and spatial precision. Using high density electrode recording, the investigators identified distinct ganglion cell types and derived their receptive fields. Spike patterns of the identified ON parasol cells elicited by a moving bar were recorded, and subsequently reproduced, with high fidelity, by focal electrical stimulation with the same pattern. Additionally, it was shown that the focal stimulation of single ON parasol cell is highly specific, driving little off-target activity from the neighboring cells. This work suggests that it is possible to mimic the visual response of a specific ganglion cell type with focal stimulation, though unwanted axonal stimulation may persist. It remains questionable whether the same method applies to other smaller and more densely packed ganglion cell populations such as midget cells, a very important cell type involved in detail-attended vision including reading and face recognition. Similar questions can also be asked about stimulation at or around foveal locations as the ganglion cells are particularly dense in this area, with cell bodies displaced from a planar to a 3D arrangement (Figure 1A). As implied by the investigators, their stimulation strategy may be more suitable for stimulation in peripheral retina. The greatest hurdle for the application of this strategy in visually impaired patients, however, may be the identification of ganglion cell types in blind retina where normal visual responses are absent (Trenholm and Roska, 2014). More recently, the group developed automated classifiers for functional identification of the ganglion cell populations on the primate retina (Richard et al., 2015). The method utilizes large scale array recording of the retinal electrical activity, therefore is applicable to the blind retina. However in order to be useful in the retinal prosthesis setting, in vivo measurement of the voltage map remains to be developed as currently the method has only been demonstrated in vitro on the isolated retina.

\subsection{Cortical changes in retinal degeneration}


Efficacy of electrical stimulation in degenerated retina is correlated with the progress of the disease. The inner retinal remodeling and reorganization reshape the physiology. Numerous studies on degenerated retina isolated from the diseased animal models, e.g. mouse RP models $\mathrm{rd} 1, \mathrm{rd} 10$ and rat RP models $\mathrm{P} 23 \mathrm{H}, \mathrm{S} 334$ ter, have revealed elevated spontaneous activity levels that are oftentimes accompanied by higher cellular response thresholds to electrical stimulation, in comparison with the normal retina (Chan et al., 2011; O'Hearn et al., 2006; Sekirnjak et al., 2009; Suzuki et al., 2004). Not surprisingly, the electrically elicited perceptual threshold in human patients is also dependent on the severity of degeneration. Humayun et al. (1999a) have shown diminished light perception in more damaged retinal areas in RP patients. Moreover, Rizzo et al. (2003) demonstrated that the charge density threshold for epiretinal stimulation with $400 \mu \mathrm{m}$ electrodes was over 4 times greater measured from severe RP patients than from the normally sighted subject. The difference in electrically elicited visual perception between blind and normal subjects is believed to correlate with alterations in inner retina, but whether or how it is influenced by neuroplasticity in cortex remains to be determined. Electrically evoked potentials (EEP) recorded from the cortex offer some information, but it does not suffice a visuotopic mapping of the brain response to electrical stimuli. Functional imaging, on the other hand, presents a power tool to visualize cortical activities with superior temporal and spatial resolution.

Functional magnetic resonance imaging ( $\mathrm{fMRI}$ ) of patients with macular degeneration indicates that part of the cortex that normally responds to foveal visual inputs are strongly activated by the peripheral stimuli, confirming some level of neuroplasiticity in visually deprived cortex (Baker et al., 2005; Dilks et al., 2009). More recently, Xie et al. (2012) utilized quantitative positron emission tomography (PET) to monitor cortical activity by means of metabolic rate of glucose, under light or transcorneal electrical stimulation. Cortical activation maps were obtained from 5 retinal degenerated subjects and 5 agematched normally sighted subjects. They found that light and particularly electrical stimulation resulted in retinotopically-matched primary visual cortex activation in the diseased and the control groups, despite lower level of activation in the diseased group (Figure 11). These findings suggest that the primary visual cortex largely maintains its retinotopy despite long term vision deprivation. A close-up look of the electrically-evoked cortical activation map may be obtained with $\mathrm{fMRI}$, under the condition of the $\mathrm{fMRI}$-compatible electrical stimulation device.

\section{Light retinal stimulation: optogenetics and chemical photoswitches}

Over the last couple of decades, electrical retinal stimulation has successfully evolved from an idea, doubted by many, to an established domain rich in scientific and clinical achievements. The current technology, however, still faces many challenges and various limitations, physiologically and technologically, as summarized above. Light stimulation, a more naturalistic form of retinal neuron activation, has been sought after as an alternative vision restoration approach potential of superior spatial and temporal resolution. The emerging optogenetics and chemical photoswitches have been quickly employed to render light responsiveness to the surviving inner retinal neurons that are not intrinsically sensitive to light (Bi et al., 2006; Busskamp et al., 2010; Lagali et al., 2008; Tochitsky et al., 2014). Optogenetics photosensitize these neurons by genetically introducing light sensitive opsin-based proteins in the cell membrane, while photoswitchable molecules interface with native membrane proteins in a light dependent fashion. Encouragingly, research in both techniques has demonstrated 
feasibility of light control of retinal activities in blind animal models, though the clinical prospects await further evaluation.

\subsection{Opsin-based approaches}

Opsin-based light responsive proteins can be divided into two distinct families - animal opsins (visual pigments) and microbial opsins, both of which are seven-transmembrane structures. Animal opsins, such as rhodopsin found in rods and photopsin in cones, are G-protein coupled receptors that function as the initial stage of a cascade of intracellular phototransduction leading to transmembrane current flow through the cation channels. In comparison, microbial opsins are oftentimes themselves ion channels or ion pumps (Figure 12). In healthy human retina, photon absorption by the rod rhodopsin or cone photopsin, located in the photoreceptor outer segment membrane, triggers isomerization of the attached chromophore from 11-cis to all-trans retinal. The photoisomerized chromophore is subsequently dissociated from the opsin and transported out of the photoreceptors for recycling that involves participation of other cell types, such as RPE and Muller cells. The complexity of the visual cycle, as well as the RPE dysfunction that is often associated with retinal degeneration, have long been considered major hindrances in the use of human opsins in vision restoration.

\subsubsection{Animal opsins and status}

A very recent study by Cehajic-Kapetanovic at al. (2015) shows that ectopic expression of the human rhodopsin is effective in restoring visual responses and some visual behavior to the rd1 mice. Virally mediated expression of rhodopsin was found at both the ganglion cell layer and the inner nuclear layer. Expressed rhodopsin exhibited reproducible responses to light pulses at the intensity levels as low as $10^{12}$ photons $\mathrm{cm}^{-2} \mathrm{~s}^{-1}$, within the range of the irradiance encountered in our daily life. Treated mice were able to respond to the spatial stimuli, flicker and natural scenes in the behavioral tests. These results were obtained without supply of any exogenous chromophore, entailing that the natural level of retinal existing in degenerated retina may be sufficient to drive the light responses. However, the responses were very slow making it unlikely to allow motion vision at the current form. Unlike human RP, the rd1 mouse model has a very early onset and rapid progression of massive photoreceptor deaths, which may result in rather different alterations in retinal circuitry and microenvironment. As such, it remains a question how reliable the findings on this animal model may predict the human responses. Nonetheless, this study is an exciting step towards human opsin therapy in vision restoration and certainly warrants further investigation.

In addition to rod rhodopsin and cone photopsin, melanopsin represents the third class of opsin in human retina. It is found in intrinsically photosensitive retinal ganglion cells (ipRGCs) and it does not lead to image-forming vision but contributes to pupillary reflex and circadian rhythm regulation. Earlier attempts of ectopically expressing melanopsin in blind $\mathrm{rd} 1$ mice resulted in the recovery of light avoidance response and light discrimination of crude resolution (Lin et al., 2008). The light sensitivity falls within a functional range but the temporal resolution is rather limited as the melanopsin-mediated cellular responses persist on for many seconds upon removal of the visual stimuli. Similar to the human 
rhodopsin-based approach, the slow offset kinetics imposes a barrier in pursuing melanopsin-based restoration of functional vision, before a fast-action variant is developed.

\subsubsection{Microbial opsins and status}

In contrast to the human opsins, microbial opsins represent physiologically less complex systems as they are light gated ion channels/pumps that do not need a multi-element network for visual cycle. They utilize all-trans retinal, a vitamin A derivative, as the active form of the chromophore. After one photocycle, the bleached chromophore thermally relaxes back to the active form while remaining attached to the opsin protein (Haupts et al., 1997). Presumably, the level of endogenous all-trans retinal in human retina is sufficient to meet the requirement of heterologously expressed microbial opsin (Deisseroth et al., 2006; Zhang et al., 2006). A key property of the microbial opsins is that the generated photoresponses are very fast, indeed faster than the intrinsic photoresponses (Busskamp et al., 2010). The most commonly used tools are channelrhodopsin (ChR), a blue light sensitive cation channel, halorhodospin (NpHR), a yellow light sensitive chloride pump and bacteriorhodopsin (BR), a green lightsensitive proton pump. Variants with altered spectral properties and light response kinetics have also been created (Gradinaru et al., 2010; Gunaydin et al., 2010; Klapoetke et al., 2014; Lin et al., 2013; Lin et al., 2009).

\subsubsection{Non-targeted expression}

Laboratory optogenetic vision restoration was first reported in 2006 by Bi et al. (2006), showing that non-targeted expression of channelrhodopsin-2 (ChR2) in the surviving retinal neurons of rd1 mice revived ON light responses recorded from the retina and visual-evoked potential recorded from the cortex. In a later paper, by coexpressing ChR2 and NpHR in inner retina, the same group described the feasibility of using multiple wavelengths to drive opposite membrane polarizations to restore both ON and OFF light responses (Zhang et al., 2009). Further advancement of optogenetic therapy may favor population targeted expression that allows for more sophisticated light stimulus encoding and a better safety profile. For instance, preferred expression of ChR2 on the ON cells and NpHR on the OFF cells, respectively, will likely achieve a more naturalistic ON-OFF mechanism than expressing the same opsin in both populations. As far as safety, a cell type specific expression may prevent viral particles from potentially leaking to the blood stream and expressing in unwanted cell types.

\subsubsection{Cone targeted expression}

RP retinal dystrophy is initiated by degeneration of rods, followed by the deterioration of cones. Depending on the stage of the disease, the dysfunctional cones may be present for years even after the light-sensing outer segment is damaged (Cotter and Noell, 1984; Li et al., 1995). On the hypothesis that these remnant cone cell bodies may be susceptible to optogenetic intervention, Busskamp et al. (2010) genetically targeted NpHR to photoreceptors in the mouse models of RP. They found that NpHRexpressing cones restored the mouse light response by activating the cone pathway, which is capable of driving retinal circuitry for complex visual functions. These findings underline the most prominent advantage of recovering light sensitivity at the front-end of the visual signal pathway, that is, the maximized utility of the retinal processing. The major disadvantages are the dwindling number of the 
remnant cones with the progression of the disease in many, but not all, patients. A careful correlation of the genetic condition and the number of remnant cones could specify which patients would benefit the most for cone based vision restoration. In general, cones are more preserved in the fovea (Milam et al., 1998), making this approach best suited to restore foveal vision.

\subsubsection{Bipolar cell targeted expression}

Immediately downstream of the photoreceptors in the visual signal pathway are retinal bipolar cells that show good survival even in severe retinal degeneration (Santos et al., 1997). Lagali et al. (2008) first reported the ON-bipolar cell specific expression of ChR2, via electroporation, in rd1 mice. Electrical responses recorded from ganglion cells demonstrated light responses mediated by the ON circuits and restoration of center-surround organization. Subsequently, Doroudchi et al. (2011) virally transfected ChR2 in multiple mouse models of retinal dystrophy and showed consistent improvements in the visually guided behavior, in the absence of measurable immune or inflammatory response. Recently, highly improved viral transfection and optogenetic stimulation of ON-bipolar cells have been reported (Cronin et al., 2014; Mace et al., 2015). Targeting bipolar cells preserves some retinal processing capacity, but remodeling of the visually deprived inner retina may reshape the visual response. On the other hand, as neurotrophic effects leading to improved visual functions in blind patients have been observed in chronic electrical signal inputs (Chow et al., 2010), similar effects may also arise from the chronic light stimulation. It remains to be determined if and/or how much our visual system could adapt to this stimulation modality.

\subsubsection{Ganglion cell targeted expression}

As the retina's output unit, ganglion cells have also been targeted for optogenetic alteration - the major drawback being bypassing the upstream neural processing. Virally transfected optogenetic tools are highly expressed in the foveal region, where the ganglion cells are not arranged in the mosaic structure. Alternatively, Thyagarajan et al. (2010) used the crossbred of rd1 mice and the transgenic mice that express ChR2 in 30-40\% ganglion cells to create more homogeneous expression in the blind retina. Despite the presence of cellular light response and pupillary reflex, the investigators did not find visual function improvements in the transgenic mice. Multiple factors may underlie the failure, one possibility being lack of visual information encoding that mimics the naturalistic inputs to the ganglion cells. Nirenberg and Pandarinath (2012) offered a stimulation paradigm that may circumvent this problem. Similar to the concept of retinal encoder envisioned for electrical retinal prostheses, the algorithm simulates transformation of image inputs to the ganglion cell firing patterns, which are played back in the form of light stimuli. This strategy has exhibited favorable results in the mouse optomotor tracking test and the image reconstruction from the ganglion cell spike trains, in comparison with the unencoded stimulation. It is yet unclear how well the algorithm, treating each ganglion cell as an independent LN filter, can be generalized to all visual scenes and how feasible it is to adapt the algorithm to each individual patient, all with a large number of ganglion cell types organized in unique ganglion cell mosaics.

\subsubsection{Light stimulation system}




\subsubsection{Challenges in light sensitivity}

Among the top challenges to the optogenetic vision restoration is the poor sensitivity to light. The threshold intensity required to activate ChR2-sensitized bipolar cells and ganglion cells is $10^{15}$ photons $\mathrm{cm}^{-2} \mathrm{~s}^{-1}$ (Bi et al., 2006; Lagali et al., 2008). NpHR expressed in cones exhibits a slightly better light sensitivity that requires a minimum of $10^{13}$ photons $\mathrm{cm}^{-2} \mathrm{~s}^{-1}$ for measurable photocurrent (Busskamp et al., 2010). In comparison, activation threshold of the endogenous photopigments in rods $\left(10^{6}\right.$ photons $\left.\mathrm{cm}^{-2} \mathrm{~s}^{-1}\right)$ and cones $\left(10^{10}\right.$ photons $\left.\mathrm{cm}^{-2} \mathrm{~s}^{-1}\right)$ is substantially lower (Lagali et al., 2008). Furthermore, microbial opsins have limited sensitivity range - ChR2 and NpHR only adapt to intensity changes of 2-3 orders of magnitude whereas rods and cones adjust their responses to much broader intensity range, 89 orders of magnitude (Busskamp et al., 2010; 2012). As a result, on one hand, the low sensitivity demands for very high intensity of light for stimulation and on the other hand, the stimulation intensity has to be carefully calibrated in order not to the saturate the cell response, which could cause failure of the cells to follow high frequency stimulation (Grossman et al., 2011).

One approach to lowering the cellular response threshold is to enhance the expression level of the lightsensitive channels, which may be achieved by utilizing stronger promoters and optimized AAV serotypes, but adverse immune responses may be of concern. Alternatively, light sensitivity can be boosted at the channel level. Kleinlogel et al. (2011) reported CatCh, a ChR2 variant with increased permeability to $\mathrm{Ca}^{2+}$ ions that, by allowing for increased cation influx at unit time, improves the light sensitivity by 70 folds. Additionally, variants with red-shifted spectral sensitivity have been generated (Klapoetke et al., 2014; Lin et al., 2013), potentially preventing phototoxicity at high intensities, as single photons at a longer wavelength possess less energy than those at a shorter wavelength. Nonetheless, these microbial opsin tools are not yet sensitive enough to enable visual responses at average daylight intensity. Therefore, it becomes crucial to have a light stimulation system to present enhanced visual scenes to the retina. Note that the lack of responses at daylight intensities can be considered as a safety mechanism for initial clinical trials as in case of photophobia or other light evoked adverse effects, the light stimulation system can be turned off.

More recently, a new generation of optogenetic tool, Opto-mGluR6, a chimeric protein that consists of the light sensing domain of melanopsin and the intracellular domains of the ON-bipolar cell specific metabotropic glutamate receptor mGluR6, has been reported to recover the mice (FVB/N and rd1) visual response under moderate daylight (van Wyk et al., 2015). The threshold light intensity to evoke the ganglion cell response in the Opto-mGluR-expressing retina was $5 \times 10^{11}$ photons $\mathrm{cm}^{-2} \mathrm{~s}^{-1}$, 4 orders of magnitude lower than that of the ChR2. The increased light sensitivity arises from the intracellular signal amplification through the G-protein associated enzymatic cascade of mGluR6. Although the speed of the responses was improved compared to ectopically expressed melanopsin in ganglion cells, when OptomGluR was expressed from AAVs the responses are still slow to allow motion vision.

\subsubsection{Light processing and enhancement goggle}

The clinically usable light delivery system is under development. Conceptually it functions similarly to the augmented reality (AR) technologies by modifying real-world information to present enhanced 
sensory inputs to the user. It is envisioned to consist of a camera for image acquisition, a processing unit, a light projection system and possibly an eye tracker, all integrated in a pair of goggles (See Figure 13A for an example).

In a simple form the camera captures images without an eye tracker. This is feasible if the photosensitized part of the retina is smaller than the projected image on the retina and the observer moves the photosensitized part on the projected image such as in "tunnel vision". In a more sophisticated situation, the camera, working together with the eye tracker, captures and sends visual information in the direction of photosensitized retinal part only. The advantage of latter design is that it limits the amount energy pumped into the retina and therefore reduces light damage.

The processor has two potential functions: spatial rearrangement of pixels, if needed, and information encoding. Spatial rearrangement becomes beneficial if the image is projected onto a retinal area where the cells are not arranged in a mosaic. For example, bipolar cells and ganglion cells in the fovea are not arranged in regular mosaics as in the peripheral retina, instead they are pushed aside to allow, in healthy patient, for more efficient photon capture by the photoreceptors. This disrupted mosaic organization may introduce distorted mapping of the visual field to the photosensitized neurons, under which circumstances, compensative algorithms that reversely distort images before projecting to the photosensitized foveal region are desirable (Roska and Pepperberg, 2014). Information encoding, on the other hand, focuses on converting visual information to cell-specific stimulation patterns. This feature mimics neural computation of the retina that is bypassed by photosensitizing inner retina. The aforementioned Nirenberg and Pandarinatch approach (2012), based on LN filtering and machine learning, unfolds a possible roadmap for this endeavor. More complex computational models of retinal processing, or a combination of several models may produce improved resolution or a sense of direction-selective motion. See (Field and Chichilnisky, 2007) for a review on retinal modeling. Ideally, the processor maps the intensity range of the visual scene to the sensitivity range of the opsins, and possibly, in the future, with wavelength mapping as well, for color vision. The spatial rearrangement of the pixels and the stimuli encoding are all conducted real-time.

The image projection system projects the encoded stimuli to the retina through a high intensity, high resolution display. This can be achieved by spatial modulation of a light source with a micromirror array (DLP, digital light processing) (Figure 13B), a liquid crystal display (LCD) (Barrett et al., 2014), or alternatively, by a compact array of individually addressable microLED emitters (Grossman et al., 2010) (Figure 13C). DLP light modulation has been widely used, but it is less energy efficient in that the reflected light is discarded. In comparison, the microLED array is more energy efficient as the emission itself is patterned, but this technology is new and faces challenges in stability. Use of microLEDs for in vitro optogenetic stimulation has been demonstrated (Degenaar et al., 2010; Grossman et al., 2010). The ring-like 3D arrangement of the inner retinal neurons in fovea makes the 2D stimuli projection insufficient to accurately convey the spatial information of the visual scene. By allowing 3D excitation of the neurons with precise spatial control, holographic stimulation is hopeful to address this problem (Goetz et al., 2013; Reutsky-Gefen et al., 2013). Teutsky-Gefen et al. reported an in vitro rapid holographic stimulation system capable of a spatial resolution of $\sim 20 \mu \mathrm{m}$ and a temporal resolution of 
$0.5 \mathrm{~ms}$. Goetz et al. proposed a miniaturized configuration that could be incorporated in the goggle for clinical use.

It is hoped that the tremendous amount of research that is being invested in AR will, in the foreseeable future, generate exciting new technologies that may be utilized to produce compact, efficient and versatile optical stimulation systems for optogenetics.

\subsection{Chemical photoswitches}

Chemical photoswitches represent a distinct strategy of engineering light-control into inner retina in the sense that it obviates the need for genetic modification. Major classes of such molecules include photoisomerizable ligands and photovoltaic switches. The former are ligands of native ion channels (neurotransmitters, neuromodulators, channels blockers and etc.) coupled to a light sensitive moiety that changes conformation, i.e., photoisomerizes, upon photon absorption. The latter are usually in the form of light-excited electrical dipoles. See Figure 14 for a comparison.

\subsubsection{Photoisomerizable ligands}

Photoisomerizable ligands interface with the ion channels of the inner retinal neurons to achieve lightregulated ion flow, and thereby depolarize or hyperpolarize the cell membrane. Photoswitchability is commonly rendered by the azobenzene moiety that can be converted between trans and cis isomeric states by light. For parent azobenzene, trans-to-cis isomerization (fast, femtosecond scale) is triggered by UV and the cis isomer remains stable in dark (thermal relaxation rate very slow, on the time scale of hours) until being converted back to trans by visible light. This bi-directional photoisomerization with two wavelengths of light affords tremendous flexibility to the optical control of the neuronal activity. Chemical modifications of the azobenzene-containing structures have produced molecules with redshifted spectral sensitivity and faster relaxation kinetics (Beharry and Woolley, 2011; Kienzler et al., 2013).

It was first demonstrated in 2012 that intravitreally injected $\mathrm{K}^{+}$channel photoswitches, namely, AAQ (acrylamide-azobenzene-quaternary ammonium), restored light avoidance and light modulated locomotor behavior in rd1 mice (Polosukhina et al., 2012). However, AAQ-mediated ganglion cell activity is poorly sensitive to light and the activating wavelength falls in the phototoxic UV range. Later, Tochitsky et al. (2014) reported DENAQ (diethylamine-azobenzene-quaternary ammonium) (channel gating mechanism shown in Figure 14A), an improved generation of AAQ that confers light sensitivity to hyperpolarization-activated channels. DENAQ triumphs over AAQ in several respects. It has red-shifted absorbance spectrum (from UV to $400-550 \mathrm{~nm}$ visible range), higher light sensitivity that is comparable to ChR2 and NpHR, much faster thermal relaxation in dark ( $\sim 300 \mathrm{~ms}$ ) and much longer half-life (2.1 days). Interestingly, DENAQ only acts on degenerated retina, whose hyperpolarization-activated inward current is presumably enhanced from the normal retina.

Both AAQ and DENAQ interface with the voltage gated ion channels, Yue et al. $(2013 ; 2012)$ reported an alternative route by targeting the ligand gated $G A B A_{A}$ receptors, a major mediator of the inhibitory signaling in retina. It is found that $\mathrm{GABA}_{A}$ receptors in the retinal ganglion cells and bipolar cells are 
preferentially activated by the trans configuration of the photoswitch, a propofol-azobenzene conjugate termed MPC088 (mechanism shown in Figure 14B). In the prospect of channel-targeted delivery of the molecules, simultaneous light control of both the excitatory and the inhibitory signaling in retina may be achieved with photoswitches that act on different channel types.

\subsubsection{Photovoltaic switches}

Photovoltaic switches modulate membrane potential by generating light-dependent nano-scale electric field across the membrane. Numata et al. (2012) were the first to report using this new class of photoswitches (Ferrocene-porphyrin-C60 molecules) to optically control cellular electrical activity, though the mechanism was not clarified. Rohan et al. (2013) described a ruthenium bipyridine-based photovoltaic switch (RubpyC17) that inserted into the plasma membrane and upon visible illumination $(460 \mathrm{~nm})$ was switched to photoexcited state that could either accept or donate an electron. In the presence of reductant ascorbate, light exposure elicited membrane depolarization that led to spike firing, whereas in the presence of oxidant ferricyanide, membrane hyperpolarization was observed. More recently, intravitreal injection of RubpyC17 has been demonstrated to readily incorporate in the ganglion cell membrane and restore light responses in photoreceptor degenerated rat retina (Yue et al., 2015b). RubpyC17 is moderately fluorescent, potentially enabling in vivo imaging of the molecules in retina to track their distribution and membrane localization. Clinical prospect of this new technology awaits further evaluation.

\subsection{Clinical perspectives}

AAV is the most commonly used viral vector for optogenetic transduction in retina. The AAV2medidated expression of ChR2 has been demonstrated in the nonhuman primate marmosets, despite that the highest level of expression was observed at the peripheral region (Ivanova et al., 2010). The expressed ChR2 restored light responses in the marmoset ganglion cells, encouraging exploration of the clinical prospects of the approach. Though experiments in the rodents and marmosets do not suggest adverse immune response with the AAV-mediated gene delivery and optogenetic protein expression, the long-term safety needs to be studied on the primate models closer to humans before entering clinical trial. An important area in the development of improved AAV vectors is the search for more efficient, immunologically tolerable serotypes (Cronin et al., 2014; Dalkara et al., 2013; Zinn et al., 2015) and for cell type specific promoters (Cronin et al., 2014).

Unlike optogenetic treatments that introduce irreversible genetic modifications to the retina, photochemical treatments, in the current form, are temporary. Photoswitchable molecules will be metabolized by or removed from the physiological system over a time course from hours to days. This reversibility reduces risks of permanent damage if serious immune responses occur. Additionally, it is possible to adjust the dose to accommodate the progression of the disease or other conditions that may arise. However, the toxicity of the photoswitchable molecules to primate eyes is not yet known. The primary drawback of the photoswitchable molecules is the decreased effective concentration over time and frequent intraocular injection for persistent effect. Novel intraocularly implanted drug delivery 
system may be a solution for controlled or sustained delivery of the molecules (Roska and Pepperberg, 2014).

Despite the differences mentioned above, both optogenetics and chemical photoswitches restore light responses in the degenerated retina by photosensitizing the remnant retinal neurons. With similar light sensitivities, both approaches need an image projection system for enhanced visual inputs. Compared to microbial opsins, azobenzene-based photoswitches generally exhibit a slower off response to the removal of light stimuli, as the thermal relaxation from cis back to trans takes time. Accelerated cis-trans isomerization may be achieved by molecular structure modification and irradiation with an off wavelength to match the temporal resolution of optogenetic tools. Overall, the goggle-like optical stimulation system discussed in Section 3.1.3.2 is suitable for both optogenetics and photoswitches, though the image processing and stimuli encoding algorithms may differ. The genetic promoter conveniently allows for targeted expression of opsins in specific neuron groups but photoswitchable molecules tend to nonselectively stain the cells, unless some targeting mechanisms are worked out. Targeted expression/staining offers an opportunity to independently control a specific cell group, potentially demanding stimulation algorithms of higher levels of complexity, particularly when multiple types of photosensors are present.

\section{Ultrasound stimulation and prosthesis}

Focused ultrasound wave has recently been explored as a non-invasive alternative in neural stimulation (Gavrilov et al., 1996; Tufail et al., 2011; Tyler et al., 2008). Focused ultrasound pulses have been demonstrated to be effective in modulating mammalian cortical and hippocampal activities, though the mechanism remains largely unknown (Tufail et al., 2010). Notably, transcranial focused ultrasound is found to evoke activities in the somatosensory cortex in human (Legon et al., 2014). Focused ultrasound stimulation of retina was first described by Naor et al. (2012), in which study, ultrasound $(0.5 \mathrm{MHz}$ and $1 \mathrm{MHz}$ ) evoked potentials were observed in anesthetized rats with normal vision. The investigators envisioned an ultrasound retinal prosthesis that is capable of simultaneous multifocal stimulation at a large visual angle. The prosthesis consists of an external camera with an image processor and an ultrasound phased array, interfaced with the cornea via an acoustic coupling component, to project complex acoustic images onto the retina. Using much higher acoustic frequency (43 MHz), Menz et al. (2013) demonstrated stable responses elicited by ultrasound stimuli in isolated salamander retina. Interestingly, ultrasound stimulation was found not to directly activate ganglion cells, but the interneurons beyond photoreceptors.

These studies, though still in a small scope, suggest that focused ultrasound stimulation may be a useful noninvasive alternative to electrical or optical stimulation. Yet a number of fundamental questions await to be addressed: 1) Which cellular compartment(s) are responsive to ultrasound and if/how they exist in degenerated human retina; 2 ) Is there any cell type-specific ultrasound stimulation mechanism; 3 ) Is there any long-term tolerance issue with the chronic ultrasound stimulation; 4) Which frequency is most efficient in inducing retinal activities and how that frequency plays into the spatial and temporal resolution of the ultrasound stimuli. With $43 \mathrm{MHz}$ stimulation, Menz et al. (2013) achieved a lateral resolution of $\sim 100 \mu \mathrm{m}$. Higher frequency leads to finer resolution, but meanwhile introduces 
exacerbated ultrasound attenuation as the wave propagates through the ocular tissues. Therefore calibration of the acoustic frequency and the duty cycle, from both the biological perspective and the technical perspective, is of great importance to assessing the effectiveness and safety of the ultrasound stimulation.

\section{Future Directions}

The bioelectronic, optogenetic, photochemical and ultrasonic approaches are all aimed to restore sight by activating the inner retinal neurons that survive the extensive photoreceptor degeneration. Bioelectronics is the most developed technology among the four and has generated two prosthetic systems that are clinically available: Argus II and Alphas IMS. These unprecedented devices have restored some vision to the end-stage RP patients that have been blind for decades. The clinical data obtained with these systems offer invaluable sights into the prosthetic vision and may serve as reference to not only bioelectronic but also other retinal stimulation modalities. Optogenetic and photochemical approaches have gained attention in more recent years and the proof-of-concept studies have shown promising effects in restoring spatially and temporally resolved light percepts in animal models, but this technology is still at the preclinical phase. Ultrasound approach is, at present, in the infant stage and advanced understanding of the cell response mechanism will tremendously help its future development. From a system perspective, the approaches reviewed here are mostly different in the actuator end, but share similarities in the image capture and processing end - all demanding a fast computational system that extracts useful visual information and encoding it into stimuli naturalistically responded by the retinal neurons. There is a looming trend in the confluence of these approaches, through shared retinal encoding platforms and novel light sensors. For example, a polymer photovoltaic film that has been developed by Ghezzi et al. (2013) to interface with the retina, technologically speaking, lies somewhere between the photodiode array and photovoltaic switches. On one hand, similar to the photovoltaic switches, the continuous light-responsive film has the potential to reach high spatial resolution and on the other hand, unlike the photovoltaic molecular switches that are gradually cleared out of the eye, this film can potentially form a stable interface with the retina and therefore obviates the need for periodic molecule replenishment. Though still in its infantry, such cross-modal technology is hopeful to break the boundaries between the existing technologies and enjoy the benefits of each. With the continued advancement in material science, electronics, microfabrication and biological techniques, facilitated by further understanding of retinal processing, prosthetic vision that better mimics normal visual percepts is anticipated. 


\section{Acknowledgement}

This work is supported by the W. M. Keck Foundation, the National Science Foundation (NSF) grant

(Award No.: CBET-1404089), the Juliette RP Vision Foundataion, the Guangdong Innovative and Entrepreneurial and Research Team Program (No. 2013S046) and Shenzhen Peacock Plan of China. 


\section{References}

Ahuja, A.K., Behrend, M.R., Kuroda, M., Humayun, M.S., Weiland, J.D., 2008. An in vitro model of a retinal prosthesis. IEEE transactions on bio-medical engineering 55, 1744-1753.

Ameri, H., Ratanapakorn, T., Ufer, S., Eckhardt, H., Humayun, M.S., Weiland, J.D., 2009. Toward a wide-field retinal prosthesis. J Neural Eng 6, 035002.

Arsiero, M., da Cruz, L., Merlini, F., Sahel, J.A., Stanga, P.E., Hafezi, F., Greenberg, R.J., Group, A.I.S., 2011. Subjects blinded by outer retinal dystrophies are able to recognize shapes using the Argus II retinal prosthesis system. Invest Ophthalmol Vis Sci 52, 4951-4951.

Ayton, L.N., Blamey, P.J., Guymer, R.H., Luu, C.D., Nayagam, D.A., Sinclair, N.C., Shivdasani, M.N., Yeoh, J., McCombe, M.F., Briggs, R.J., Opie, N.L., Villalobos, J., Dimitrov, P.N., Varsamidis, M., Petoe, M.A., McCarthy, C.D., Walker, J.G., Barnes, N., Burkitt, A.N., Williams, C.E., Shepherd, R.K., Allen, P.J., Consortium, B.V.A.R., 2014. First-in-human trial of a novel suprachoroidal retinal prosthesis. PLoS One 9, e115239.

Baker, C.I., Peli, E., Knouf, N., Kanwisher, N.G., 2005. Reorganization of visual processing in macular degeneration. The Journal of neuroscience : the official journal of the Society for Neuroscience 25, 614618.

Barrett, J.M., Berlinguer-Palmini, R., Degenaar, P., 2014. Optogenetic approaches to retinal prosthesis. Vis Neurosci 31, 345-354.

Beck, H., Boden, W.E., Patibandla, S., Kireyev, D., Gutpa, V., Campagna, F., Cain, M.E., Marine, J.E., 2010. 50th Anniversary of the first successful permanent pacemaker implantation in the United States: historical review and future directions. Am J Cardiol 106, 810-818.

Beharry, A.A., Woolley, G.A., 2011. Azobenzene photoswitches for biomolecules. Chem Soc Rev 40, 44224437.

Behrend, M.R., Ahuja, A.K., Humayun, M.S., Chow, R.H., Weiland, J.D., 2011. Resolution of the epiretinal prosthesis is not limited by electrode size. IEEE transactions on neural systems and rehabilitation engineering : a publication of the IEEE Engineering in Medicine and Biology Society 19, 436-442.

Beltran, W.A., Cideciyan, A.V., Lewin, A.S., Iwabe, S., Khanna, H., Sumaroka, A., Chiodo, V.A., Fajardo, D.S., Roman, A.J., Deng, W.T., Swider, M., Aleman, T.S., Boye, S.L., Genini, S., Swaroop, A., Hauswirth, W.W., Jacobson, S.G., Aguirre, G.D., 2012. Gene therapy rescues photoreceptor blindness in dogs and paves the way for treating human $\mathrm{X}$-linked retinitis pigmentosa. Proceedings of the National Academy of Sciences of the United States of America 109, 2132-2137.

Bi, A., Cui, J., Ma, Y.P., Olshevskaya, E., Pu, M., Dizhoor, A.M., Pan, Z.H., 2006. Ectopic expression of a microbial-type rhodopsin restores visual responses in mice with photoreceptor degeneration. Neuron 50 , 23-33.

Binsted, G., Chua, R., Helsen, W., Elliott, D., 2001. Eye-hand coordination in goal-directed aiming. Hum Mov Sci 20, 563-585.

Boinagrov, D., Pangratz-Fuehrer, S., Goetz, G., Palanker, D., 2014. Selectivity of direct and network-mediated stimulation of the retinal ganglion cells with epi-, sub- and intraretinal electrodes. J Neural Eng 11, 026008.

Bomash, I., Roudi, Y., Nirenberg, S., 2013. A virtual retina for studying population coding. PLoS One 8, e53363.

Bressler, N.M., 2004. Age-related macular degeneration is the leading cause of blindness. Jama 291, 19001901.

Brindley, G.S., Lewin, W., 1968. The sensations produced by electrical stimulation of the visual cortex. J Neurophysiol 196, 479-493.

Brummer, S., Turner, M., 1975. Electrical stimulation of the nervous system: the principle of safe charge injection with noble metal electrodes. Bioelectrochem Bioenerg 2, 13-25. 
Busskamp, V., Duebel, J., Balya, D., Fradot, M., Viney, T.J., Siegert, S., Groner, A.C., Cabuy, E., Forster, V., Seeliger, M., Biel, M., Humphries, P., Paques, M., Mohand-Said, S., Trono, D., Deisseroth, K., Sahel, J.A., Picaud, S., Roska, B., 2010. Genetic reactivation of cone photoreceptors restores visual responses in retinitis pigmentosa. Science $329,413-417$.

Busskamp, V., Picaud, S., Sahel, J.A., Roska, B., 2012. Optogenetic therapy for retinitis pigmentosa. Gene Ther 19, 169-175.

Butterwick, A., Huie, P., Jones, B.W., Marc, R.E., Marmor, M., Palanker, D., 2009. Effect of shape and coating of a subretinal prosthesis on its integration with the retina. Exp Eye Res 88, 22-29.

Caspi, A., Dorn, J.D., McClure, K.H., Humayun, M.S., Greenberg, R.J., McMahon, M.J., 2009. Feasibility study of a retinal prosthesis: spatial vision with a 16-electrode implant. Arch Ophthalmol 127, 398-401.

Cehajic-Kapetanovic, J., Eleftheriou, C., Allen, A.E., Milosavljevic, N., Pienaar, A., Bedford, R., Davis, K.E., Bishop, P.N., Lucas, R.J., 2015. Restoration of Vision with Ectopic Expression of Human Rod Opsin. Current biology : CB 25, 2111-2122.

Cha, K., Horch, K., Normann, R.A., 1992a. Simulation of a phosphene-based visual field: visual acuity in a pixelized vision system. Ann Biomed Eng 20, 439-449.

Cha, K., Horch, K.W., Normann, R.A., Boman, D.K., 1992b. Reading speed with a pixelized vision system. Journal of the Optical Society of America. A, Optics and image science 9, 673-677.

Chan, L.L., Lee, E.-J., Humayun, M.S., Weiland, J.D., 2011. Both electrical stimulation thresholds and SMI-32immunoreactive retinal ganglion cell density correlate with age in S334ter line 3 rat retina. J Neurophysiol 105, 2687-2697.

Chow, A.Y., Bittner, A.K., Pardue, M.T., 2010. The artificial silicon retina in retinitis pigmentosa patients (an American Ophthalmological Association thesis). Trans Am Ophthalmol Soc 108, 120-154.

Chow, A.Y., Chow, V.Y., Packo, K.H., Pollack, J.S., Peyman, G.A., Schuchard, R., 2004. The artificial silicon retina microchip for the treatment of visionloss from retinitis pigmentosa. Arch Ophthalmol 122, 460469.

Cogan, S.F., 2008. Neural stimulation and recording electrodes. Annual review of biomedical engineering 10, 275-309.

Cohen, E., Agrawal, A., Connors, M., Hansen, B., Charkhkar, H., Pfefer, J., 2011. Optical coherence tomography imaging of retinal damage in real time under a stimulus electrodeThis paper was originally submitted for the special issue containing contributions from the Sixth Biennial Research Congress of The Eye and the Chip. J Neural Eng 8, 056017.

Cotter, J.R., Noell, W.K., 1984. Ultrastructure of remnant photoreceptors in advanced hereditary retinal degeneration. Invest Ophthalmol Vis Sci 25, 1366-1375.

Cronin, T., Vandenberghe, L.H., Hantz, P., Juttner, J., Reimann, A., Kacso, A.E., Huckfeldt, R.M., Busskamp, V., Kohler, H., Lagali, P.S., Roska, B., Bennett, J., 2014. Efficient transduction and optogenetic stimulation of retinal bipolar cells by a synthetic adeno-associated virus capsid and promoter. EMBO Mol Med 6, 11751190.

Curcio, C.A., Owsley, C., Jackson, G.R., 2000. Spare the rods, save the cones in aging and age-related maculopathy. Investigative ophthalmology \& visual science 41, 2015-2018.

da Cruz, L., Coley, B.F., Dorn, J., Merlini, F., Filley, E., Christopher, P., Chen, F.K., Wuyyuru, V., Sahel, J., Stanga, P., Humayun, M., Greenberg, R.J., Dagnelie, G., Argus, I.I.S.G., 2013. The Argus II epiretinal prosthesis system allows letter and word reading and long-term function in patients with profound vision loss. The British journal of ophthalmology 97, 632-636.

da Silveira, R.A., Roska, B., 2011. Cell types, circuits, computation. Curr Opin Neurobiol 21, 664-671.

Dacey, D.M., 1999. Primate retina: cell types, circuits and color opponency. Prog Retin Eye Res 18, 737-763.

Dacey, D.M., 2008. Physiology. morphology and spatial densities of identified ganglion cell. Ciba F Symp 765, 12. 
Dagnelie, G., Keane, P., Narla, V., Yang, L., Weiland, J., Humayun, M., 2007. Real and virtual mobility performance in simulated prosthetic vision. J Neural Eng 4, S92-101.

Daiger, S.P., Bowne, S.J., Sullivan, L.S., Blanton, S.H., Weinstock, G.M., Koboldt, D.C., Fulton, R.S., Larsen, D., Humphries, P., Humphries, M.M., Pierce, E.A., Chen, R., Li, Y., 2014. Application of next-generation sequencing to identify genes and mutations causing autosomal dominant retinitis pigmentosa (adRP), Retinal Degenerative Diseases. Springer, pp. 123-129.

Dalkara, D., Byrne, L.C., Klimczak, R.R., Visel, M., Yin, L., Merigan, W.H., Flannery, J.G., Schaffer, D.V., 2013. In vivo-directed evolution of a new adeno-associated virus for therapeutic outer retinal gene delivery from the vitreous. Sci Transl Med 5, 189ra176.

de Balthasar, C., Patel, S., Roy, A., Freda, R., Greenwald, S., Horsager, A., Mahadevappa, M., Yanai, D., McMahon, M.J., Humayun, M.S., Greenberg, R.J., Weiland, J.D., Fine, I., 2008. Factors affecting perceptual thresholds in epiretinal prostheses. Invest Ophthalmol Vis Sci 49, 2303-2314.

Degenaar, P., McGovern, B., Berlinguer-Palmini, R., Vysokov, N., Grossman, N., Pohrer, V., Drakakis, E., Neil, M., 2010. Individually addressable optoelectronic arrays for optogenetic neural stimulation, Biomedical Circuits and Systems Conference (BioCAS), 2010 IEEE. IEEE, pp. 170-173.

Deisseroth, K., Feng, G., Majewska, A.K., Miesenbock, G., Ting, A., Schnitzer, M.J., 2006. Next-generation optical technologies for illuminating genetically targeted brain circuits. The Journal of neuroscience : the official journal of the Society for Neuroscience 26, 10380-10386.

den Hollander, A.I., ten Brink, J.B., de Kok, Y.J., van Soest, S., van den Born, L.I., van Driel, M.A., van de Pol, D.J., Payne, A.M., Bhattacharya, S.S., Kellner, U., Hoyng, C.B., Westerveld, A., Brunner, H.G., BleekerWagemakers, E.M., Deutman, A.F., Heckenlively, J.R., Cremers, F.P., Bergen, A.A., 1999. Mutations in a human homologue of Drosophila crumbs cause retinitis pigmentosa (RP12). Nat Genet 23, 217-221.

Dilks, D.D., Baker, C.I., Peli, E., Kanwisher, N., 2009. Reorganization of visual processing in macular degeneration is not specific to the "preferred retinal locus". The Journal of neuroscience : the official journal of the Society for Neuroscience 29, 2768-2773.

Djilas, M., Oles, C., Lorach, H., Bendali, A., Degardin, J., Dubus, E., Lissorgues-Bazin, G., Rousseau, L., Benosman, R., leng, S.H., Joucla, S., Yvert, B., Bergonzo, P., Sahel, J., Picaud, S., 2011. Three-dimensional electrode arrays for retinal prostheses: modeling, geometry optimization and experimental validation. J Neural Eng 8, 046020.

Dobelle, W.H., Mladejovsky, M., Girvin, J., 1974. Artificial vision for the blind: Electrical stimulation of visual cortex offers hope for a functional prosthesis. Science 183, 440-444.

Doroudchi, M.M., Greenberg, K.P., Liu, J., Silka, K.A., Boyden, E.S., Lockridge, J.A., Arman, A.C., Janani, R., Boye, S.E., Boye, S.L., Gordon, G.M., Matteo, B.C., Sampath, A.P., Hauswirth, W.W., Horsager, A., 2011. Virally delivered channelrhodopsin-2 safely and effectively restores visual function in multiple mouse models of blindness. Molecular therapy : the journal of the American Society of Gene Therapy 19, $1220-$ 1229.

Dowling, J., 2009. Current and future prospects for optoelectronic retinal prostheses. Eye (Lond) 23, 19992005.

Eckhorn, R., Wilms, M., Schanze, T., Eger, M., Hesse, L., Eysel, U.T., Kisvarday, Z.F., Zrenner, E., Gekeler, F., Schwahn, H., Shinoda, K., Sachs, H., Walter, P., 2006. Visual resolution with retinal implants estimated from recordings in cat visual cortex. Vision Res 46, 2675-2690.

Eckmiller, R., Neumann, D., Baruth, O., 2005. Tunable retina encoders for retina implants: why and how. J Neural Eng 2, S91.

Fariss, R.N., Li, Z.Y., Milam, A.H., 2000. Abnormalities in rod photoreceptors, amacrine cells, and horizontal cells in human retinas with retinitis pigmentosa. Am J Ophthalmol 129, 215-223.

Field, G.D., Chichilnisky, E.J., 2007. Information processing in the primate retina: circuitry and coding. Annual review of neuroscience $30,1-30$. 
Freeman, D.K., Eddington, D.K., Rizzo III, J.F., Fried, S.I., 2010. Selective activation of neuronal targets with sinusoidal electric stimulation. J Neurophysiol 104, 2778-2791.

Freeman, D.K., Fried, S.I., 2011. Multiple components of ganglion cell desensitization in response to prosthetic stimulation. J Neural Eng 8, 016008.

Fried, S.I., Hsueh, H.-A., Werblin, F.S., 2006. A method for generating precise temporal patterns of retinal spiking using prosthetic stimulation. J Neurophysiol 95, 970-978.

Friedman, D.S., O'Colmain, B.J., Munoz, B., Tomany, S.C., McCarty, C., de Jong, P.T., Nemesure, B., Mitchell, P., Kempen, J., Eye Diseases Prevalence Research, G., 2004. Prevalence of age-related macular degeneration in the United States. Arch Ophthalmol 122, 564-572.

Frishman, L.J., Freeman, A.W., Troy, J.B., Schweitzer-Tong, D.E., Enroth-Cugell, C., 1987. Spatiotemporal frequency responses of cat retinal ganglion cells. J Gen Physiol 89, 599-628.

Fujikado, T., Kamei, M., Sakaguchi, H., Kanda, H., Morimoto, T., Ikuno, Y., Nishida, K., Kishima, H., Maruo, T., Konoma, K., Ozawa, M., Nishida, K., 2011. Testing of semichronically implanted retinal prosthesis by suprachoroidal-transretinal stimulation in patients with retinitis pigmentosa. Invest Ophthalmol Vis Sci $52,4726-4733$.

Gavrilov, L.R., Tsirulnikov, E.M., Davies, I.A., 1996. Application of focused ultrasound for the stimulation of neural structures. Ultrasound Med Biol 22, 179-192.

Ghezzi, D., Antognazza, M.R., Maccarone, R., Bellani, S., Lanzarini, E., Martino, N., Mete, M., Pertile, G., Bisti, S., Lanzani, G., Fabio, B., 2013. A polymer optoelectronic interface restores light sensitivity in blind rat retinas. Nat Photonics 7, 400-406.

Goetz, G.A., Mandel, Y., Manivanh, R., Palanker, D.V., Cizmar, T., 2013. Holographic display system for restoration of sight to the blind. J Neural Eng 10, 056021.

Gradinaru, V., Zhang, F., Ramakrishnan, C., Mattis, J., Prakash, R., Diester, I., Goshen, I., Thompson, K.R., Deisseroth, K., 2010. Molecular and cellular approaches for diversifying and extending optogenetics. Cell 141, 154-165.

Grossman, N., Nikolic, K., Toumazou, C., Degenaar, P., 2011. Modeling study of the light stimulation of a neuron cell with channelrhodopsin-2 mutants. IEEE transactions on bio-medical engineering 58, 17421751.

Grossman, N., Poher, V., Grubb, M.S., Kennedy, G.T., Nikolic, K., McGovern, B., Palmini, R.B., Gong, Z., Drakakis, E.M., Neil, M.A., 2010. Multi-site optical excitation using ChR2 and micro-LED array. J Neural Eng 7, 016004.

Gunaydin, L.A., Yizhar, O., Berndt, A., Sohal, V.S., Deisseroth, K., Hegemann, P., 2010. Ultrafast optogenetic control. Nat Neurosci 13, 387-392.

Habib, A.G., Cameron, M.A., Suaning, G.J., Lovell, N.H., Morley, J.W., 2013. Spatially restricted electrical activation of retinal ganglion cells in the rabbit retina by hexapolar electrode return configuration. J Neural Eng 10, 036013.

Hadjinicolaou, A.E., Meffin, H., Maturana, M.I., Cloherty, S.L., Ibbotson, M.R., 2015. Prosthetic vision: devices, patient outcomes and retinal research. Clinical \& experimental optometry 98, 395-410.

Hartong, D.T., Berson, E.L., Dryja, T.P., 2006. Retinitis pigmentosa. Lancet 368, 1795-1809.

Haupts, U., Tittor, J., Bamberg, E., Oesterhelt, D., 1997. General concept for ion translocation by halobacterial retinal proteins: the isomerization/switch/transfer (IST) model. Biochemistry 36, 2-7.

Hayes, J.S., Yin, V.T., Piyathaisere, D., Weiland, J.D., Humayun, M.S., Dagnelie, G., 2003. Visually guided performance of simple tasks using simulated prosthetic vision. Artif Organs 27, 1016-1028.

Heier, J.S., Brown, D.M., Chong, V., Korobelnik, J.F., Kaiser, P.K., Nguyen, Q.D., Kirchhof, B., Ho, A., Ogura, Y., Yancopoulos, G.D., Stahl, N., Vitti, R., Berliner, A.J., Soo, Y., Anderesi, M., Groetzbach, G., Sommerauer, B., Sandbrink, R., Simader, C., Schmidt-Erfurth, U., Groups, V.S., 2012. Intravitreal aflibercept (VEGF trapeye) in wet age-related macular degeneration. Ophthalmology 119, 2537-2548. 
Ho, A.C., Humayun, M.S., Dorn, J.D., da Cruz, L., Dagnelie, G., Handa, J., Barale, P.O., Sahel, J.A., Stanga, P.E., Hafezi, F., Safran, A.B., Salzmann, J., Santos, A., Birch, D., Spencer, R., Cideciyan, A.V., de Juan, E., Duncan, J.L., Eliott, D., Fawzi, A., Olmos de Koo, L.C., Brown, G.C., Haller, J.A., Regillo, C.D., Del Priore, L.V., Arditi, A., Geruschat, D.R., Greenberg, R.J., Group, A.I.S., 2015. Long-Term Results from an Epiretinal Prosthesis to Restore Sight to the Blind. Ophthalmology 122, 1547-1554.

Hornig, R., Zehnder, T., Velikay-Parel, M., Laube, T., Feucht, M., Richard, G., 2007. The IMI retinal implant system, Artificial Sight. Springer, pp. 111-128.

Horsager, A., Greenwald, S.H., Weiland, J.D., Humayun, M.S., Greenberg, R.J., McMahon, M.J., Boynton, G.M., Fine, I., 2009. Predicting visual sensitivity in retinal prosthesis patients. Invest Ophthalmol Vis Sci 50, $1483-1491$.

Huang, Y., Enzmann, V., Ildstad, S.T., 2011. Stem cell-based therapeutic applications in retinal degenerative diseases. Stem cell reviews 7, 434-445.

Humayun, M.S., de Juan, E., Jr., Weiland, J.D., Dagnelie, G., Katona, S., Greenberg, R., Suzuki, S., 1999a. Pattern electrical stimulation of the human retina. Vision Res 39, 2569-2576.

Humayun, M.S., Dorn, J.D., da Cruz, L., Dagnelie, G., Sahel, J.A., Stanga, P.E., Cideciyan, A.V., Duncan, J.L., Eliott, D., Filley, E., Ho, A.C., Santos, A., Safran, A.B., Arditi, A., Del Priore, L.V., Greenberg, R.J., Group, A.I.S., 2012. Interim results from the international trial of Second Sight's visual prosthesis. Ophthalmology 119, 779-788.

Humayun, M.S., Prince, M., de Juan, E., Jr., Barron, Y., Moskowitz, M., Klock, I.B., Milam, A.H., 1999b. Morphometric analysis of the extramacular retina from postmortem eyes with retinitis pigmentosa. Invest Ophthalmol Vis Sci 40, 143-148.

Humayun, M.S., Weiland, J.D., Fujii, G.Y., Greenberg, R., Williamson, R., Little, J., Mech, B., Cimmarusti, V., Van Boemel, G., Dagnelie, G., de Juan, E., 2003. Visual perception in a blind subject with a chronic microelectronic retinal prosthesis. Vision Res 43, 2573-2581.

Ivanova, E., Hwang, G.S., Pan, Z.H., Troilo, D., 2010. Evaluation of AAV-mediated expression of Chop2-GFP in the marmoset retina. Invest Ophthalmol Vis Sci 51, 5288-5296.

Jackson, G.R., Owsley, C., Curcio, C.A., 2002. Photoreceptor degeneration and dysfunction in aging and agerelated maculopathy. Ageing Res Rev 1, 381-396.

Jensen, R.J., Rizzo III, J.F., 2007. Responses of ganglion cells to repetitive electrical stimulation of the retina. J Neural Eng 4, S1-6.

Jensen, R.J., Rizzo, J.F., 3rd, 2006. Thresholds for activation of rabbit retinal ganglion cells with a subretinal electrode. Exp Eye Res 83, 367-373.

Jensen, R.J., Ziv, O.R., Rizzo, J.F., 2005. Responses of rabbit retinal ganglion cells to electrical stimulation with an epiretinal electrode. J Neural Eng 2, S16-21.

Jepson, L.H., Hottowy, P., Mathieson, K., Gunning, D.E., Dabrowski, W., Litke, A.M., Chichilnisky, E.J., 2013. Focal electrical stimulation of major ganglion cell types in the primate retina for the design of visual prostheses. The Journal of neuroscience : the official journal of the Society for Neuroscience 33, 71947205.

Jepson, L.H., Hottowy, P., Weiner, G.A., Dabrowski, W., Litke, A.M., Chichilnisky, E.J., 2014. High-fidelity reproduction of spatiotemporal visual signals for retinal prosthesis. Neuron 83, 87-92.

Joucla, S., Yvert, B., 2009. Improved focalization of electrical microstimulation using microelectrode arrays: a modeling study. PLoS One 4, e4828.

Kelly, S.K., Shire, D.B., Chen, J., Doyle, P., Gingerich, M.D., Cogan, S.F., Drohan, W.A., Behan, S., Theogarajan, L., Wyatt, J.L., Rizzo III, J.F., 2011. A hermetic wireless subretinal neurostimulator for vision prostheses. IEEE transactions on bio-medical engineering 58, 3197-3205.

Kelly, S.K., Shire, D.B., Chen, J., Gingerich, M.D., Cogan, S.F., Drohan, W., Ellersick, W., Krishnan, A., Behan, S., Wyatt, J.L., Rizzo III, J.F., 2013a. Developments on the Boston 256-channel retinal implant, Multimedia and Expo Workshops (ICMEW), 2013 IEEE International Conference on. IEEE, pp. 1-6. 
Kelly, S.K., Shire, D.B., Chen, J., Gingerich, M.D., Cogan, S.F., Drohan, W., Ellersick, W., Krishnan, A., Behan, S., Wyatt, J.L., Rizzo, J.F., 2013b. Developments on the Boston 256-channel retinal implant, Multimedia and Expo Workshops (ICMEW), 2013 IEEE International Conference on. IEEE, pp. 1-6.

Keseru, M., Feucht, M., Bornfeld, N., Laube, T., Walter, P., Rossler, G., Velikay-Parel, M., Hornig, R., Richard, G., 2012. Acute electrical stimulation of the human retina with an epiretinal electrode array. Acta Ophthalmol 90, e1-8.

Kienzler, M.A., Reiner, A., Trautman, E., Yoo, S., Trauner, D., Isacoff, E.Y., 2013. A red-shifted, fast-relaxing azobenzene photoswitch for visible light control of an ionotropic glutamate receptor. J Am Chem Soc $135,17683-17686$.

Kim, S.Y., Sadda, S., Pearlman, J., Humayun, M.S., de Juan, E., Jr., Melia, B.M., Green, W.R., 2002. Morphometric analysis of the macula in eyes with disciform age-related macular degeneration. Retina 22, 471-477.

Klapoetke, N.C., Murata, Y., Kim, S.S., Pulver, S.R., Birdsey-Benson, A., Cho, Y.K., Morimoto, T.K., Chuong, A.S., Carpenter, E.J., Tian, Z., Wang, J., Xie, Y., Yan, Z., Chow, B.Y., Surek, B., Melkonian, M., Jayaraman, V., Constantine-Paton, M., Wong, G.K., Boyden, E.S., 2014. Independent optical excitation of distinct neural populations. Nat Methods 11, 338-346.

Klauke, S., Goertz, M., Rein, S., Hoehl, D., Thomas, U., Eckhorn, R., Bremmer, F., Wachtler, T., 2011. Stimulation with a wireless intraocular epiretinal implant elicits visual percepts in blind humans. Invest Ophthalmol Vis Sci 52, 449-455.

Kleinlogel, S., Feldbauer, K., Dempski, R.E., Fotis, H., Wood, P.G., Bamann, C., Bamberg, E., 2011. Ultra lightsensitive and fast neuronal activation with the Ca2+-permeable channelrhodopsin CatCh. Nat Neurosci 14, 513-518.

Kringelbach, M.L., Jenkinson, N., Owen, S.L., Aziz, T.Z., 2007. Translational principles of deep brain stimulation. Nature reviews. Neuroscience 8, 623-635.

Lagali, P.S., Balya, D., Awatramani, G.B., Munch, T.A., Kim, D.S., Busskamp, V., Cepko, C.L., Roska, B., 2008. Light-activated channels targeted to $\mathrm{ON}$ bipolar cells restore visual function in retinal degeneration. Nat Neurosci 11, 667-675.

Legon, W., Sato, T.F., Opitz, A., Mueller, J., Barbour, A., Williams, A., Tyler, W.J., 2014. Transcranial focused ultrasound modulates the activity of primary somatosensory cortex in humans. Nat Neurosci 17, 322329.

Li, Z.Y., Kljavin, I.J., Milam, A.H., 1995. Rod photoreceptor neurite sprouting in retinitis pigmentosa. The Journal of neuroscience : the official journal of the Society for Neuroscience 15, 5429-5438.

Lilly, J.C., Austin, G.M., Chambers, W.W., 1952. Threshold movements produced by excitation of cerebral cortex and efferent fibers with some parametric regions of rectangular current pulses (cats and monkeys). J Neurophysiol 15, 319-341.

Lilly, J.C., Hughes, J.R., Alvord, E.C., Jr., Galkin, T.W., 1955. Brief, noninjurious electric waveform for stimulation of the brain. Science 121, 468-469.

Lin, B., Koizumi, A., Tanaka, N., Panda, S., Masland, R.H., 2008. Restoration of visual function in retinal degeneration mice by ectopic expression of melanopsin. Proceedings of the National Academy of Sciences of the United States of America 105, 16009-16014.

Lin, J.Y., Knutsen, P.M., Muller, A., Kleinfeld, D., Tsien, R.Y., 2013. ReaChR: a red-shifted variant of channelrhodopsin enables deep transcranial optogenetic excitation. Nat Neurosci 16, 1499-1508.

Lin, J.Y., Lin, M.Z., Steinbach, P., Tsien, R.Y., 2009. Characterization of engineered channelrhodopsin variants with improved properties and kinetics. Biophys J 96, 1803-1814.

Liu, Y., Park, J., Lang, R.J., Emami-Neyestanak, A., Pellegrino, S., Humayun, M.S., Tai, Y.-C., 2013. Parylene origami structure for intraocular implantation, Solid-State Sensors, Actuators and Microsystems (TRANSDUCERS \& EUROSENSORS XXVII), 2013 Transducers \& Eurosensors XXVII: The 17th International Conference on. IEEE, pp. 1549-1552. 
Lorach, H., Benosman, R., Marre, O., leng, S.H., Sahel, J.A., Picaud, S., 2012. Artificial retina: the multichannel processing of the mammalian retina achieved with a neuromorphic asynchronous light acquisition device. J Neural Eng 9, 066004.

Lorach, H., Goetz, G., Mandel, Y., Lei, X., Galambos, L., Kamins, T.I., Mathieson, K., Huie, P., Dalal, R., Harris, J.S., Palanker, D., 2015a. Performance of photovoltaic arrays in-vivo and characteristics of prosthetic vision in animals with retinal degeneration. Vision Res 111, 142-148.

Lorach, H., Goetz, G., Smith, R., Lei, X., Mandel, Y., Kamins, T., Mathieson, K., Huie, P., Harris, J., Sher, A., Palanker, D., 2015b. Photovoltaic restoration of sight with high visual acuity. Nat Med 21, 476-482.

Lorach, H., Wang, J., Lee, D.Y., Dalal, R., Huie, P., Palanker, D., 2016. Retinal safety of near infrared radiation in photovoltaic restoration of sight. Biomed Opt Express 7, 13-21.

Luo, Y.H.-L., da Cruz, L., 2016. The Argus ${ }^{\circledR}$ II retinal prosthesis system. Prog Retin Eye Res 50, 89-107.

Luo, Y.H.-L., Zhong, J., Merlini, F., Anaflous, F., Arsiero, M., Stanga, P.E., Da Cruz, L., 2014a. The use of Argus ${ }^{\circledR}$ II Retinal Prosthesis to Identify Common Objects in Blind Subjects with Outer Retinal Dystrophies. Invest Ophthalmol Vis Sci 55, 1834-1834.

Luo, Y.H.-L., Zhong, J.J., da Cruz, L., 2014b. The use of Argus ${ }^{\circledR}$ II retinal prosthesis by blind subjects to achieve localisation and prehension of objects in 3-dimensional space. Graefe's archive for clinical and experimental ophthalmology = Albrecht von Graefes Archiv fur klinische und experimentelle Ophthalmologie, 1-8.

Mace, E., Caplette, R., Marre, O., Sengupta, A., Chaffiol, A., Barbe, P., Desrosiers, M., Bamberg, E., Sahel, J.A., Picaud, S., Duebel, J., Dalkara, D., 2015. Targeting channelrhodopsin-2 to ON-bipolar cells with vitreally administered AAV Restores ON and OFF visual responses in blind mice. Molecular therapy : the journal of the American Society of Gene Therapy 23, 7-16.

Mahadevappa, M., Weiland, J.D., Yanai, D., Fine, I., Greenberg, R.J., Humayun, M.S., 2005. Perceptual thresholds and electrode impedance in three retinal prosthesis subjects. IEEE transactions on neural systems and rehabilitation engineering : a publication of the IEEE Engineering in Medicine and Biology Society 13, 201-206.

Marc, R.E., Jones, B.W., Watt, C.B., Strettoi, E., 2003. Neural remodeling in retinal degeneration. Prog Retin Eye Res 22, 607-655.

Marconi, B., Genovesio, A., Battaglia-Mayer, A., Ferraina, S., Squatrito, S., Molinari, M., Lacquaniti, F., Caminiti, R., 2001. Eye-hand coordination during reaching. I. Anatomical relationships between parietal and frontal cortex. Cereb Cortex 11, 513-527.

Margalit, E., Thoreson, W.B., 2006. Inner retinal mechanisms engaged by retinal electrical stimulation. Invest Ophthalmol Vis Sci 47, 2606-2612.

Martinez-Conde, S., Macknik, S.L., Troncoso, X.G., Dyar, T.A., 2006. Microsaccades counteract visual fading during fixation. Neuron 49, 297-305.

Mathieson, K., Loudin, J., Goetz, G., Huie, P., Wang, L., Kamins, T.I., Galambos, L., Smith, R., Harris, J.S., Sher, A., Palanker, D., 2012. Photovoltaic Retinal Prosthesis with High Pixel Density. Nat Photonics 6, 391-397.

McCreery, D.B., Agnew, W.F., Yuen, T.G., Bullara, L., 1990. Charge density and charge per phase as cofactors in neural injury induced by electrical stimulation. IEEE transactions on bio-medical engineering $37,996-$ 1001.

Medeiros, N.E., Curcio, C.A., 2001. Preservation of ganglion cell layer neurons in age-related macular degeneration. Invest Ophthalmol Vis Sci 42, 795-803.

Meister, M., Berry, M.J., 2nd, 1999. The neural code of the retina. Neuron 22, 435-450.

Menz, M.D., Oralkan, Ö., Khuri-Yakub, P.T., Baccus, S.A., 2013. Precise neural stimulation in the retina using focused ultrasound. The Journal of neuroscience : the official journal of the Society for Neuroscience 33, 4550-4560. 
Menzel-Severing, J., Laube, T., Brockmann, C., Bornfeld, N., Mokwa, W., Mazinani, B., Walter, P., Roessler, G., 2012. Implantation and explantation of an active epiretinal visual prosthesis: 2-year follow-up data from the EPIRET3 prospective clinical trial. Eye (Lond) 26, 501-509.

Merrill, D.R., Bikson, M., Jefferys, J.G., 2005. Electrical stimulation of excitable tissue: design of efficacious and safe protocols. J Neurosci Methods 141, 171-198.

Meyer, R.D., Cogan, S.F., Nguyen, T.H., Rauh, R.D., 2001. Electrodeposited iridium oxide for neural stimulation and recording electrodes. IEEE transactions on neural systems and rehabilitation engineering : a publication of the IEEE Engineering in Medicine and Biology Society 9, 2-11.

Milam, A.H., Li, Z.Y., Fariss, R.N., 1998. Histopathology of the human retina in retinitis pigmentosa. Prog Retin Eye Res 17, 175-205.

Monge, M., Emami, A., 2014. Design considerations for high-density fully intraocular epiretinal prostheses, Biomedical Circuits and Systems Conference (BioCAS), 2014 IEEE. IEEE, pp. 224-227.

Morimoto, T., Kamei, M., Nishida, K., Sakaguchi, H., Kanda, H., Ikuno, Y., Kishima, H., Maruo, T., Konoma, K., Ozawa, M., Nishida, K., Fujikado, T., 2011. Chronic implantation of newly developed suprachoroidaltransretinal stimulation prosthesis in dogs. Invest Ophthalmol Vis Sci 52, 6785-6792.

Mortimer, J.T., Shealy, C.N., Wheeler, C., 1970. Experimental nondestructive electrical stimulation of the brain and spinal cord. J Neurosurg 32, 553-559.

Nanduri, D., Fine, I., Horsager, A., Boynton, G.M., Humayun, M.S., Greenberg, R.J., Weiland, J.D., 2012. Frequency and amplitude modulation have different effects on the percepts elicited by retinal stimulation. Invest Ophthalmol Vis Sci 53, 205.

Nanduri, D., Humayun, M., Greenberg, R., McMahon, M., Weiland, J., 2008. Retinal prosthesis phosphene shape analysis, Engineering in Medicine and Biology Society, 2008. EMBS 2008. 30th Annual International Conference of the IEEE. IEEE, pp. 1785-1788.

Naor, O., Hertzberg, Y., Zemel, E., Kimmel, E., Shoham, S., 2012. Towards multifocal ultrasonic neural stimulation II: design considerations for an acoustic retinal prosthesis. J Neural Eng 9, 026006.

Niparko, J.K., 2009. Cochlear implants: principles \& practices. Lippincott Williams \& Wilkins.

Nirenberg, S., Pandarinath, C., 2012. Retinal prosthetic strategy with the capacity to restore normal vision. Proceedings of the National Academy of Sciences of the United States of America 109, 15012-15017.

Numata, T., Murakami, T., Kawashima, F., Morone, N., Heuser, J.E., Takano, Y., Ohkubo, K., Fukuzumi, S., Mori, Y., Imahori, H., 2012. Utilization of photoinduced charge-separated state of donor-acceptor-linked molecules for regulation of cell membrane potential and ion transport. J Am Chem Soc 134, 6092-6095.

O'Hearn, T.M., Sadda, S.R., Weiland, J.D., Maia, M., Margalit, E., Humayun, M.S., 2006. Electrical stimulation in normal and retinal degeneration (rd1) isolated mouse retina. Vision Res 46, 3198-3204.

Olmedo-Payá, A., Martínez-Álvarez, A., Cuenca-Asensi, S., Ferrández, J.M., Fernández, E., 2015. Modeling the role of fixational eye movements in real-world scenes. Neurocomputing 151, 78-84.

Opie, N.L., Burkitt, A.N., Meffin, H., Grayden, D.B., 2012. Heating of the eye by a retinal prosthesis: modeling, cadaver and in vivo study. IEEE transactions on bio-medical engineering 59, 339-345.

Palanker, D., Vankov, A., Huie, P., Baccus, S., 2005. Design of a high-resolution optoelectronic retinal prosthesis. J Neural Eng 2, S105-120.

Parver, L.M., Auker, C.R., Carpenter, D.O., 1983. Choroidal blood flow. III. Reflexive control in human eyes. Arch Ophthalmol 101, 1604-1606.

Peachey, N.S., Chow, A.Y., 1999. Subretinal implantation of semiconductor-based photodiodes: progress and challenges. J Rehabil Res Dev 36, 371-376.

Perez Fornos, A., Sommerhalder, J., da Cruz, L., Sahel, J.A., Mohand-Said, S., Hafezi, F., Pelizzone, M., 2012. Temporal properties of visual perception on electrical stimulation of the retina. Invest Ophthalmol Vis Sci 53, 2720-2731.

Pezaris, J.S., Eskandar, E.N., 2009. Getting signals into the brain: visual prosthetics through thalamic microstimulation. Neurosurg Focus 27, E6. 
Polosukhina, A., Litt, J., Tochitsky, I., Nemargut, J., Sychev, Y., De Kouchkovsky, I., Huang, T., Borges, K., Trauner, D., Van Gelder, R.N., Kramer, R.H., 2012. Photochemical restoration of visual responses in blind mice. Neuron 75, 271-282.

Potts, A.M., Inoue, J., 1969. The electrically evoked response (EER) of the visual system II. Effect of adaptation and retinitis pigmentosa. Invest Ophthalmol Vis Sci 8, 605-612.

Rakoczy, E.P., Lai, C.M., Magno, A.L., Wikstrom, M.E., French, M.A., Pierce, C.M., Schwartz, S.D., Blumenkranz, M.S., Chalberg, T.W., Degli-Esposti, M.A., Constable, I.J., 2015. Gene therapy with recombinant adenoassociated vectors for neovascular age-related macular degeneration: 1 year follow-up of a phase 1 randomised clinical trial. Lancet 386, 2395-2403.

Rattay, F., 1986. Analysis of models for external stimulation of axons. IEEE transactions on bio-medical engineering 33, 974-977.

Reutsky-Gefen, I., Golan, L., Farah, N., Schejter, A., Tsur, L., Brosh, I., Shoham, S., 2013. Holographic optogenetic stimulation of patterned neuronal activity for vision restoration. Nat Commun 4, 1509.

Richard, E., Goetz, G.A., Chichilnisky, E., 2015. Recognizing retinal ganglion cells in the dark, Advances in Neural Information Processing Systems, pp. 2467-2475.

Richard, G., Hornig, R., Keserü, M., Feucht, M., 2007. Chronic epiretinal chip implant in blind patients with retinitis pigmentosa: long-term clinical results. Invest Ophthalmol Vis Sci 48, 666-666.

Richer, S., Stiles, W., Statkute, L., Pulido, J., Frankowski, J., Rudy, D., Pei, K., Tsipursky, M., Nyland, J., 2004. Double-masked, placebo-controlled, randomized trial of lutein and antioxidant supplementation in the intervention of atrophic age-related macular degeneration: the Veterans LAST study (Lutein Antioxidant Supplementation Trial). Optometry 75, 216-230.

Rizzo, J.F., 3rd, Wyatt, J., Loewenstein, J., Kelly, S., Shire, D., 2003. Perceptual efficacy of electrical stimulation of human retina with a microelectrode array during short-term surgical trials. Invest Ophthalmol Vis Sci 44, 5362-5369.

Rizzo, J.F., Wyatt, J., 1997. Review: Prospects for a Visual Prosthesis. Neuroscientist 3, 251-262.

Rodieck, R., Kiang, N.-S., Gerstein, G., 1962. Some quantitative methods for the study of spontaneous activity of single neurons. Biophys J 2, 351.

Roessler, G., Laube, T., Brockmann, C., Kirschkamp, T., Mazinani, B., Goertz, M., Koch, C., Krisch, I., Sellhaus, B., Trieu, H.K., Weis, J., Bornfeld, N., Rothgen, H., Messner, A., Mokwa, W., Walter, P., 2009. Implantation and explantation of a wireless epiretinal retina implant device: observations during the EPIRET3 prospective clinical trial. Invest Ophthalmol Vis Sci 50, 3003-3008.

Rohan, J.G., Citron, Y.R., Durrell, A.C., Cheruzel, L.E., Gray, H.B., Grubbs, R.H., Humayun, M., Engisch, K.L., Pikov, V., Chow, R.H., 2013. Light-triggered modulation of cellular electrical activity by ruthenium diimine nanoswitches. ACS Chem Neurosci 4, 585-593.

Rose, S., 2015. http://www.blindness.org/blog/index.php/first-amd-patient-delighted-to-receive-argus-iibionic-retina/.

Roska, B., Pepperberg, D., 2014. Restoring Vision to the Blind: Optogenetics. Transl Vis Sci Technol 3, 4.

Sahel, J., Mohand-Said, S., Stanga, P., Caspi, A., Greenberg, R., 2013. Acuboost ${ }^{\mathrm{TM}}$ : enhancing the maximum acuity of the Argus II Retinal Prosthesis System. Investigative Ophthalmology \& Visual Science 54, 13891389.

Sailer, H., Shinoda, K., Blatsios, G., Kohler, K., Bondzio, L., Zrenner, E., Gekeler, F., 2007. Investigation of thermal effects of infrared lasers on the rabbit retina: a study in the course of development of an active subretinal prosthesis. Graefe's archive for clinical and experimental ophthalmology = Albrecht von Graefes Archiv fur klinische und experimentelle Ophthalmologie 245, 1169-1178.

Santos, A., Humayun, M.S., de Juan, E., Jr., Greenburg, R.J., Marsh, M.J., Klock, I.B., Milam, A.H., 1997. Preservation of the inner retina in retinitis pigmentosa. A morphometric analysis. Arch Ophthalmol 115, 511-515. 
Schwartz, S.D., Regillo, C.D., Lam, B.L., Eliott, D., Rosenfeld, P.J., Gregori, N.Z., Hubschman, J.P., Davis, J.L., Heilwell, G., Spirn, M., Maguire, J., Gay, R., Bateman, J., Ostrick, R.M., Morris, D., Vincent, M., Anglade, E., Del Priore, L.V., Lanza, R., 2015. Human embryonic stem cell-derived retinal pigment epithelium in patients with age-related macular degeneration and Stargardt's macular dystrophy: follow-up of two open-label phase $1 / 2$ studies. Lancet 385, 509-516.

Sekirnjak, C., Hottowy, P., Sher, A., Dabrowski, W., Litke, A.M., Chichilnisky, E.J., 2006. Electrical stimulation of mammalian retinal ganglion cells with multielectrode arrays. J Neurophysiol 95, 3311-3327.

Sekirnjak, C., Hottowy, P., Sher, A., Dabrowski, W., Litke, A.M., Chichilnisky, E.J., 2008. High-resolution electrical stimulation of primate retina for epiretinal implant design. The Journal of neuroscience : the official journal of the Society for Neuroscience 28, 4446-4456.

Sekirnjak, C., Hulse, C., Jepson, L.H., Hottowy, P., Sher, A., Dabrowski, W., Litke, A.M., Chichilnisky, E., 2009. Loss of responses to visual but not electrical stimulation in ganglion cells of rats with severe photoreceptor degeneration. J Neurol 102, 3260-3269.

Shannon, R.V., 1992. A model of safe levels for electrical stimulation. IEEE transactions on bio-medical engineering 39, 424-426.

Shire, D.B., Jones, W.K., Karbasi, A., Behan, S., Gingerich, M., Kelly, S., Wyatt, J.L., Rizzo, J.F., 2014. Advanced Hermetic Feedthrough and Packaging Technology for the Boston Retinal Prosthesis. Invest Ophthalmol Vis Sci 55, 1835-1835.

Shivdasani, M.N., Sinclair, N.C., Dimitrov, P.N., Varsamidis, M., Ayton, L.N., Luu, C.D., Perera, T., McDermott, H.J., Blamey, P.J., 2014. Factors Affecting Perceptual Thresholds in a Suprachoroidal Retinal ProsthesisFactors Affecting Retinal Prosthesis Thresholds. Invest Ophthalmol Vis Sci 55, 6467-6481.

Singh, M.S., Charbel Issa, P., Butler, R., Martin, C., Lipinski, D.M., Sekaran, S., Barnard, A.R., MacLaren, R.E., 2013. Reversal of end-stage retinal degeneration and restoration of visual function by photoreceptor transplantation. Proceedings of the National Academy of Sciences of the United States of America 110, 1101-1106.

Sommerhalder, J., Rappaz, B., de Haller, R., Fornos, A.P., Safran, A.B., Pelizzone, M., 2004. Simulation of artificial vision: II. Eccentric reading of full-page text and the learning of this task. Vision Res 44, 16931706.

Stanga, P.E., Hafezi, F., Sahel, J.A., Merlini, F., Coley, B., Greenberg, R.J., Group, A.I.S., 2011. Patients Blinded By Outer Retinal Dystrophies Are Able To Perceive Color Using The ArgusTm II Retinal Prosthesis System. Invest Ophthalmol Vis Sci 52, 4949-4949.

Stanga, P.E., Sahel Jr, J.A., Hafezi, F., Merlini, F., Coley, B., Greenberg, R.J., Group, A.I.S., 2012. Patients blinded by outer retinal dystrophies are able to perceive simultaneous colors using the $\operatorname{Argus}^{\circledR}$ II retinal prosthesis system. Invest Ophthalmol Vis Sci 53, 6952-6952.

Stiles, N.R., Mclntosh, B.P., J, N.P., Hauer, M.C., Weiland, J.D., Humayun, M.S., Tanguay JR, A.R., 2011. An intraocular camera for retinal prostheses: Restoring sight to the blind. Optical Processes in Microparticles and Nanostructures: A Festschrift Dedicated to Richard Kounai Chang on His Retirement from Yale University 6, 385.

Stingl, K., Bach, M., Bartz-Schmidt, K.U., Braun, A., Bruckmann, A., Gekeler, F., Greppmaier, U., Hortdorfer, G., Kusnyerik, A., Peters, T., Wilhelm, B., Wilke, R., Zrenner, E., 2013a. Safety and efficacy of subretinal visual implants in humans: methodological aspects. Clinical \& experimental optometry 96, 4-13.

Stingl, K., Bartz-Schmidt, K.U., Besch, D., Braun, A., Bruckmann, A., Gekeler, F., Greppmaier, U., Hipp, S., Hortdorfer, G., Kernstock, C., Koitschev, A., Kusnyerik, A., Sachs, H., Schatz, A., Stingl, K.T., Peters, T., Wilhelm, B., Zrenner, E., 2013b. Artificial vision with wirelessly powered subretinal electronic implant alpha-IMS. Proceedings. Biological sciences / The Royal Society 280, 20130077.

Stingl, K., Bartz-Schmidt, K.U., Besch, D., Chee, C.K., Cottriall, C.L., Gekeler, F., Groppe, M., Jackson, T.L., MacLaren, R.E., Koitschev, A., Kusnyerik, A., Neffendorf, J., Nemeth, J., Naeem, M.A.N., Peters, T., 
Ramsden, J.D., Sachs, H., Simpson, A., Mandeep, S.S., Wilhelm, B., Wong, D., Zrenner, E., 2015. Subretinal Visual Implant Alpha IMS-Clinical trial interim report. Vision Res 111, 149-160.

Stingl, K., Bartz-Schmidt, K.U., Gekeler, F., Kusnyerik, A., Sachs, H., Zrenner, E., 2013c. Functional outcome in subretinal electronic implants depends on foveal eccentricity. Invest Ophthalmol Vis Sci 54, 7658-7665.

Stronks, H.C., Dagnelie, G., 2014. The functional performance of the Argus II retinal prosthesis. Expert Rev Med Devices 11, 23-30.

Suesserman, M.F., Spelman, F., Rubinstein, J.T., 1991. In vitro measurement and characterization of current density profiles produced by nonrecessed, simple recessed, and radially varying recessed stimulating electrodes. IEEE transactions on bio-medical engineering 38, 401-408.

Suzuki, S., Humayun, M.S., Weiland, J.D., Chen, S.J., Margalit, E., Piyathaisere, D.V., de Juan, E., Jr., 2004. Comparison of electrical stimulation thresholds in normal and retinal degenerated mouse retina. Jpn J Ophthalmol 48, 345-349.

Szlyk, J.P., Fishman, G.A., Alexander, K.R., Revelins, B.I., Derlacki, D.J., Anderson, R.J., 1997. Relationship between difficulty in performing daily activities and clinical measures of visual function in patients with retinitis pigmentosa. Arch Ophthalmol 115, 53-59.

Thyagarajan, S., van Wyk, M., Lehmann, K., Lowel, S., Feng, G., Wassle, H., 2010. Visual function in mice with photoreceptor degeneration and transgenic expression of channelrhodopsin 2 in ganglion cells. The Journal of neuroscience : the official journal of the Society for Neuroscience 30, 8745-8758.

Tochitsky, I., Polosukhina, A., Degtyar, V.E., Gallerani, N., Smith, C.M., Friedman, A., Van Gelder, R.N., Trauner, D., Kaufer, D., Kramer, R.H., 2014. Restoring visual function to blind mice with a photoswitch that exploits electrophysiological remodeling of retinal ganglion cells. Neuron 81, 800-813.

Trenholm, S., Roska, B., 2014. Cell-type-specific electric stimulation for vision restoration. Neuron 83, 1-2.

Tsai, D., Chen, S., Protti, D.A., Morley, J.W., Suaning, G.J., Lovell, N.H., 2012. Responses of retinal ganglion cells to extracellular electrical stimulation, from single cell to population: model-based analysis. PLoS One 7, e53357.

Tufail, Y., Matyushov, A., Baldwin, N., Tauchmann, M.L., Georges, J., Yoshihiro, A., Tillery, S.I., Tyler, W.J., 2010. Transcranial pulsed ultrasound stimulates intact brain circuits. Neuron 66, 681-694.

Tufail, Y., Yoshihiro, A., Pati, S., Li, M.M., Tyler, W.J., 2011. Ultrasonic neuromodulation by brain stimulation with transcranial ultrasound. Nat Protoc 6, 1453-1470.

Tyler, W.J., Tufail, Y., Finsterwald, M., Tauchmann, M.L., Olson, E.J., Majestic, C., 2008. Remote excitation of neuronal circuits using low-intensity, low-frequency ultrasound. PloS One 3, e3511.

van Balken, M.R., Vergunst, H., Bemelmans, B.L., 2004. The use of electrical devices for the treatment of bladder dysfunction: a review of methods. J Neurol 172, 846-851.

Van Rullen, R., Thorpe, S.J., 2001. Rate coding versus temporal order coding: what the retinal ganglion cells tell the visual cortex. Neural Comput 13, 1255-1283.

van Wyk, M., Pielecka-Fortuna, J., Lowel, S., Kleinlogel, S., 2015. Restoring the ON Switch in Blind Retinas: Opto-mGluR6, a Next-Generation, Cell-Tailored Optogenetic Tool. PLoS Biol 13, e1002143.

Vanhoestenberghe, A., Donaldson, N., 2013. Corrosion of silicon integrated circuits and lifetime predictions in implantable electronic devices. J Neural Eng 10, 031002.

Veraart, C., Raftopoulos, C., Mortimer, J.T., Delbeke, J., Pins, D., Michaux, G., Vanlierde, A., Parrini, S., WanetDefalque, M.-C., 1998. Visual sensations produced by optic nerve stimulation using an implanted selfsizing spiral cuff electrode. Brain Res 813, 181-186.

Wang, L., Mathieson, K., Kamins, T.I., Loudin, J.D., Galambos, L., Goetz, G., Sher, A., Mandel, Y., Huie, P., Lavinsky, D., Harris, J.S., Palanker, D.V., 2012. Photovoltaic retinal prosthesis: implant fabrication and performance. J Neural Eng 9, 046014.

Weiland, J.D., Anderson, D.J., Humayun, M.S., 2002. In vitro electrical properties for iridium oxide versus titanium nitride stimulating electrodes. IEEE transactions on bio-medical engineering 49, 1574-1579. 
Weiland, J.D., Cho, A.K., Humayun, M.S., 2011. Retinal prostheses: current clinical results and future needs. Ophthalmology 118, 2227-2237.

Weiland, J.D., Humayun, M.S., 2008. Visual prosthesis. Proceedings of the IEEE 96, 1076-1084.

Weiland, J.D., Humayun, M.S., 2014. Retinal prosthesis. IEEE transactions on bio-medical engineering 61, 1412-1424.

Weitz, A.C., Behrend, M.R., Ahuja, A.K., Christopher, P., Wei, J., Wuyyuru, V., Patel, U., Greenberg, R.J., Humayun, M.S., Chow, R.H., 2014. Interphase gap as a means to reduce electrical stimulation thresholds for epiretinal prostheses. J Neural Eng 11, 016007.

Weitz, A.C., Nanduri, D., Behrend, M.R., Gonzalez-Calle, A., Greenberg, R.J., Humayun, M.S., Chow, R.H., Weiland, J.D., 2015. Improving the spatial resolution of epiretinal implants by increasing stimulus pulse duration. Sci Transl Med 7, 318ra203.

Wells, J., Wroblewski, J., Keen, J., Inglehearn, C., Jubb, C., Eckstein, A., Jay, M., Arden, G., Bhattacharya, S., Fitzke, F., 1993. Mutations in the human retinal degeneration slow (RDS) gene can cause either retinitis pigmentosa or macular dystrophy, Retinal Degeneration. Springer, pp. 53-59.

Wilke, R., Gabel, V.P., Sachs, H., Bartz Schmidt, K.U., Gekeler, F., Besch, D., Szurman, P., Stett, A., Wilhelm, B., Peters, T., Harscher, A., Greppmaier, U., Kibbel, S., Benav, H., Bruckmann, A., Stingl, K., Kusnyerik, A., Zrenner, E., 2011a. Spatial resolution and perception of patterns mediated by a subretinal 16-electrode array in patients blinded by hereditary retinal dystrophies. Invest Ophthalmol Vis Sci 52, 5995-6003.

Wilke, R.G., Moghadam, G.K., Lovell, N.H., Suaning, G.J., Dokos, S., 2011b. Electric crosstalk impairs spatial resolution of multi-electrode arrays in retinal implants. J Neural Eng 8, 046016.

Wilms, M., Eger, M., Schanze, T., Eckhorn, R., 2003. Visual resolution with epi-retinal electrical stimulation estimated from activation profiles in cat visual cortex. Vis Neurosci 20, 543-555.

Wong, I.Y., Poon, M.W., Pang, R.T., Lian, Q., Wong, D., 2011. Promises of stem cell therapy for retinal degenerative diseases. Graefe's archive for clinical and experimental ophthalmology = Albrecht von Graefes Archiv fur klinische und experimentelle Ophthalmologie 249, 1439-1448.

Wood, A.J., Fine, S.L., Berger, J.W., Maguire, M.G., Ho, A.C., 2000. Age-related macular degeneration. N Engl J Med 342, 483-492.

Xie, J., Wang, G.J., Yow, L., Humayun, M.S., Weiland, J.D., Cela, C.J., Jadvar, H., Lazzi, G., Dhrami-Gavazi, E., Tsang, S.H., 2012. Preservation of retinotopic map in retinal degeneration. Exp Eye Res 98, 88-96.

Yamauchi, Y., Franco, L.M., Jackson, D.J., Naber, J.F., Ziv, R.O., Rizzo, J.F., Kaplan, H.J., Enzmann, V., 2005. Comparison of electrically evoked cortical potential thresholds generated with subretinal or suprachoroidal placement of a microelectrode array in the rabbit. J Neural Eng 2, S48-56.

Yanai, D., Weiland, J.D., Mahadevappa, M., Greenberg, R.J., Fine, I., Humayun, M.S., 2007. Visual performance using a retinal prosthesis in three subjects with retinitis pigmentosa. Am J Ophthalmol 143, 820-827. e822.

Yue, L., Falabella, P., Christopher, P., Wuyyuru, V., Dorn, J., Schor, P., Greenberg, R.J., Weiland, J.D., Humayun, M.S., 2015a. Ten-Year Follow-up of a Blind Patient Chronically Implanted with Epiretinal Prosthesis Argus I. Ophthalmology 122, 2545-2552 e2541.

Yue, L., Pawlowski, M., Bruzik, K., Pepperberg, D., 2013. Potentiation of bipolar cell GABAA receptors by a photo-isomerizable compound. Invest Ophthalmol Vis Sci 54, 1761-1761.

Yue, L., Pawlowski, M., Dellal, S.S., Xie, A., Feng, F., Otis, T.S., Bruzik, K.S., Qian, H., Pepperberg, D.R., 2012. Robust photoregulation of GABAA receptors by allosteric modulation with a propofol analogue. Nat Comm 3, 1095.

Yue, L., Walston, S., Lin, M.S., Pribisko, M., Dougherty, D., Grubbs, R., Gray, H., Chow, R., Humayun, M.S., 2015b. Imaging Novel Ruthenium bipyridine-based Nanophotoswitches in Retina. Invest Ophthalmol Vis Sci 56, 1676-1676.

Zhang, F., Wang, L.P., Boyden, E.S., Deisseroth, K., 2006. Channelrhodopsin-2 and optical control of excitable cells. Nat Methods 3, 785-792. 
Zhang, Y., Ivanova, E., Bi, A., Pan, Z.H., 2009. Ectopic expression of multiple microbial rhodopsins restores ON and OFF light responses in retinas with photoreceptor degeneration. The Journal of neuroscience : the official journal of the Society for Neuroscience 29, 9186-9196.

Zhang, Y., Rauen, S.L., Koss, M., Calle, A., Brant, R., Swenson, S., Markland, F.S., Ufer, S., Eckhardt, H., Humayun, M.S., Weiland, J.D., 2013. Wide-field Retinal Prosthesis with Three-Dimensionally Contoured Hybrid Silicone/Polyimide Substrates, IEEE Neural Engineering Conference, San Diego, CA, USA.

Zhou, D.D., Dorn, J.D., Greenberg, R.J., 2013. The Argus ${ }^{\circledR}$ II retinal prosthesis system: An overview, Multimedia and Expo Workshops (ICMEW), 2013 IEEE International Conference on. IEEE, pp. 1-6.

Zhu, J., Yang, J., 2002. Subpixel eye gaze tracking, Automatic face and gesture recognition, 2002. proceedings. fifth ieee international conference on. IEEE, pp. 124-129.

Zinn, E., Pacouret, S., Khaychuk, V., Turunen, H.T., Carvalho, L.S., Andres-Mateos, E., Shah, S., Shelke, R., Maurer, A.C., Plovie, E., Xiao, R., Vandenberghe, L.H., 2015. In Silico Reconstruction of the Viral Evolutionary Lineage Yields a Potent Gene Therapy Vector. Cell Rep 12, 1056-1068.

Zrenner, E., Bartz-Schmidt, K.U., Benav, H., Besch, D., Bruckmann, A., Gabel, V.P., Gekeler, F., Greppmaier, U., Harscher, A., Kibbel, S., Koch, J., Kusnyerik, A., Peters, T., Stingl, K., Sachs, H., Stett, A., Szurman, P., Wilhelm, B., Wilke, R., 2011. Subretinal electronic chips allow blind patients to read letters and combine them to words. Proceedings. Biological sciences / The Royal Society 278, 1489-1497.

Zrenner, E., Stingl, K., Hafed, Z.M., 2015. Oculomotor behavior of blind patients seeing with subretinal visual implant Alpha IMS. Invest Ophthalmol Vis Sci 56, 751-751. 
Table 1. Comparison of the bioelectronic stimulation systems in electrodes and clinical outcomes.

Abbreviations: Epi.(Epiretinal), Sub.(subretinal), Supra.(suprachoroidal); Pt (platinum), IrO $_{x}$ (iridium oxide), TiN (titanium nitride); IOC (intraocular coil); A (acute), C (chronic); VGA (visual grating acuity), LCA (Landolt C acuity). The Photovoltaic Prosthesis and Boston Implant have not entered the clinical phase.

Figure 1. Retina and retinal degenerative diseases. (A) Schematic representation of the stratified structure of neural retina. Pink-shaded area represents the macular region. (B) Effects of retinal degeneration on visual field. Left: Visual field of a normally sighted subject; Middle: Central vision loss in macular degeneration. (C) Peripheral vision loss in retinitis pigmentosa.

Figure 2. Electrical activation of retinal ganglion cells. (A-B) Influence of pulse polarity on the membrane charge redistribution and neuronal activating function: cathodic (A) versus anodic (B) current stimulation. Striped areas represent activated membrane segments. (C) Schematic presentation of the direct (leftmiddle) and network-mediated indirect (right) electrical activation of a retinal ganglion cell. Left: membrane depolarization initiated at the soma of the ganglion cell (yellow) propagates to the axon. Middle: membrane depolarization initiated at an axonal segment propagates orthodromically to the soma and antidromically to the distal end of the axon. Right: membrane depolarization of the bipolar cell (purple) indirectly activates the ganglion cell via synaptic transmission. The waveforms represent extracellularly recorded changes in the membrane potential and the red one represents the potential at the site of initiation.

Figure 3. Illustration of the implantation sites of the epiretinal, subretinal and suprachoroidal prostheses. Ganglion cells (yellow) and biploar cells (purple) are shown and damaged/eliminated photoreceptors are not shown.

Figure 4. Epiretinal prostheses. (A-B) External (A) and implant (B) part of the Argus II system. (C) Electrode array of the Argus I (left) and Argus II (right) implant, containing 16 and 60 electrodes, respectively. (D) Schematic drawing of the IMI system and the implant prototype. The stimulating array is circled in red. Images adapted from (Hornig et al., 2007).

Figure 5. Subretinal prostheses. (A) Prototype of the Alpha-IMS predecessor, an investigational device that includes 16 additional electrodes for direct stimulation. The overview of the implant (top) and the detailed view of the microphotodiode array (MPDA) with an additional $4 \times 4$ array of the TiN electrodes attached to the end (bottom). The MPDA chip consists of 1,500 photodiodes on a surface area of $3 \times 3 \mathrm{~mm}$. Figure from . (B) MPDA of the photovoltaic prosthesis developed by the Palanker group. Inset: blown-up view of a single stimulating element with 3 photodiodes in series. Images from (Wang et al., 2012). (C) Prototype of the 256-channel Boston retinal implant. Left: concept of the device with the secondary coil surrounding the cornea. Right: electrodes bonded to the feedthrough of the hermetic case. Images from (Kelly et al., 2013a).

Figure 6. Suprachoroidal prostheses. (A) The STS implant including the suprachoroidal stimulating array and the remote return electrode. Inset: the exploded view of the stimulating array containing 49 electrodes. Images courtesy of Dr. Takashi Fujikado. (B) The BVA implant with 1 remote return and 2 other return electrodes on the suprachoroidal array. Inset: the exploded view of the implant chip consisting of 33 
platinum stimulating electrodes and 2 large return electrodes on the silicone substrate. Images adapted from (Ayton et al., 2014).

Figure 7. Origami spherical paralyne-C array. (A) The crease-patterned array before (bottom) and after (top) folding. (B) Comparison between the creased (i) and uncreased (ii) array when placed on the spherical surface. Red circles: winkles formed from unmatched curvature of the uncreased array and the sphere. From (Liu et al., 2013).

Figure 8. Implantation of a wide-field array in an enucleated porcine eye. (A) Unfolded shape of the concentric array. (B) The folded array with the arms overlapped on the central part. (C) The overlapped arms are grabbed with a forceps for implantation. (D) The implanted array is fixed onto the retina with a tack. The two holes at the tip of the peripheral arms are for purposes of surgical manipulation. From (Ameri et al., 2009).

Figure 9. Phosphene elongation and axonal activation. (A) Stimulation in Argus I subjects produced elongated phosphene shapes in the orientation of the axons. Left: stimulation electrodes in red circles; Middle: phosphene drawing by the subject; Right: phosphenes predicted from the axonal activation. (B) Stimulation in Argus II subjects also produced elongated phosphenes tracking axonal trajectories. From (Nanduri et al., 2012).

Figure 10. Intraocular camera positioned in place of the crystalline lens to allow scanning of the visual field with eye movement. Courtesy of Dr. Armand Tanguay.

Figure 11. PET images of the cortical activity of normal (NC) and retinal degenerated (RD) subjects in light stimulation and transcorneal electrical stimulation (TCES). Selected Brodmann areas that exhibited increased activity during stimulation are labeled as yellow numeric values. From (Xie et al., 2012).

Figure 12. Schematics of different forms of optogenetic proteins. Left to right: light signaling of the microbial blue light sensitive channelrhodopsin (ChR), yellow light sensitive halorhodopsin (NpHR), green light sensitive bacteriorhodopsin (BR) and G-protein coupled blue light sensitive animal melanopsin.

Figure 13. Image projection system for optogenetic retinal stimulation. (A) Augmented reality goggle with eye tracking integrated (Sensomotoric Instruments). (B) Microphotograph of tilted elements in a digital micromirror array (Texas Instrument). (C) Neurons expressing ChR2 are covered by a $64 \times 64$ matrix of individually addressable micro-LEDs. Inset: the exploded view of the micro-LED array. Images in C from (Grossman et al., 2010).

Figure 14. Schematic mechanisms of photosensitization of native neurons with chemical photoswitches. (A) Photoisomerization of azobenzene-containing photoswitches DENAQ and MPC088 that act on potassium channels and $\mathrm{GABA}_{A}$ receptors respectively. (B) Light-induced membrane polarization with photovoltaic switch RubpyC17. Diagram in B from (Rohan et al., 2013). 
A

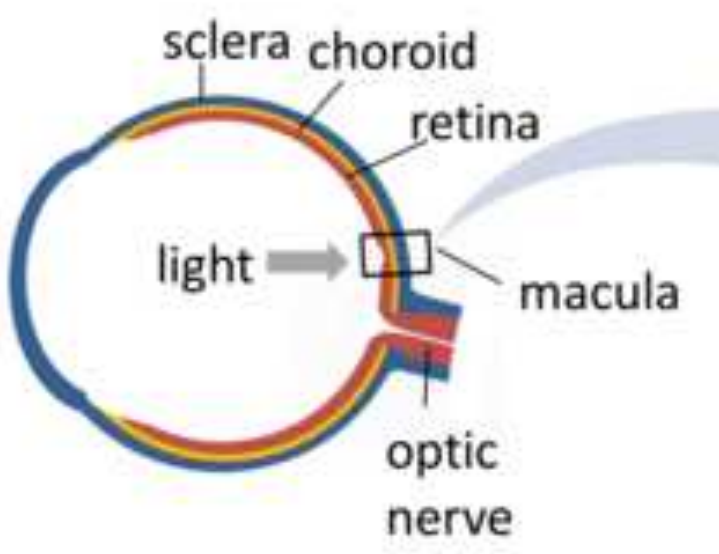

B
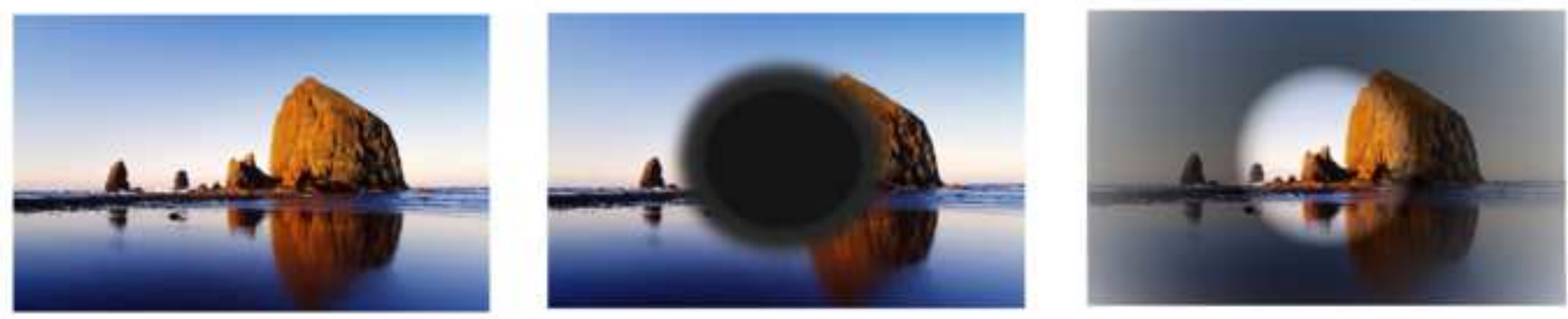

Ganglion cells Amacrine cells Bipolar cells Horizontal cells

Photoreceptors

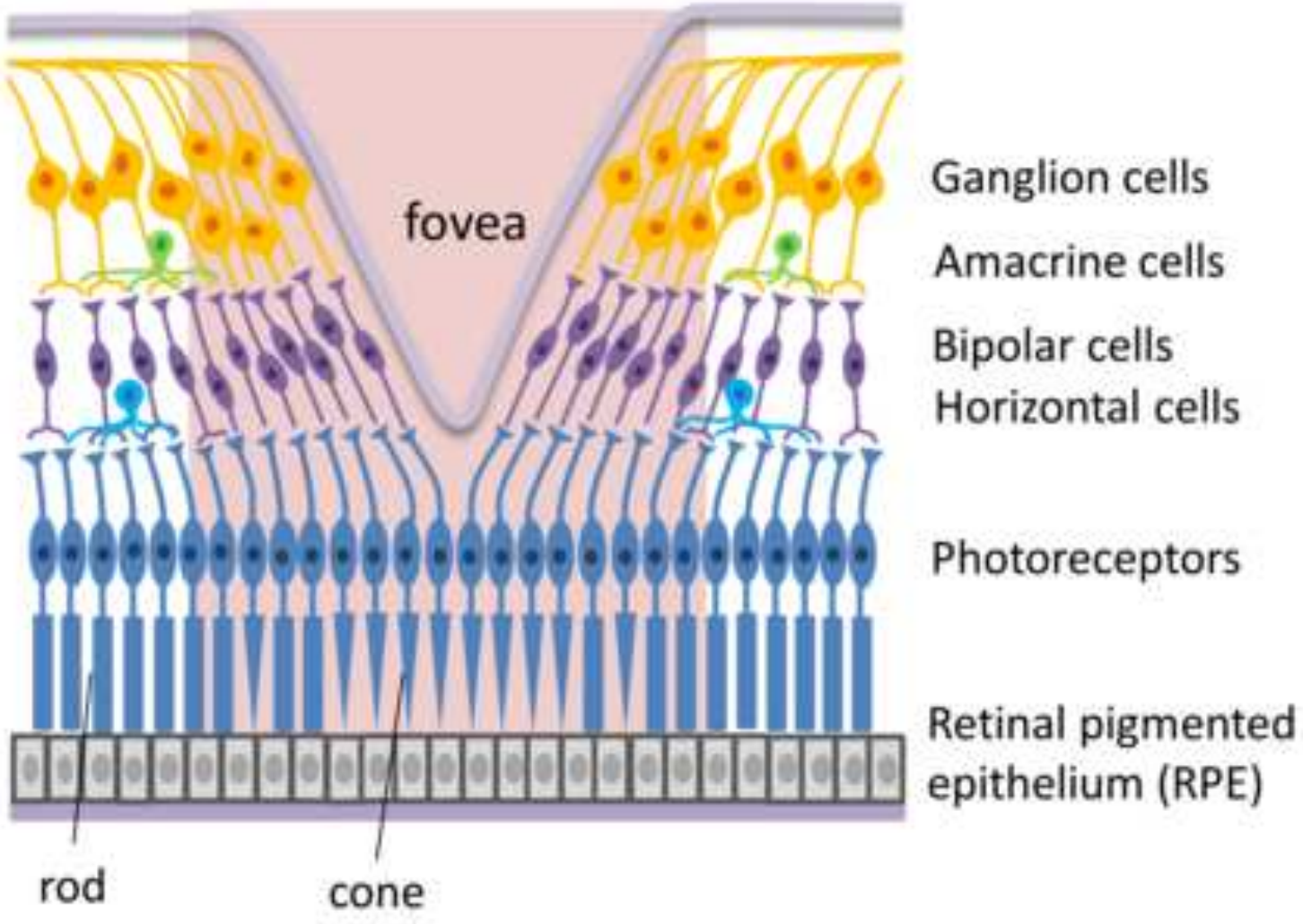

Retinal pigmented epithelium (RPE)

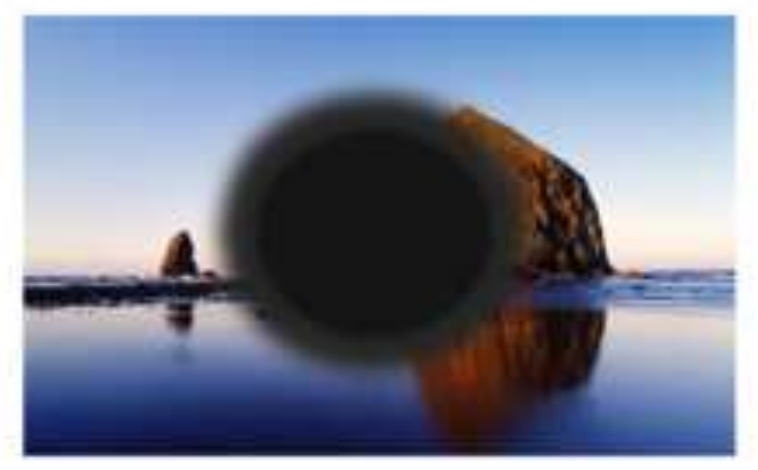

\section{nerve}


A

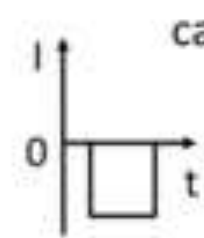

I
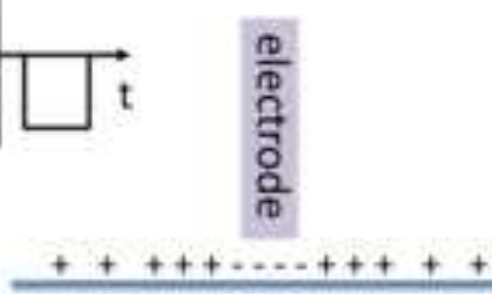

Extracellular
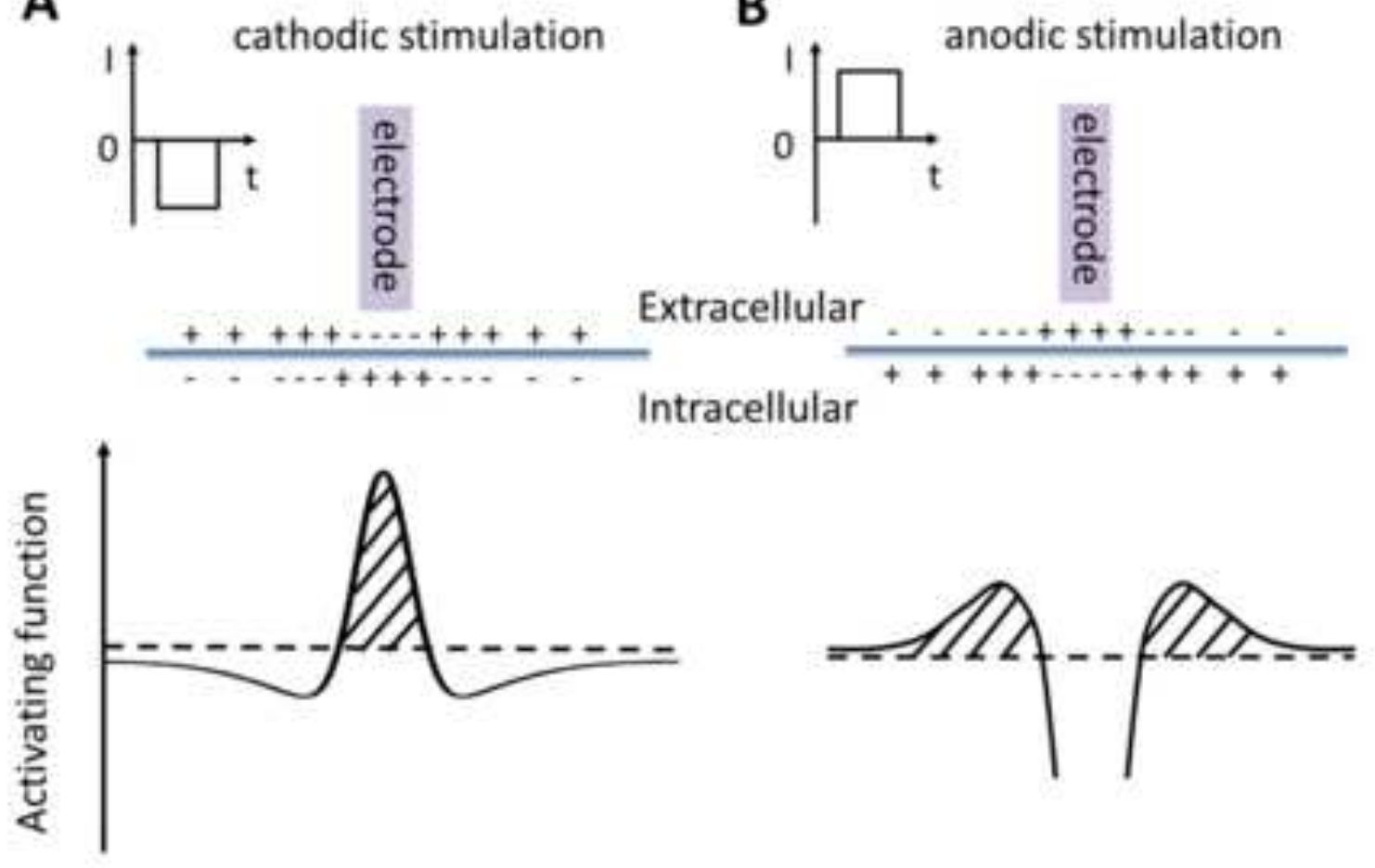

c v
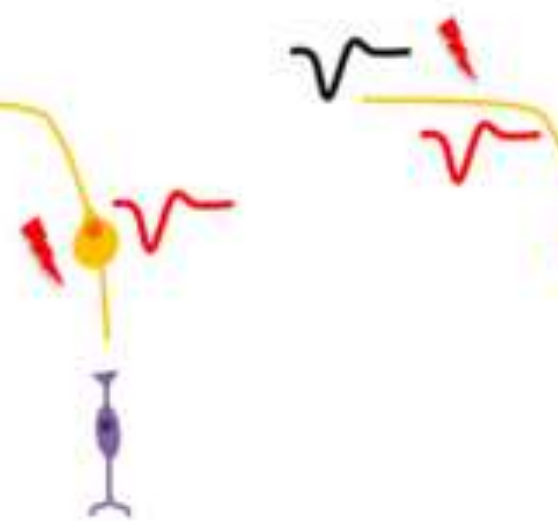

direct stimulation

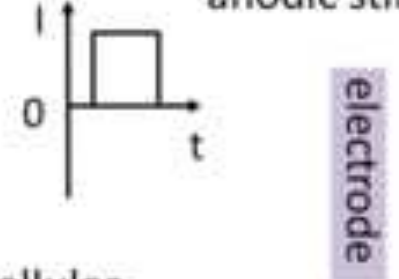

$\frac{\frac{1}{9}}{\frac{7}{8}}$
,

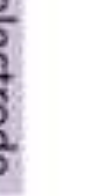




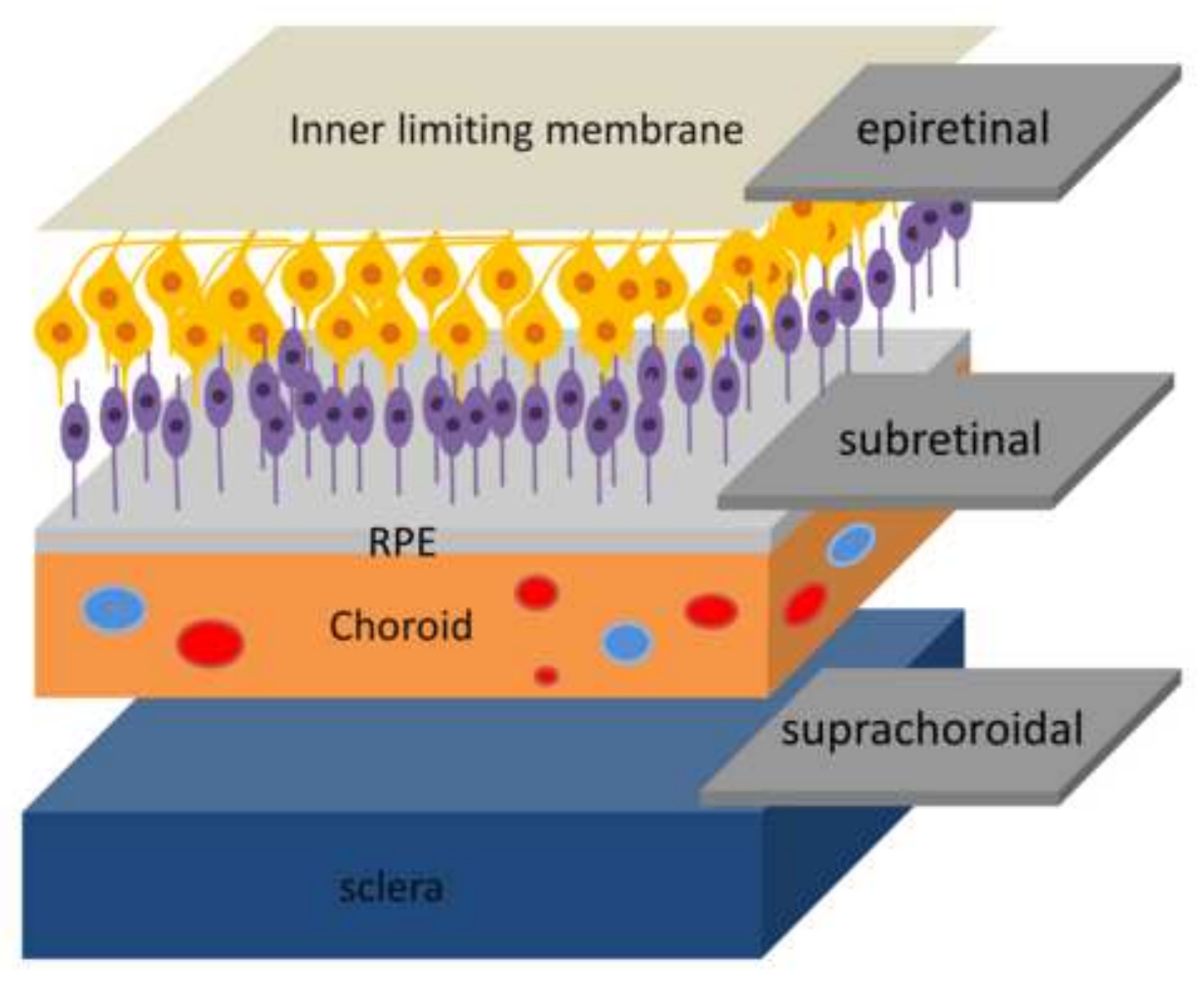


B

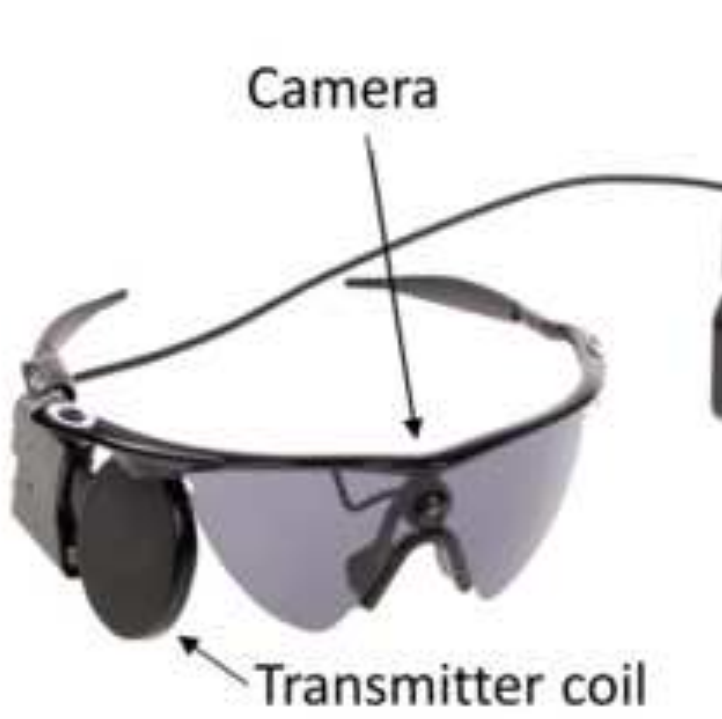

\section{Electronic case}

(extraocular)
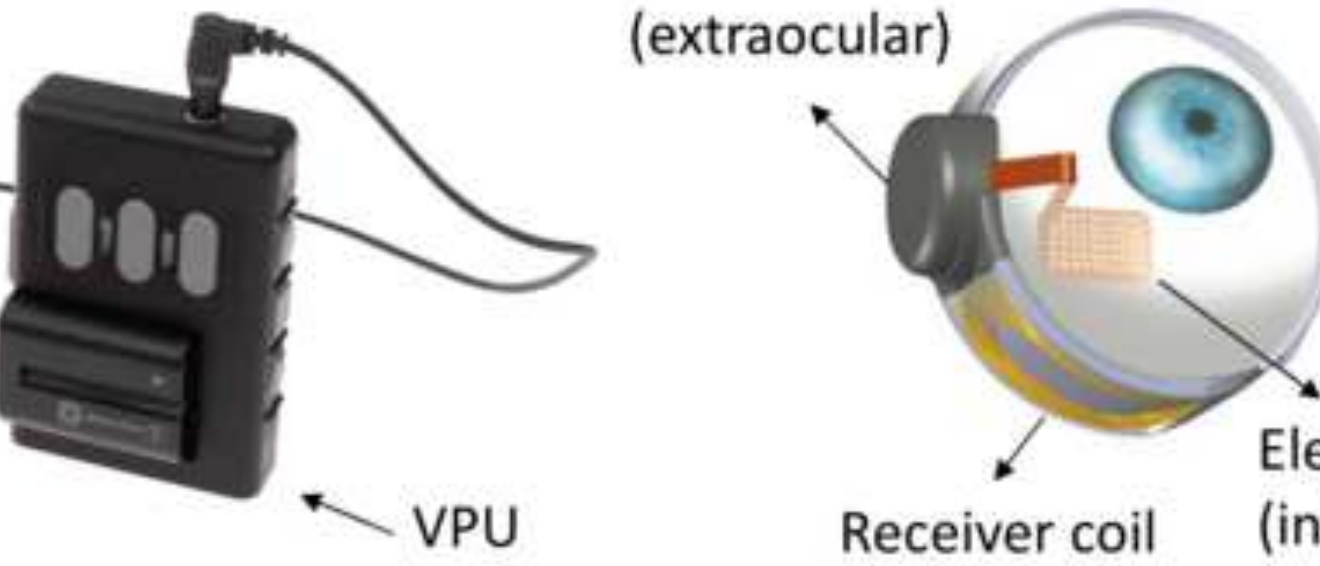

Receiver coil (intraocular)

(extraocular)

C
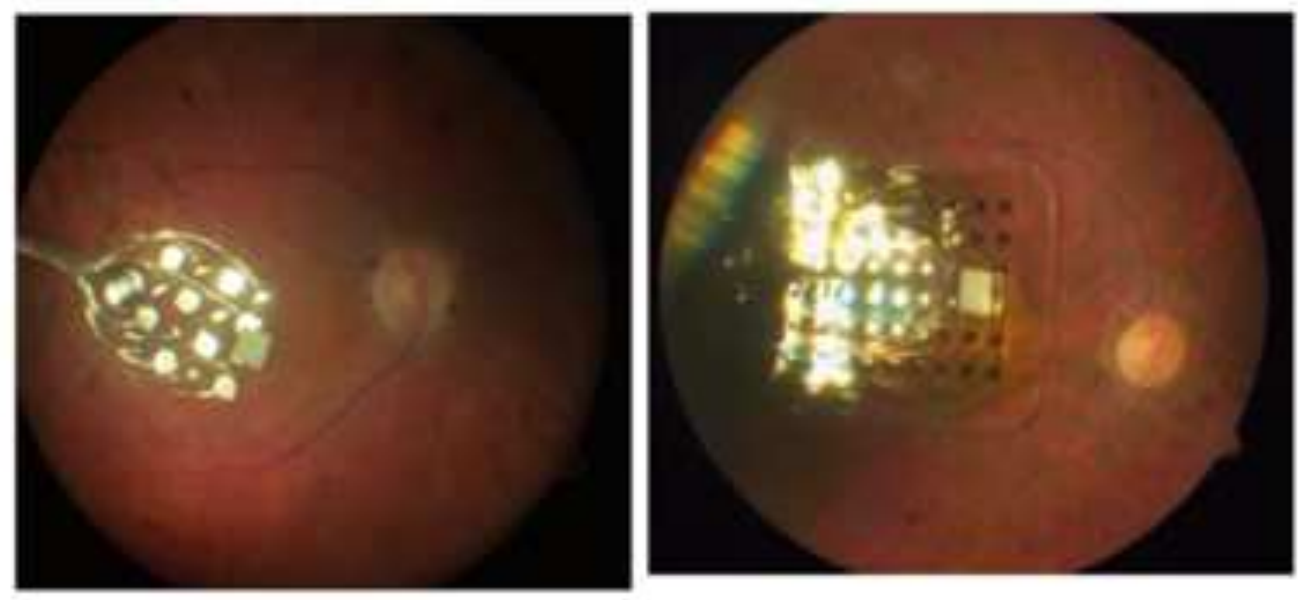

D

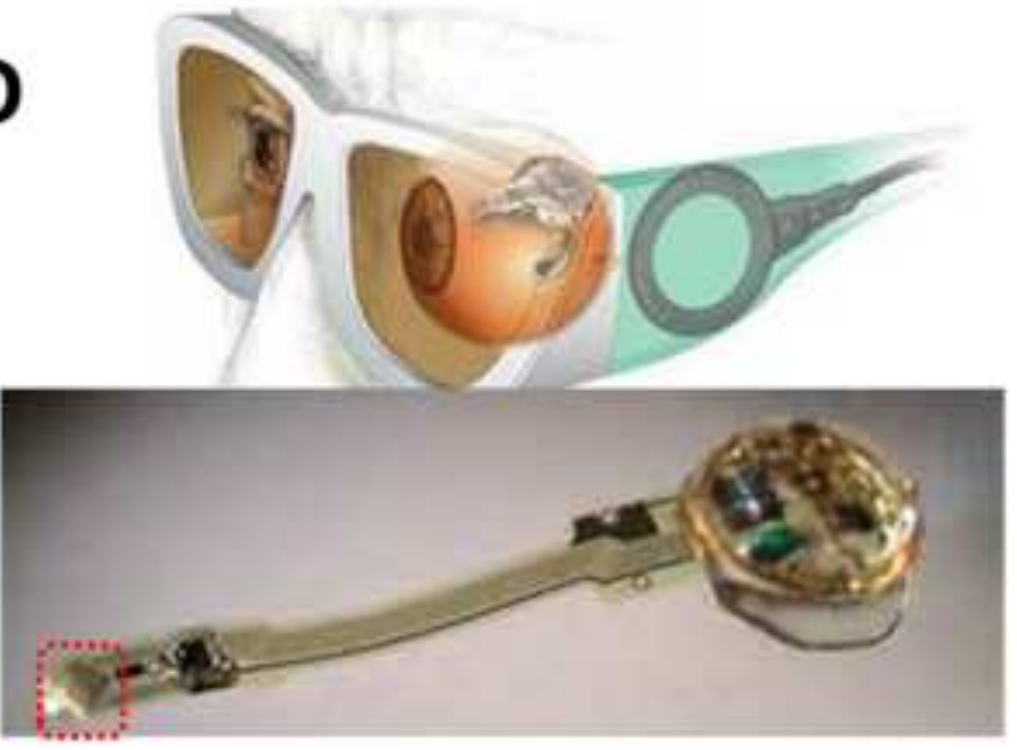


A

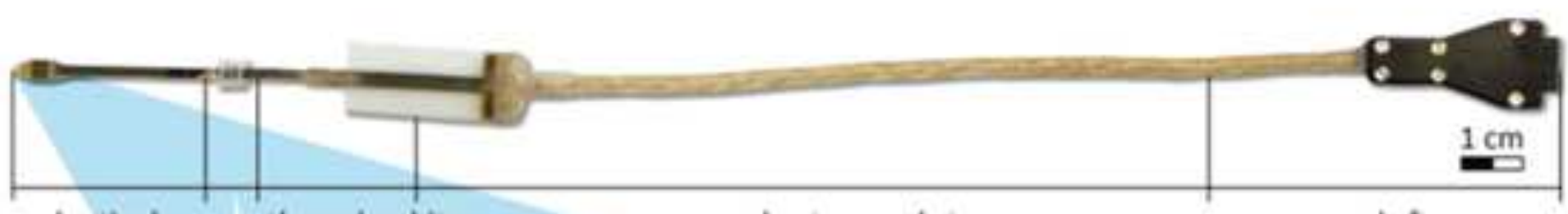

subretinal

through orbita to orbital rim

episcleral

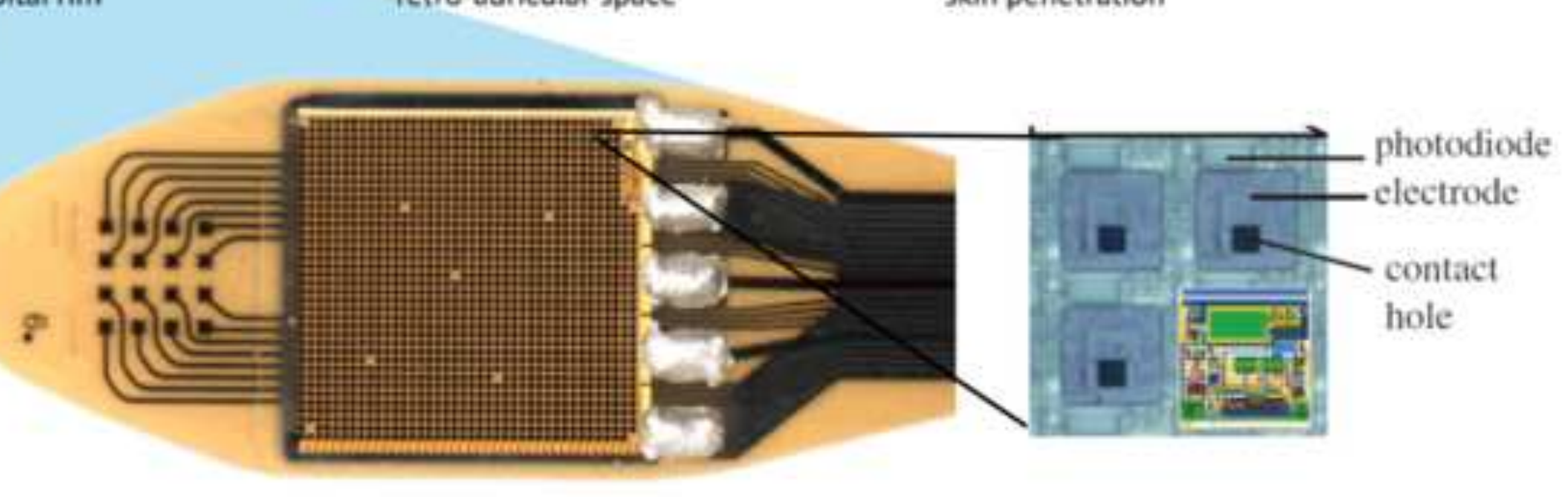

B
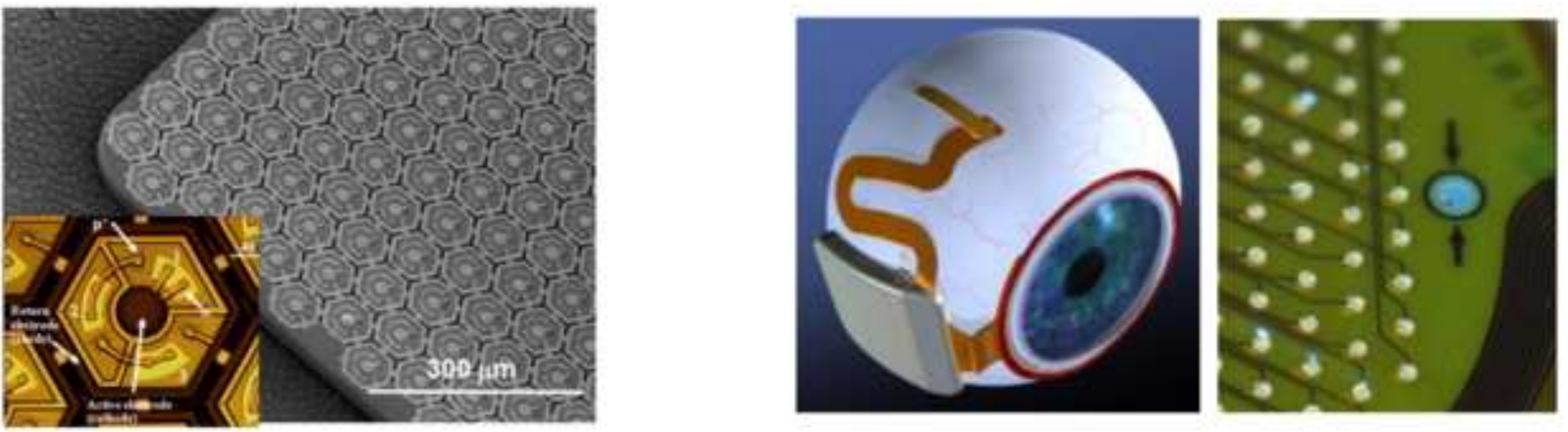

exposed after

skin penetration
C 


\section{A}
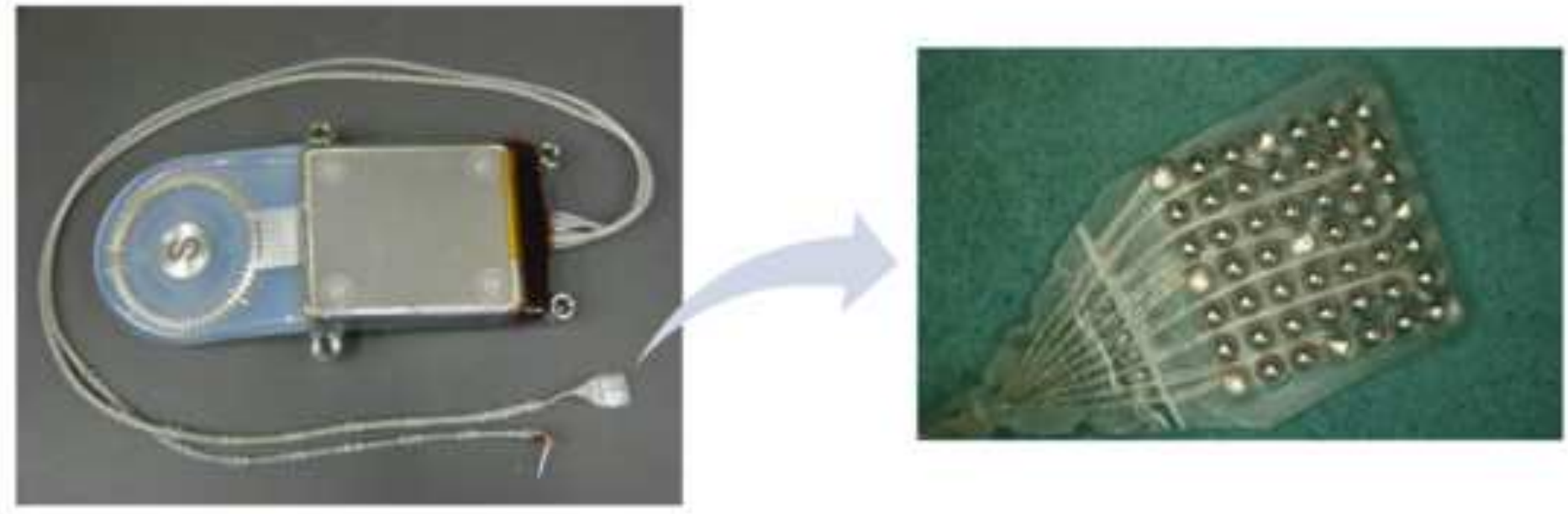

B
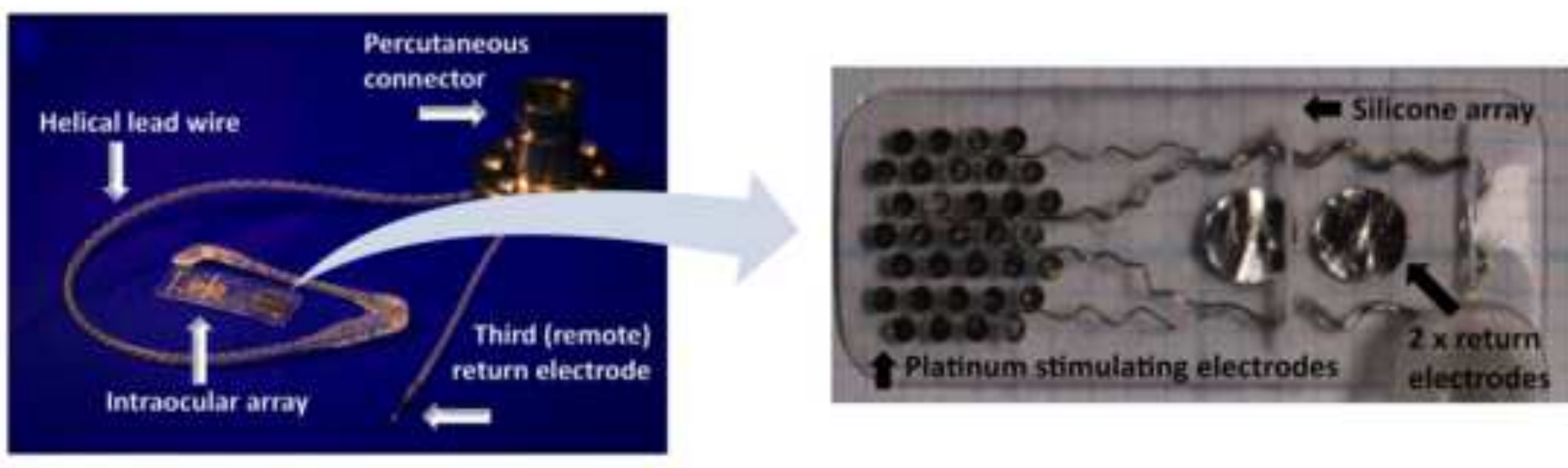

Figure 6 
A

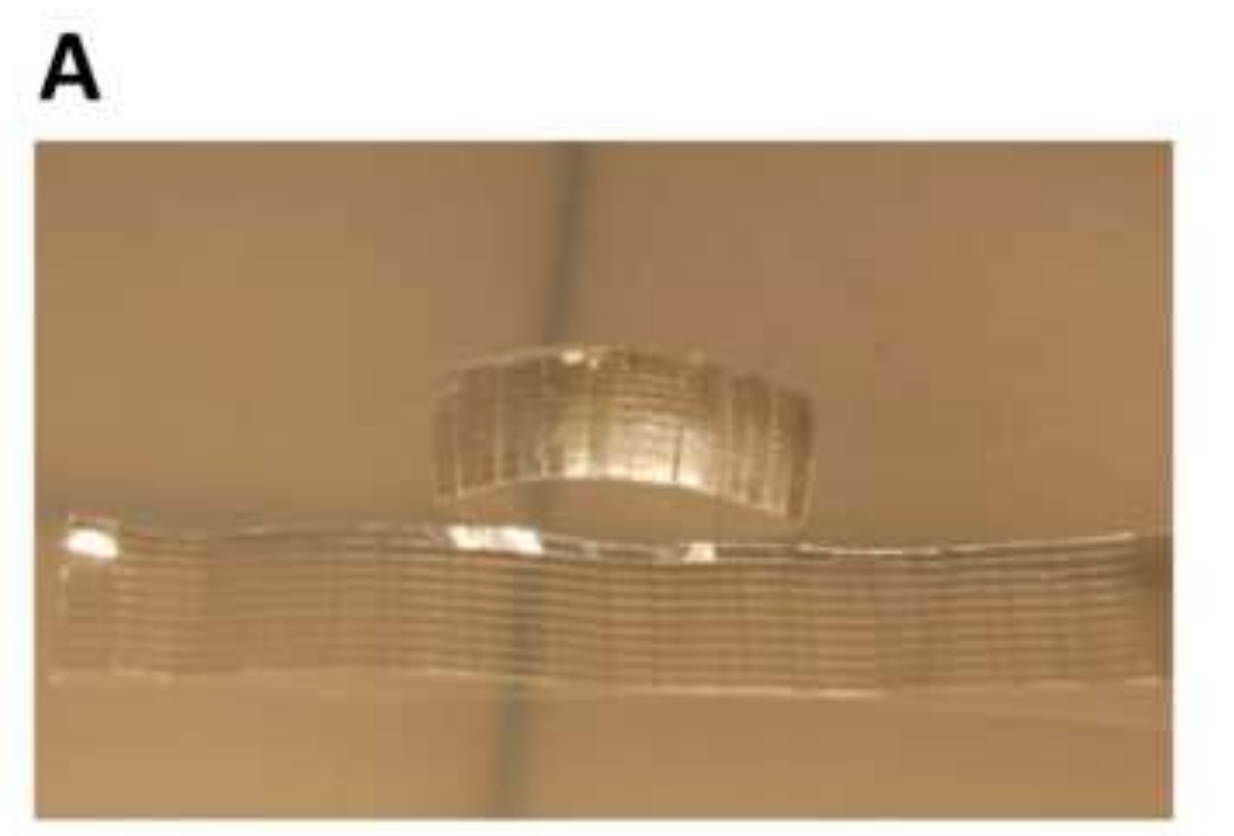

A

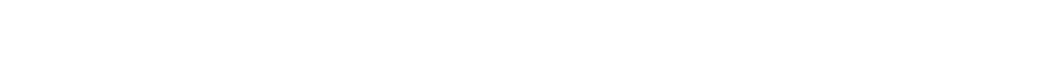

B
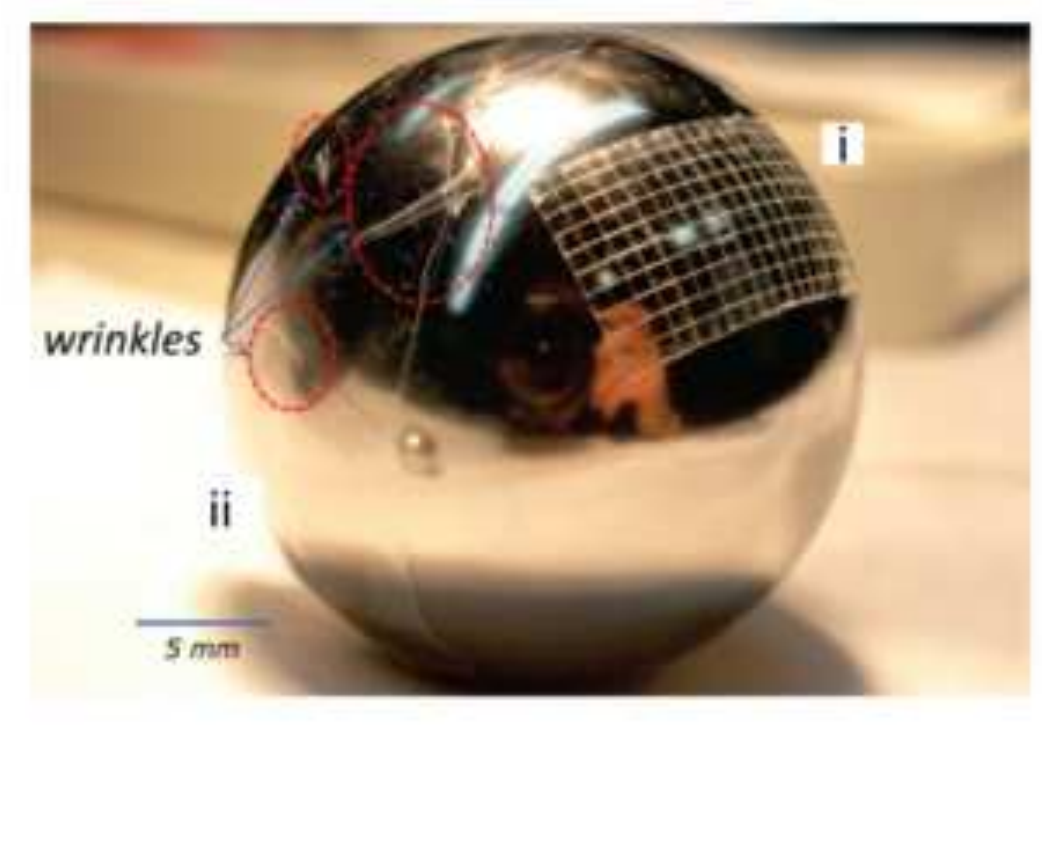
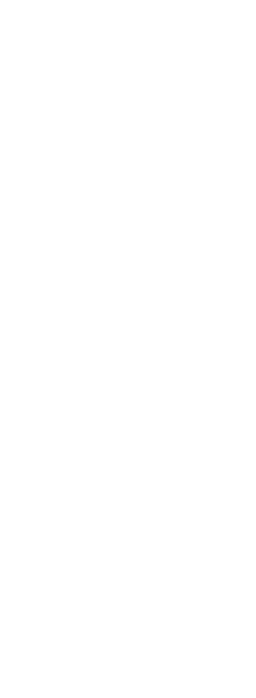


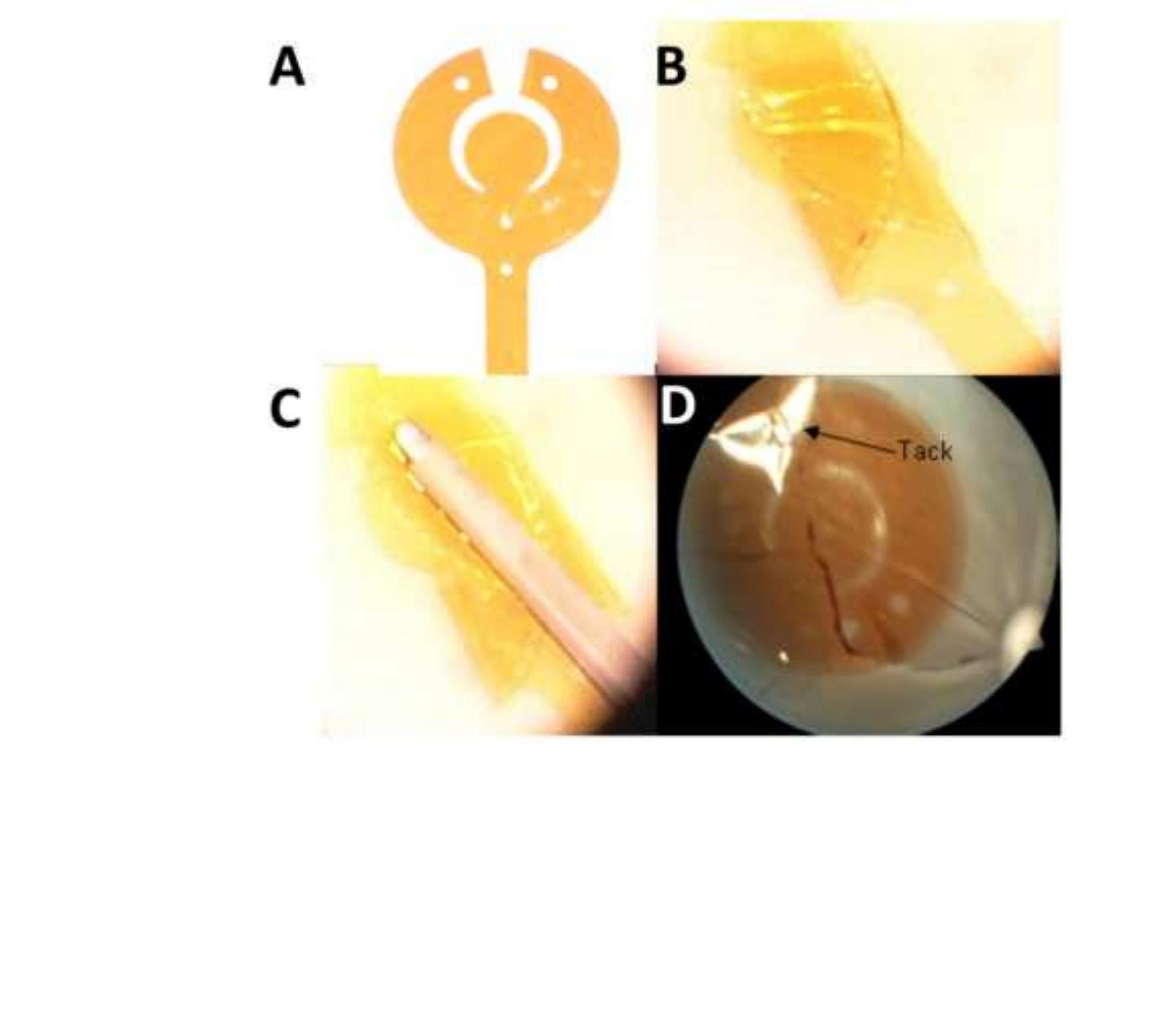

Figure 8
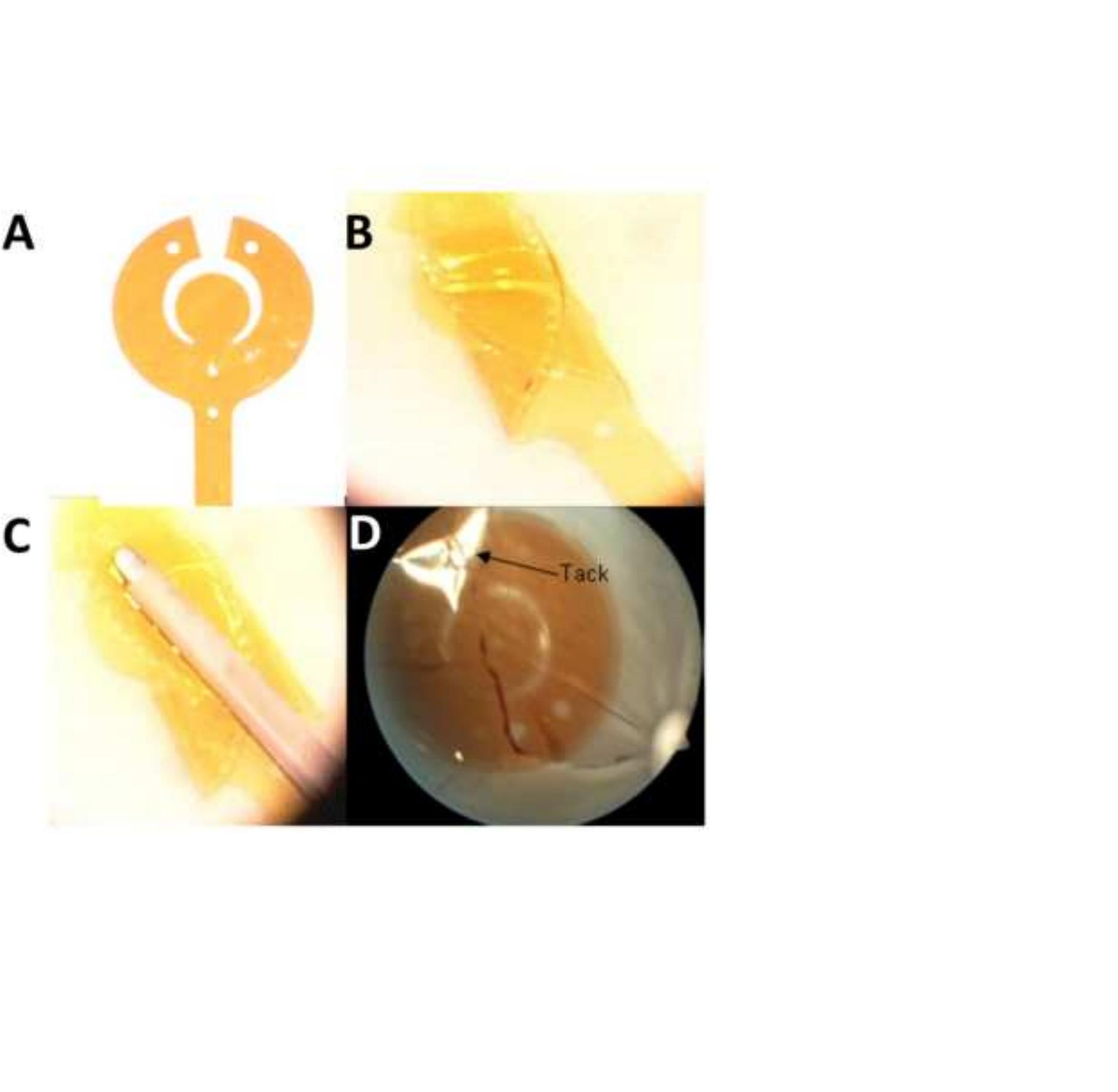

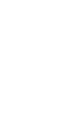
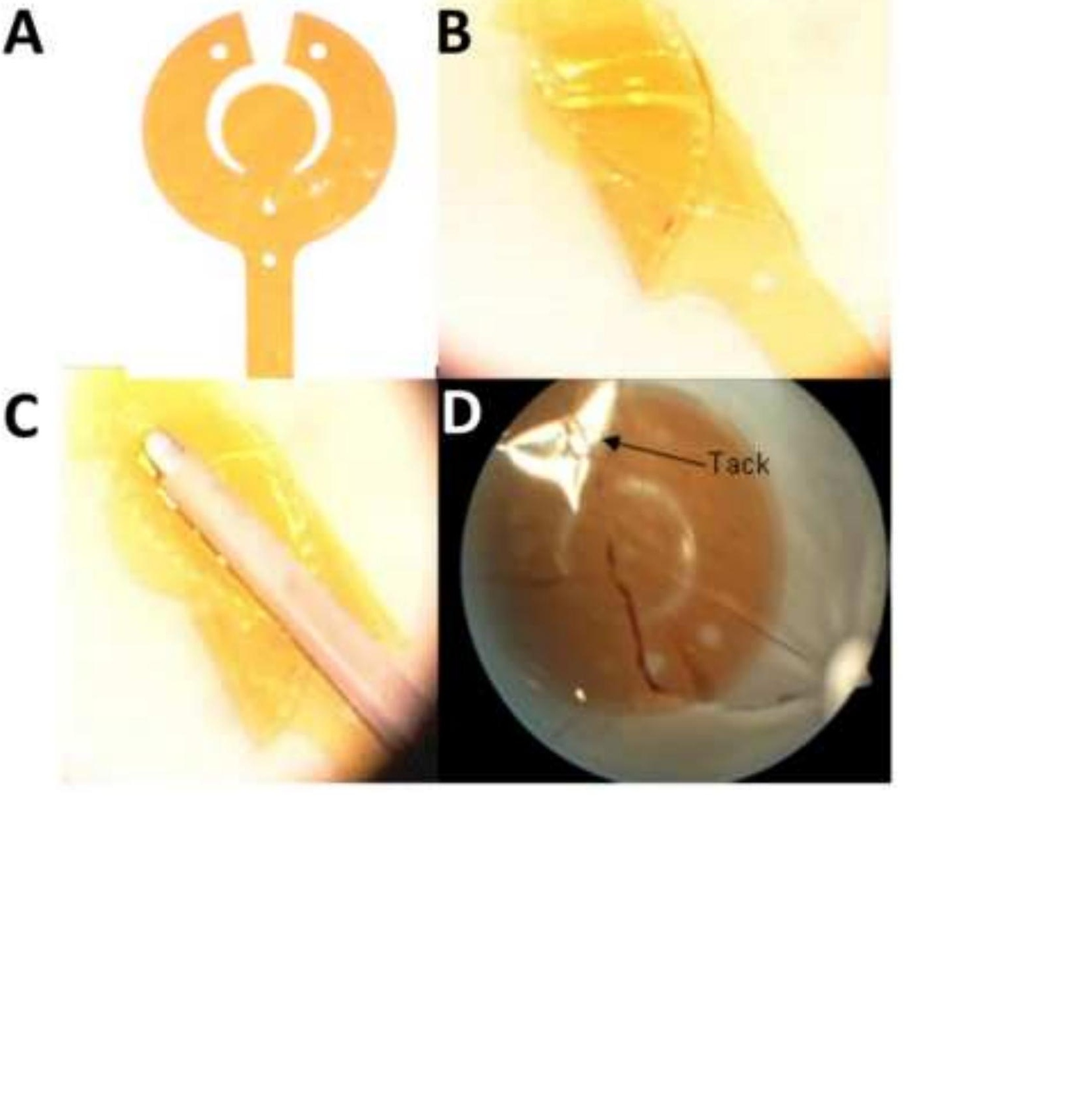

.

.

.
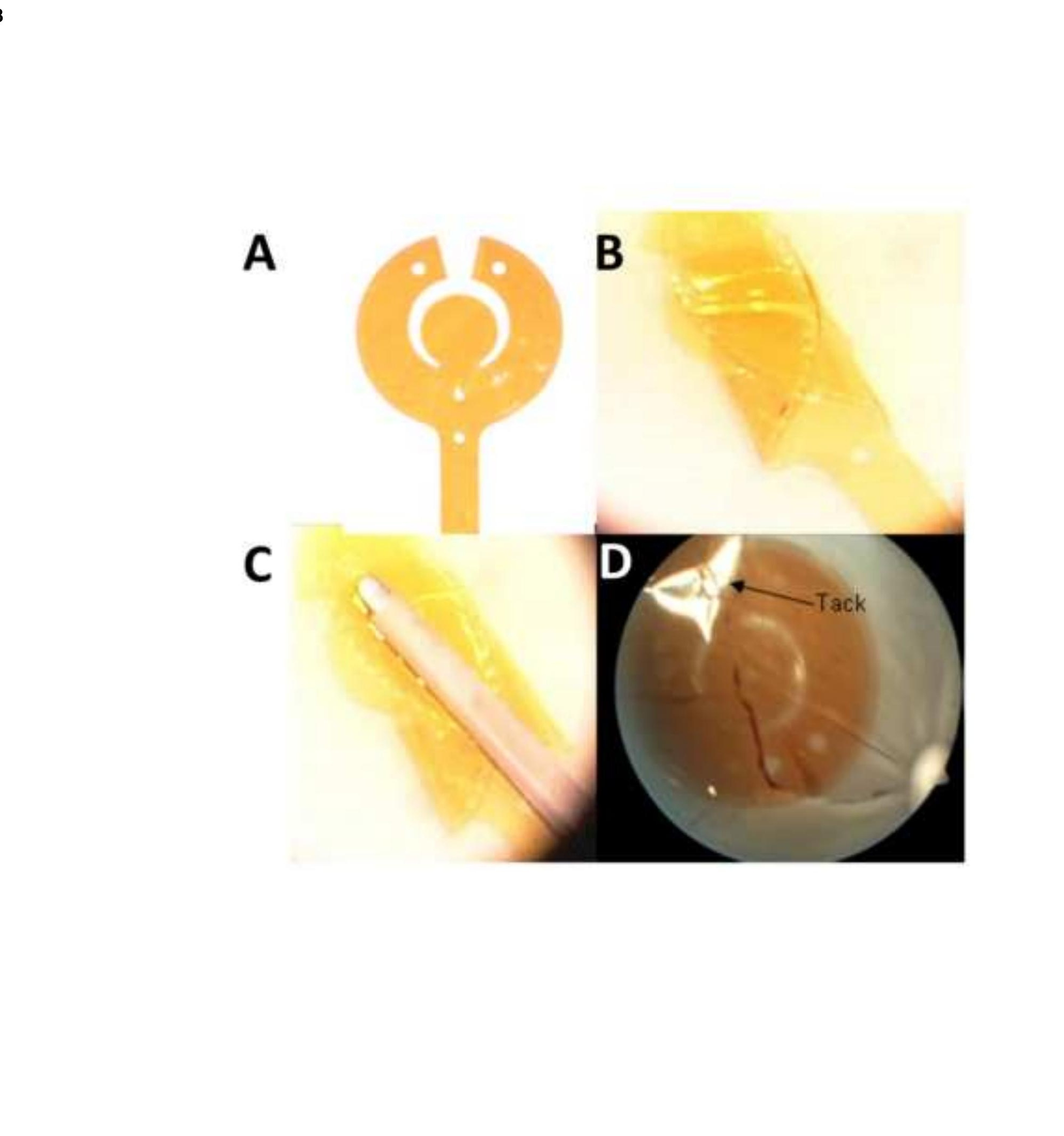


\section{Figure 10}

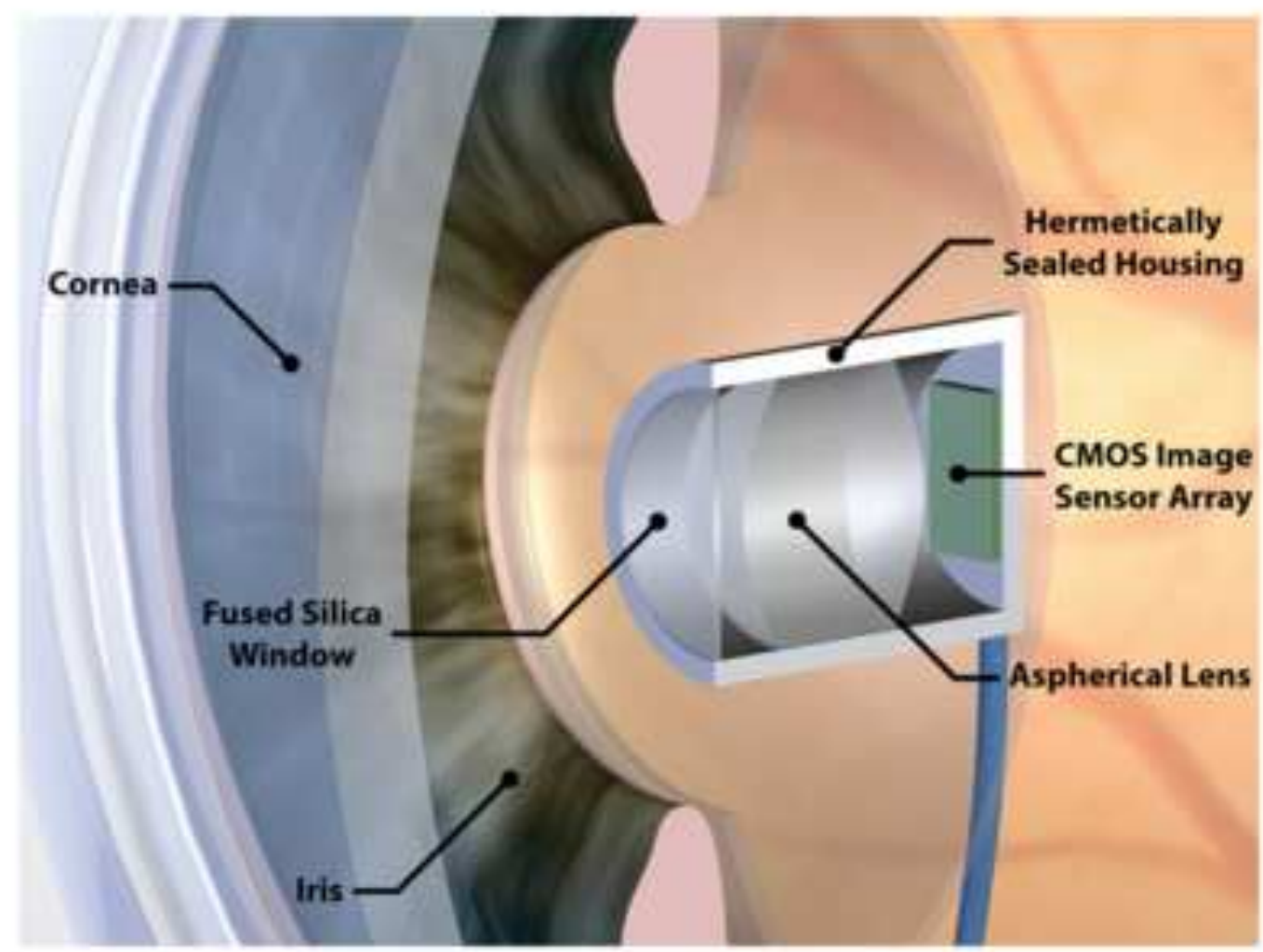




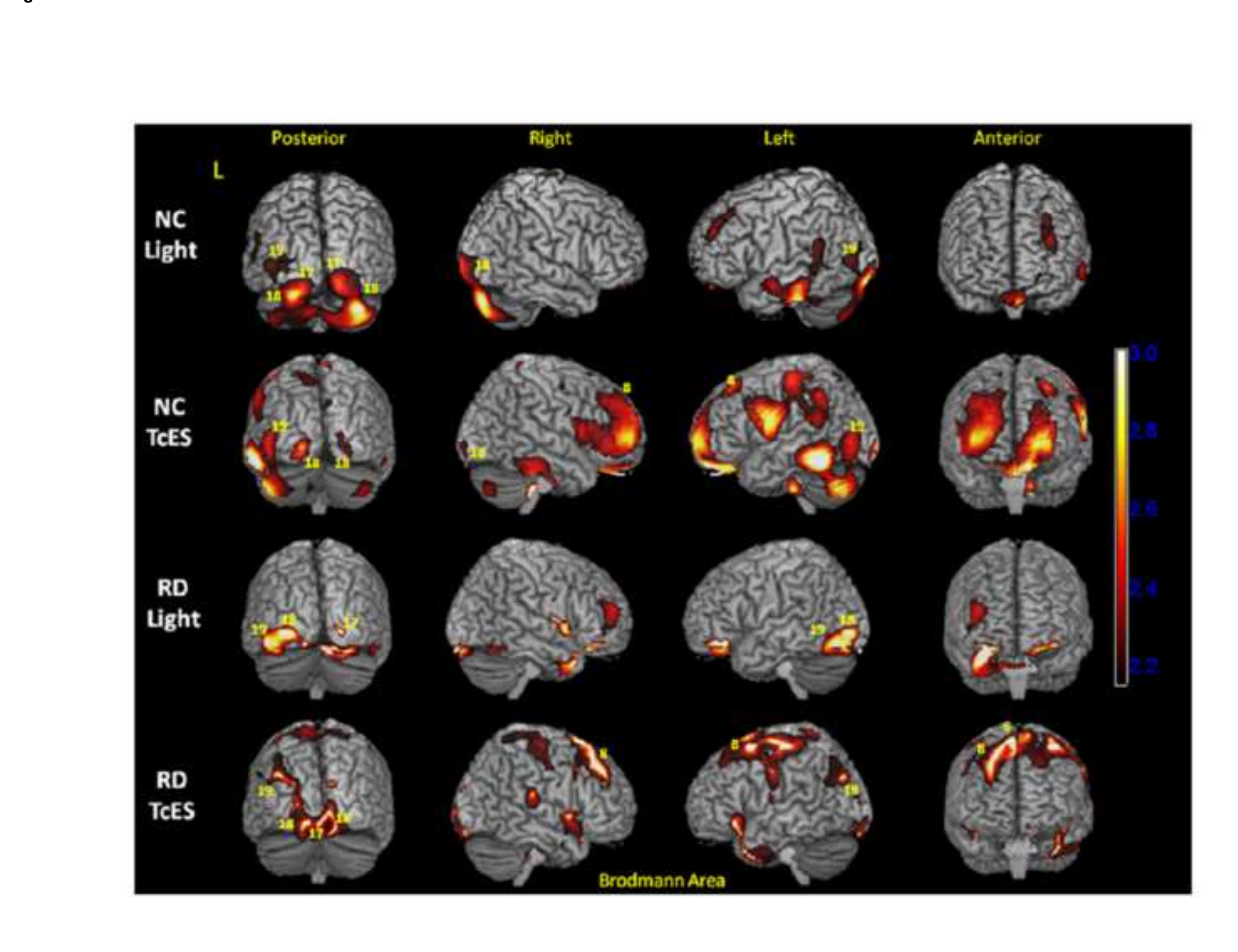

.
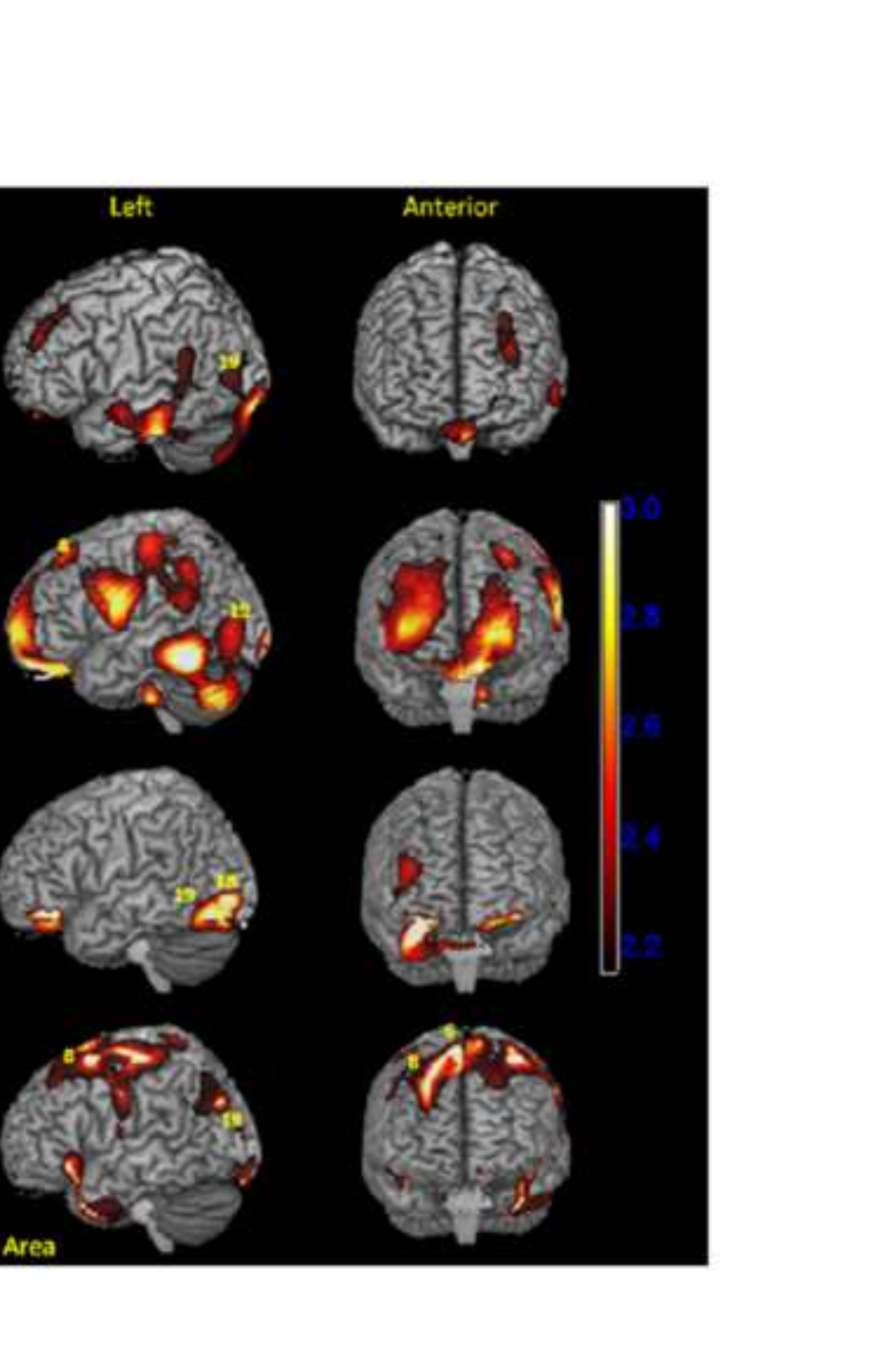
$\begin{array}{llll}\text { ChR NpHR } & \text { BR } & \text { melanopsin }\end{array}$

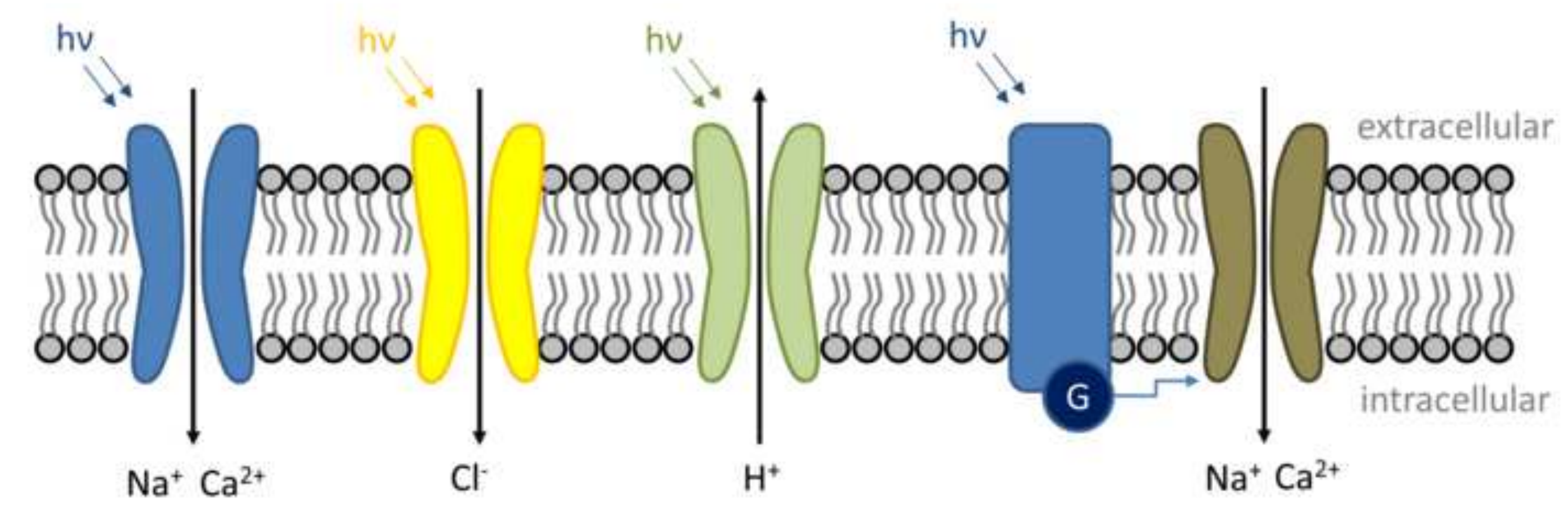


A

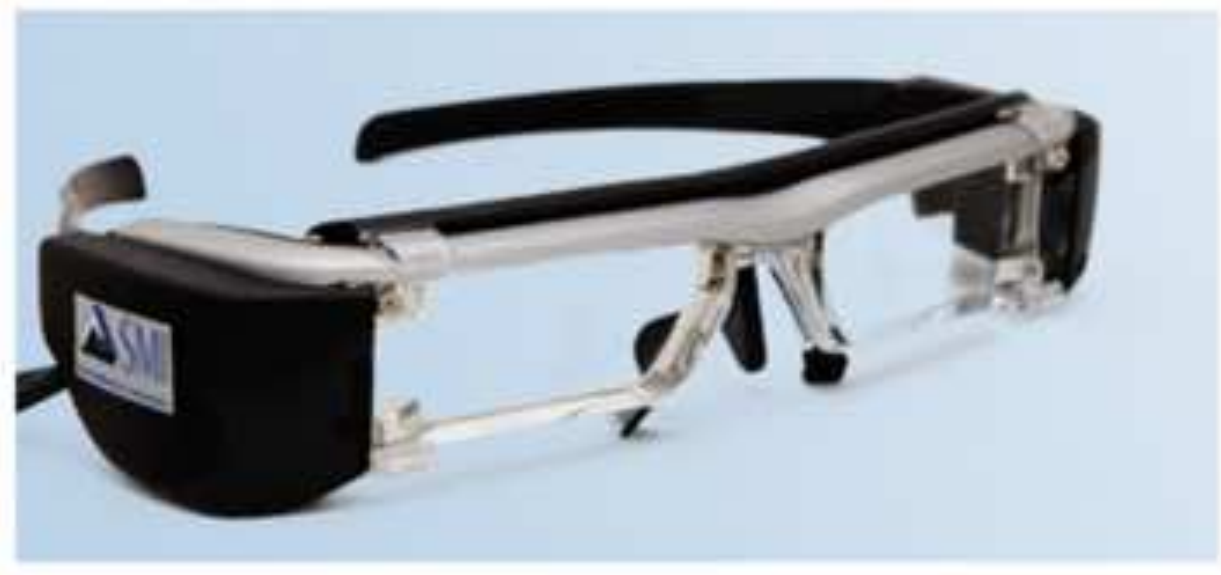

B

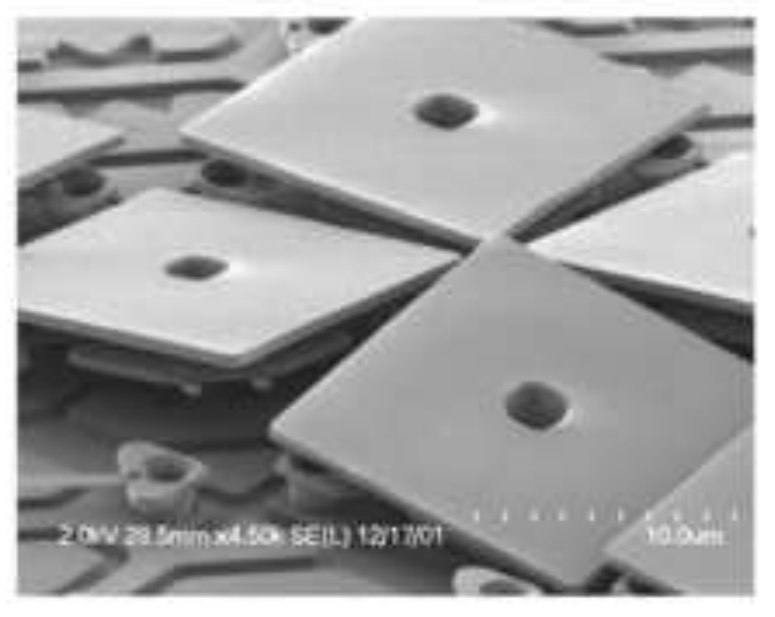

C
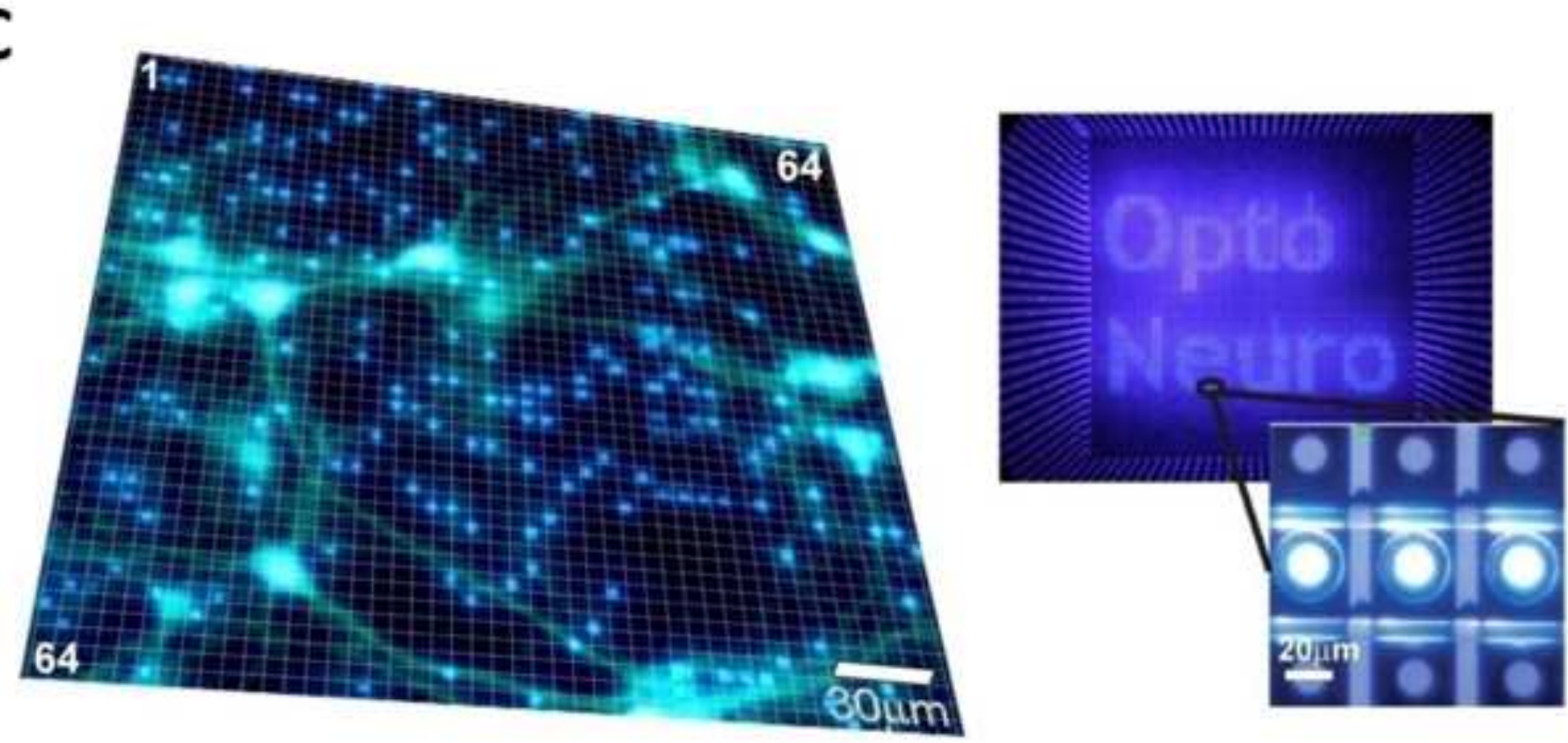
A Light-gated potassium channel

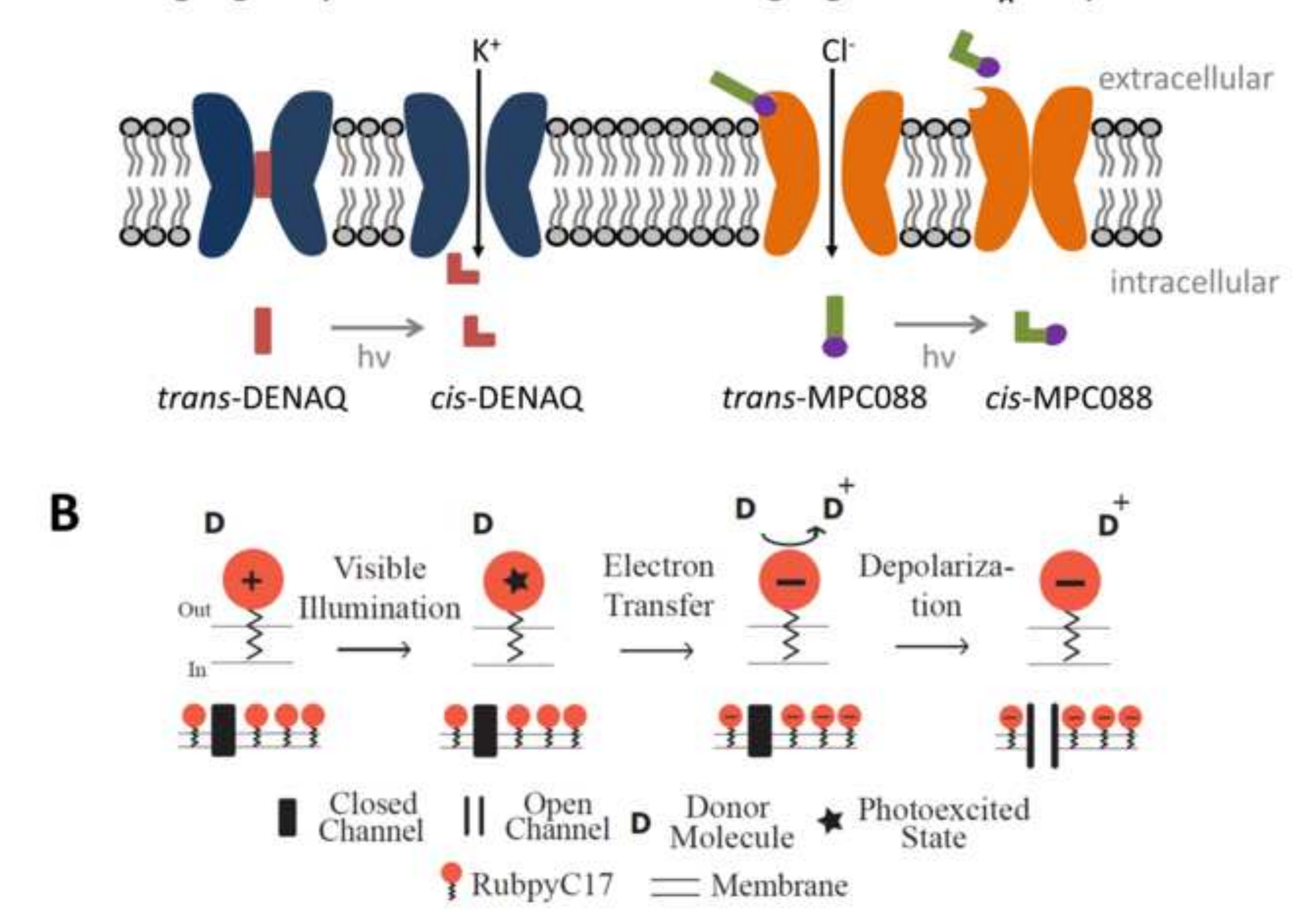

B

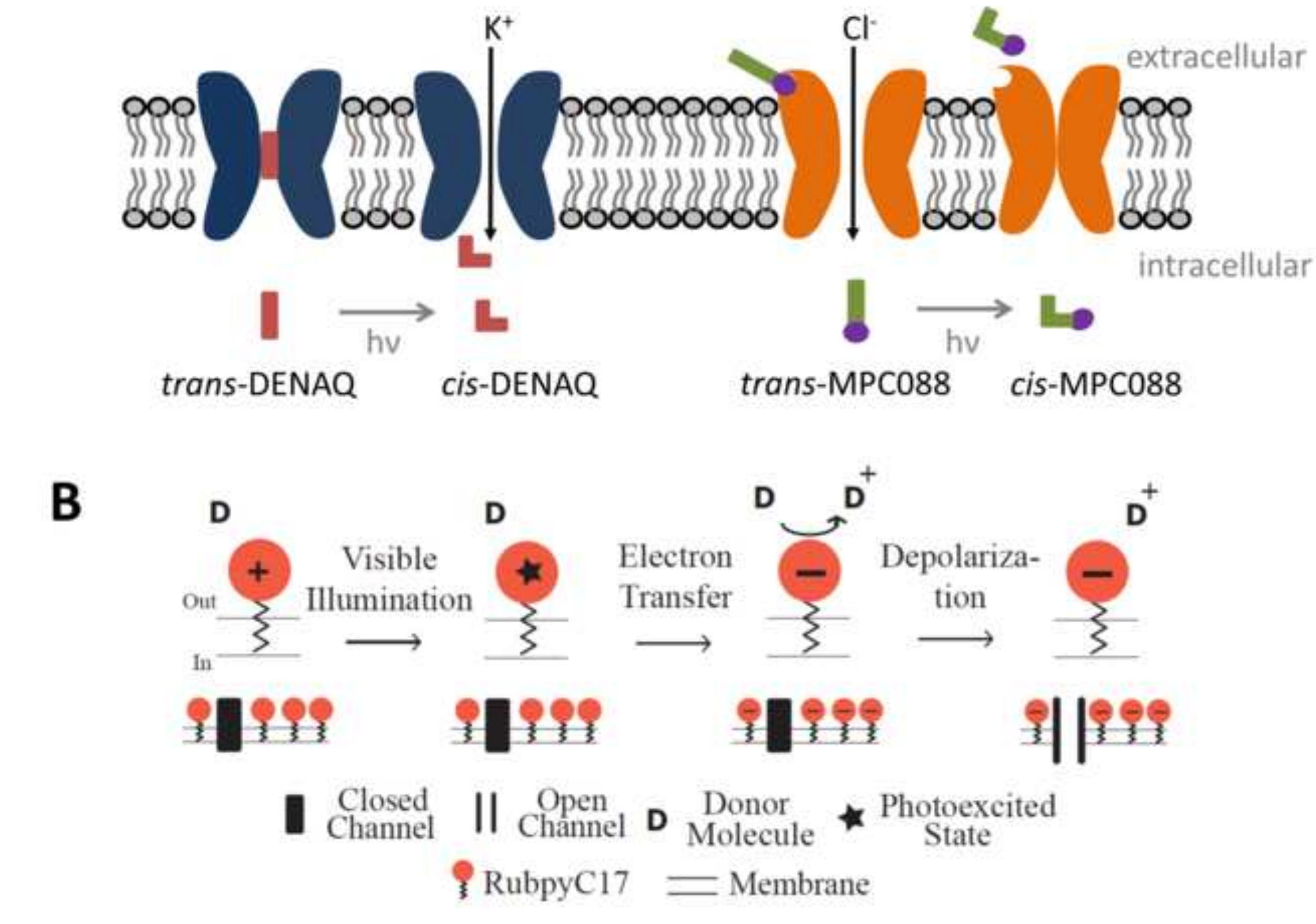

Light-gated $\mathrm{GABA}_{\mathrm{A}}$ receptor

trans-MPC088 cis-MPC088 


\begin{tabular}{|c|c|c|c|c|c|c|c|c|c|c|c|}
\hline \multirow[b]{2}{*}{ Location } & \multirow[b]{2}{*}{ Device } & \multicolumn{4}{|c|}{ Electrode } & \multirow{2}{*}{$\begin{array}{c}\text { Power } \\
\text { / } \\
\text { Data } \\
\text { link }\end{array}$} & \multicolumn{4}{|c|}{ Clinical Results } & \multirow[b]{2}{*}{ Reference } \\
\hline & & Material & Count & $\begin{array}{l}\text { Size } \\
(\mu \mathrm{m})\end{array}$ & $\begin{array}{l}\text { Pitch } \\
(\mu \mathrm{m})\end{array}$ & & $\begin{array}{c}\text { Number } \\
\text { of } \\
\text { subjects }\end{array}$ & $\begin{array}{l}\text { Implant } \\
\text { duration }\end{array}$ & $\begin{array}{l}\text { Visual } \\
\text { Acuity }\end{array}$ & $\begin{array}{l}\text { Visual } \\
\text { Field }\end{array}$ & \\
\hline \multirow{4}{*}{ Epi. } & Argus I & Pt & 16 & $\begin{array}{l}250 \\
500\end{array}$ & 800 & $\mathbf{R F}$ & 6 & $\begin{array}{l}11 \text { yrs } \\
\text { and } \\
\text { ongoing }\end{array}$ & 20/3244 VGA & $\begin{array}{c}10^{\circ} \mathrm{X} \\
10^{\circ}\end{array}$ & $\begin{array}{l}\text { Capsi et al., } 2009 \\
\text { Yue et al., } 2015\end{array}$ \\
\hline & Argus II & Pt & 60 & 200 & 525 & RF & 30 & $\begin{array}{l}8 \text { yrs and } \\
\text { ongoing }\end{array}$ & $\begin{array}{c}20 / 1262 \text { VGA } \\
\text { (20/200 with } \\
16 x \\
\text { magnification) }\end{array}$ & $\begin{array}{c}19^{\circ} \mathrm{X} \\
11^{\circ}\end{array}$ & $\begin{array}{c}\text { Humayun et al., } 2012 \\
\text { Ho et al., } 2015 \\
\text { Sahel et al., } 2013\end{array}$ \\
\hline & IMI & $\mathrm{IrO}_{\mathrm{x}}$ & 49 & $\begin{array}{l}50 \\
100 \\
200 \\
360\end{array}$ & N/A & RF, IR & $\begin{array}{c}20(A) \\
4(C)\end{array}$ & $\begin{array}{l}3 \text { mths } \\
\text { (A) } 9 \\
\text { mths (C) }\end{array}$ & N/A & N/A & $\begin{array}{l}\text { Hornig et al., } 2007 \\
\text { Richard et al., } 2007\end{array}$ \\
\hline & EPIRET3 & $\mathrm{IrO}_{\mathrm{x}}$ & 25 & 100 & 500 & $\begin{array}{c}\text { RF } \\
(\mathrm{IOC})\end{array}$ & 6 & 4 wks & N/A & N/A & $\begin{array}{l}\text { Roessler et al. } 2009 \\
\text { Klauke et al., } 2011\end{array}$ \\
\hline \multirow{3}{*}{ Sub. } & Alpha IMS & TiN & 1500 & 50 & 70 & $\begin{array}{l}\text { MPDA, } \\
\text { RF }\end{array}$ & 29 & $\begin{array}{l}6 \text { yrs and } \\
\text { ongoing }\end{array}$ & $\begin{array}{l}20 / 200 \text { VGA } \\
20 / 546 \text { LCA }\end{array}$ & $\begin{array}{c}11^{\circ} \mathrm{X} \\
11^{\circ}\end{array}$ & $\begin{array}{l}\text { Stingl et al., 2013b } \\
\text { Stingl et al., } 2015\end{array}$ \\
\hline & $\begin{array}{c}\text { Photovoltaic } \\
\text { Prosthesis }\end{array}$ & $\mathrm{IrO}_{\mathrm{x}}$ & N/A & $\begin{array}{l}20 \\
40\end{array}$ & $\begin{array}{l}75 \\
145\end{array}$ & $\begin{array}{l}\text { MPDA, } \\
\text { IR }\end{array}$ & N/A & N/A & N/A & N/A & $\begin{array}{l}\text { Mathieson et al., } \\
2012 \\
\text { Lorach et al., 2015a }\end{array}$ \\
\hline & $\begin{array}{l}\text { Boston } \\
\text { Implant }\end{array}$ & $\mathrm{IrO}_{\mathrm{x}}$ & 256 & N/A & N/A & RF & N/A & N/A & N/A & N/A & Kelly et al., 2013 \\
\hline \multirow{2}{*}{ Supra. } & STS & Pt & $\begin{array}{c}49 \text { (9 } \\
\text { active) }\end{array}$ & 500 & 700 & $\mathbf{R F}$ & 2 & 4 wks & N/A & $\begin{array}{c}20^{\circ} X \\
16^{\circ}\end{array}$ & Fujikado et al., 2011 \\
\hline & BVA & Pt & 33 & $\begin{array}{l}400 \\
600\end{array}$ & 1000 & wired & 3 & $\begin{array}{l}3 \text { yrs and } \\
\text { ongoing }\end{array}$ & 20/4451 LCA & $\begin{array}{c}12^{\circ} X \\
12^{\circ}\end{array}$ & Ayton et al., 2014 \\
\hline
\end{tabular}

